University of Louisville

ThinkIR: The University of Louisville's Institutional Repository

Electronic Theses and Dissertations

$12-2017$

\title{
The relationship between positive behavioral interventions and supports in elementary schools and mathematics achievement.
}

\author{
Robert Larry Taylor \\ University of Louisville
}

Follow this and additional works at: https://ir.library.louisville.edu/etd

Part of the Educational Leadership Commons

\section{Recommended Citation}

Taylor, Robert Larry, "The relationship between positive behavioral interventions and supports in elementary schools and mathematics achievement." (2017). Electronic Theses and Dissertations. Paper 2876.

https://doi.org/10.18297/etd/2876

This Doctoral Dissertation is brought to you for free and open access by ThinkIR: The University of Louisville's Institutional Repository. It has been accepted for inclusion in Electronic Theses and Dissertations by an authorized administrator of ThinkIR: The University of Louisville's Institutional Repository. This title appears here courtesy of the author, who has retained all other copyrights. For more information, please contact thinkir@louisville.edu. 
THE RELATIONSHIP BETWEEN POSITIVE BEHAVIORAL INTERVENTIONS AND SUPPORTS IN ELEMENTARY SCHOOLS AND MATHEMATICS ACHIEVEMENT

By

\author{
Robert Larry Taylor \\ B.S., Cumberland College, 1982 \\ M.A., Cumberland College, 1985
}

\begin{abstract}
A Dissertation
Submitted to the Faculty of the

College of Education and Human Development of the University of Louisville in Partial Fulfillment of the Requirements

for the Degree of
\end{abstract}

Doctor of Education

in Educational Leadership and Organizational Development

Department of Educational Leadership, Evaluation, and Organizational Development University of Louisville

Louisville, Kentucky

December 2017 
Copyright 2017 by Robert Larry Taylor

All rights reserved 

THE RELATIONSHIP BETWEEN POSITIVE BEHAVIORAL INTERVENTIONS AND SUPPORTS IN ELEMENTARY SCHOOLS AND MATHEMATICS ACHIEVEMENT

By

\author{
Robert Larry Taylor \\ B.S., Cumberland College, 1982 \\ M.A., Cumberland College, 1985
}

A Dissertation Approved on

October 19, 2017

by the following Dissertation Committee:

BBBBBBBBBBBBBBBBBBBBBBBBBBBBBBBBBBBBB]

Jeffrey Sun, J.D., Ph.D., Dissertation Chair

BBBBBBBBBBBBBBBBBBBBBBBBBBBBBBBBBBB]

Namok Choi, Ph.D., Committee Member

BBBBBBBBBBBBBBBBBBBBBBBBBBBBBBBBBBBBBBB]

William Kyle Ingle, Ph.D., Committee Member

BBBBBBBBBBBBBBBBBBBBBBBBBBBBBBBBBBBB]

Terrance Scott, Ph.D., Committee Member 


\section{DEDICATION}

First and foremost, I would like to thank my wife and best friend, Cheryl Stephens Taylor. Her unwavering support and patience for the many paths, which I have taken over the years to realize my calling as an educator, have been incomparable. Her words and presence in my life serve as a constant reminder that my sacrifices, commitments, and achievements are worthwhile.

Next, my children, Adam and Rachael Taylor, who are a daily reminder to me that father does not always know best, I thank them. While both have taken journeys I never envisioned for them and endured hardships I never wanted for them, they have emerged stronger and smarter, and they are progressing toward admirable life's work in service to others. Adam and Rachael make their families, especially me, proud.

Finally, to Mary Jane and Larry Morrow, my sister and brother-in-law, I value your guidance and encouragement, which not only made a crucial difference in my childhood and helped shape me into the adult I have become, but they also motivate me every day to keep reaching higher, in spite of any adversities I may face. Their loyalty to one another, to their families, and to other people is a model and a guiding light in my life, for which I am infinitely appreciative. 


\section{ACKNOWLEDGMENTS}

Throughout my life, I have been incredibility privileged to have been surrounded by people who had confidence in my abilities and encouraged me to continue learning. As I was completing my doctoral program, oftentimes, I would reflect on these individuals who have motivated me to reach higher. Those relationships energized me to keep progressing during those times when I wanted to give up. While there have been many people who have encouraged me and to whom I am infinitely grateful, I feel compelled to name a few: Linda France for serving as the foremost example of the personnel commitment necessary to accomplish much in order to better serve others; Paul Hamann for his belief in me and for helping me believe in myself; Dr. Lois AdamsRodgers for her wisdom to say exactly what I needed to hear when I needed to hear it; Dr. Blake Haselton for his ability to grow others and taking the time to grow me; Dr. Rob Pennington for being the epitome of a supportive colleague and friend; and, Dr. Ann Larson whose optimistic enthusiasm motivates me each day to be better than the day before.

Lastly, I would like to thank my dissertation committee, Drs. Jeffrey Sun, Namok Choi, Kyle Ingle, and Terry Scott. Each member has contributed to my scholarly growth in completing my dissertation, using their own professional strengths: Dr. Choi with her unsurpassed knowledge as a statistician and desire to see others learn; Dr. Ingle with his

extreme attention to detail and questioning that promotes critical thinking; Dr. Scott with 
his deep knowledge of student behavior and gift to simplify complex ideas; and, Dr.

Sunfor his patience, tenacity, and forgiveness to continue to guide me in spite of many episodes of obstinance. Thanks for not giving up on me 


\title{
ABSTRACT \\ THE RELATIONSHIP BETWEEN POSITIVE BEHAVIORAL INTERVENTIONS AND SUPPORTS IN ELEMENTARY SCHOOLS AND MATHEMATICS ACHIEVEMENT
}

\author{
Robert Larry Taylor
}

October 19,2017

This causal-comparative study examined the relationship between Positive Behavioral Interventions and Supports (PBIS) and academic achievement in elementary school mathematics. Research has shown that PBIS may help establish a positive school climate, which supports the conditions for effective teaching and learning (Bradshaw, Koth, Bevans, Ialongo, \& Leaf, 2008; Horner, Sugai, \& Vincent, 2005; Hoy, Tarter, \& Bliss, 1990). Accordingly, this study examined variables of particular interest, which were mathematical performance, including mathematical performance by male academic achievement, female academic achievement, and socioeconomic status, based on PBIS implementationThe data used were school-level, $5^{\text {th }}$ grade mathematics achievement scores. Elementary schools, which participated in PBIS implementation for the 201213, 2013-14, and 2014-15 school years and reported a high rate of fidelity of implementation for each of the 3 years, served as the treatment group for this study. The control group was schools that did not attempt to implement PBIS. School-level percentages of students who obtained a proficient or distinguished rating were used as the 
performance levels to determine the successful acquisition of mathematics achievemResults from the analysis of the Mann-Whitney $U$ test revealed no statistically significant difference between the total percentages of students scoring at the performance level of proficient or distinguished between PBIS and non-PBIS schools ( $p$ $=.535)$. Differences in the achievement of males were examined using an independent samples $t$-test. Results indicated no significant differences in the academic achievement of males between PBIS and non-PBIS schools $(p=.626)$. The Mann-Whitney U test was conducted to determine if a difference in the percentage of female students who achieved the performance level of proficient or distinguished; no statistical significance was found $(p=.27)$ between PBIS and non-PBIS students. The concluding analysis of an ANCOVA was used to determine whether a statistically significant difference in the percentage of mathematics scores reaching proficient or distinguished would be found between PBIS and non-PBIS schools, when using SES as a covariate. Results from this analysis also found no statistically significant difference $(p<.700)$.

Lack of statistically significant differences in academic achievement as the result of PBIS implementation were contrary to previous studies. This study presents some mitigating factors, which may have contributed to these findings: (a) multiple PBIS coaches provided training to the PBIS schools and no data were available to know if the training were standardized among trainers and truly achieved reliable reporting of fidelity; (b) data were not available to ascertain if the fidelity measure, which is known as the benchmarks of quality, was administered within the same time period at the end of each of the 3 years of implementation; and (c) data regarding other initiatives or activities 
at the schools, which may have been implemented for both PBIS and non-PBIS schools, may have inhibited the true examination of the respective variables. 


\section{TABLE OF CONTENTS}

\section{PAGE}

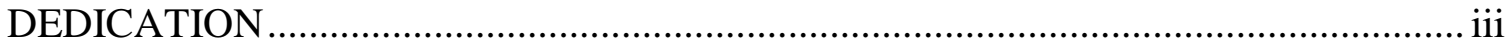

ACKNOWLEDGMENTS .............................................................................. iv

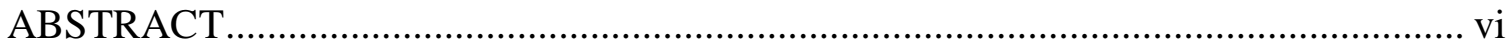

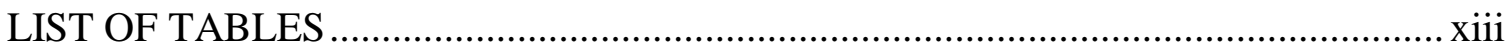

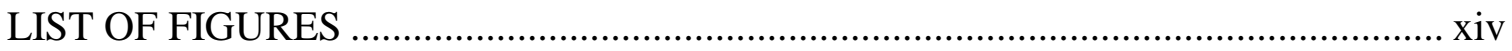

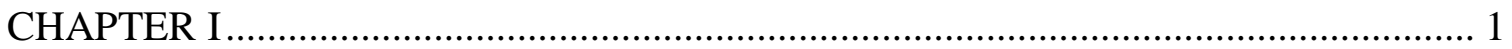

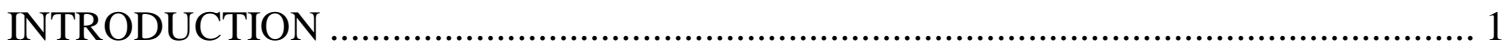

Government Accountability ........................................................................... 1

Assessment of Academic Outcomes ..........................................................................................

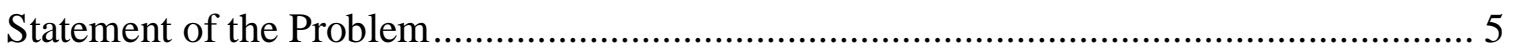

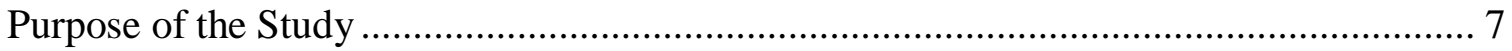

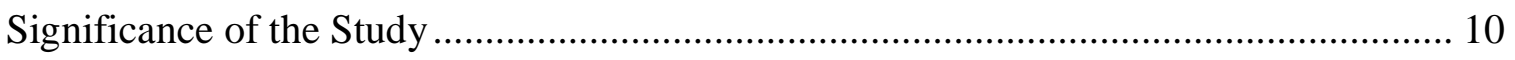

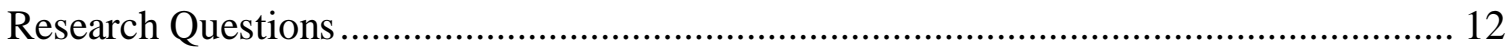

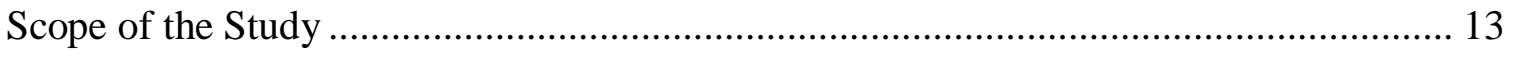

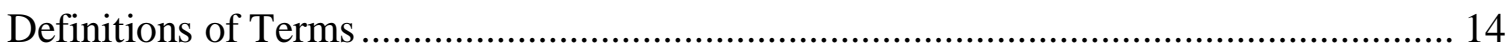

Summary and Organization ...................................................................................... 16

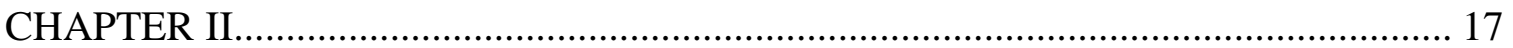




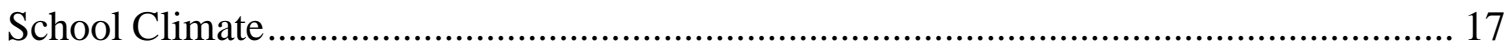

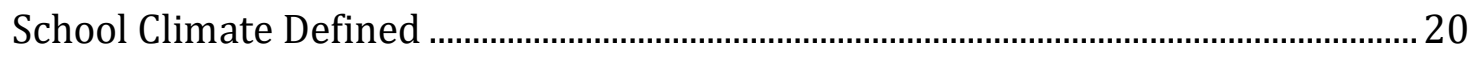

Assessing School Climate .......................................................................................... 21

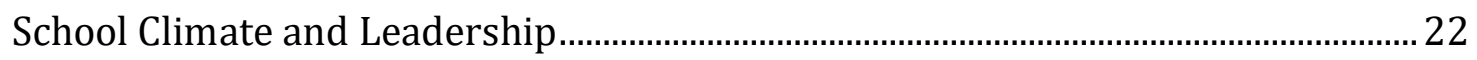

School Climate and Academic Achievement..................................................................... 23

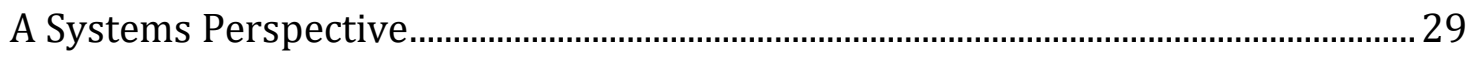

Positive Behavioral Interventions and Supports …………….................................... 31

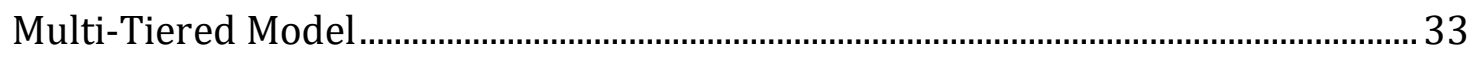

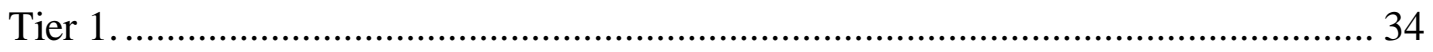

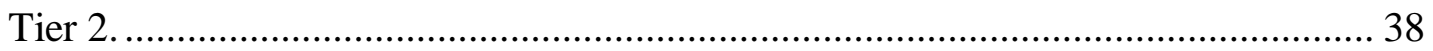

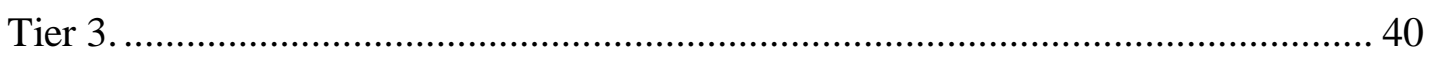

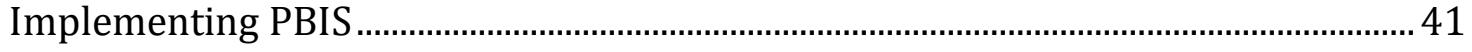

Fidelity of PBIS Implementation ................................................................................. 47

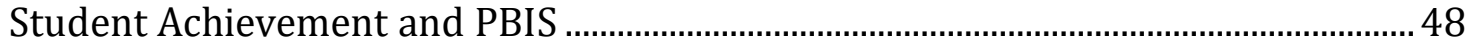

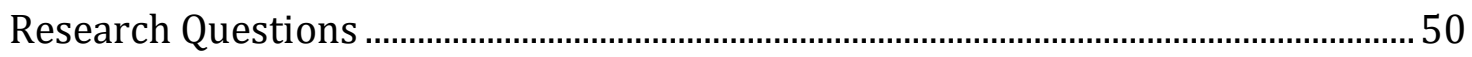

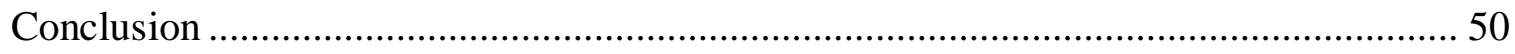

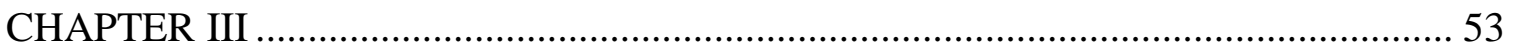

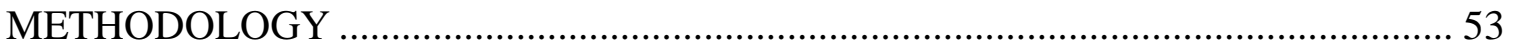

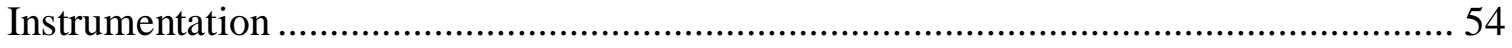

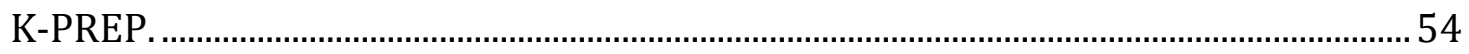

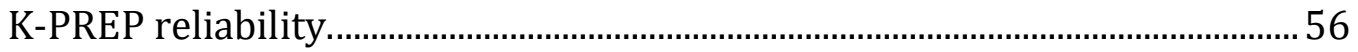

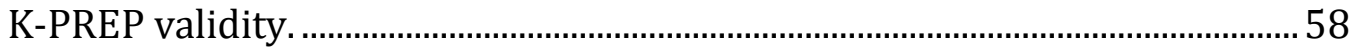




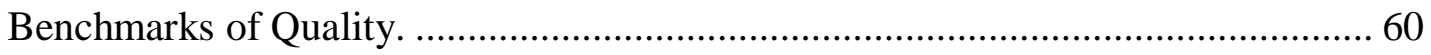

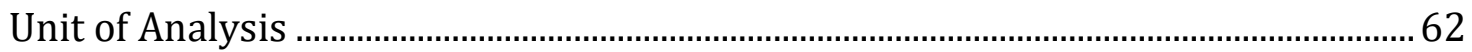

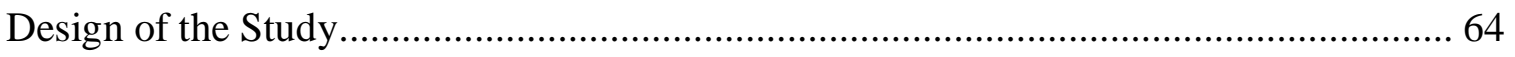

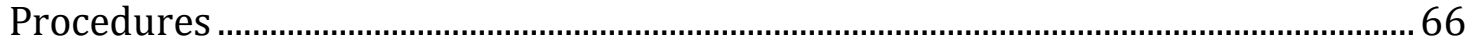

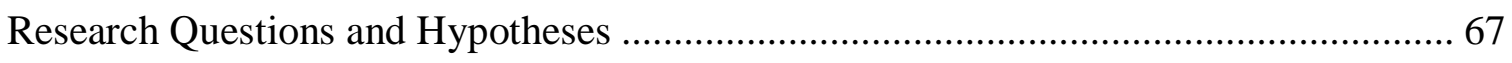

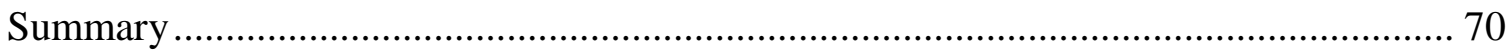

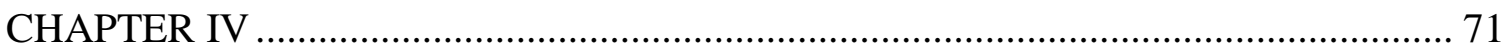

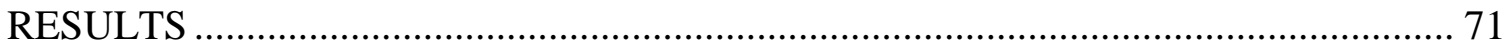

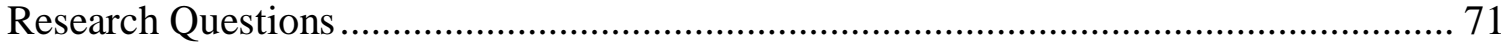

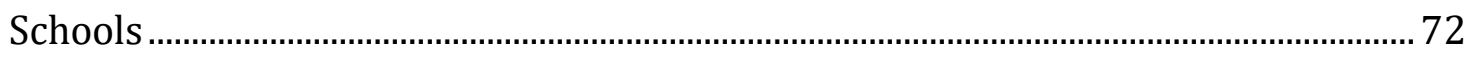

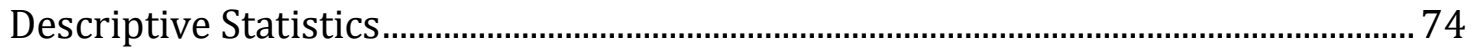

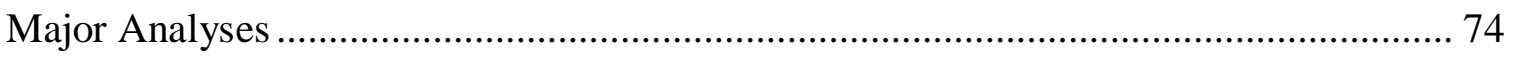

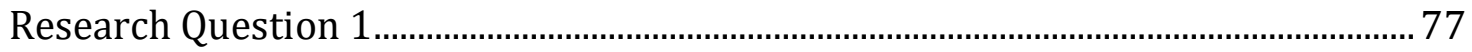

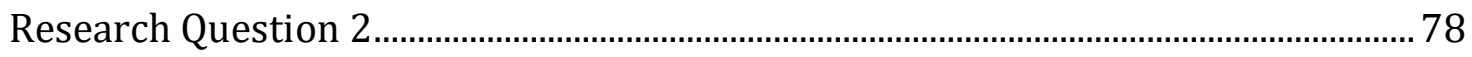

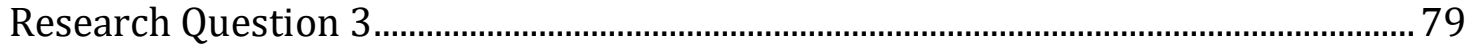

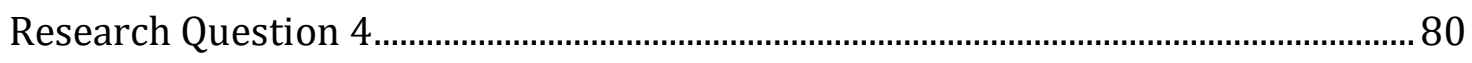

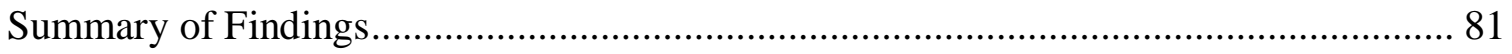

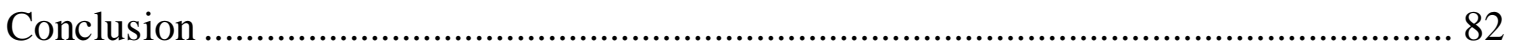

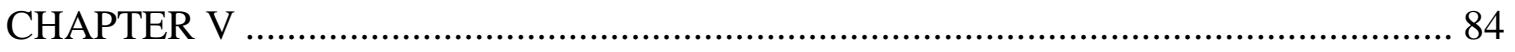

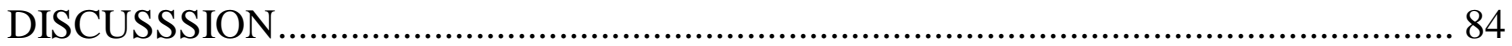

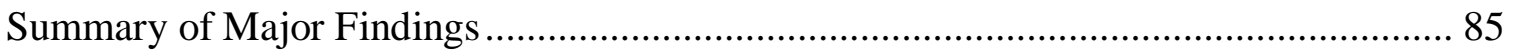




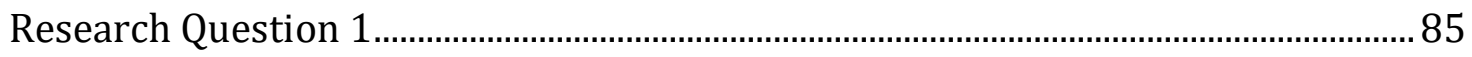

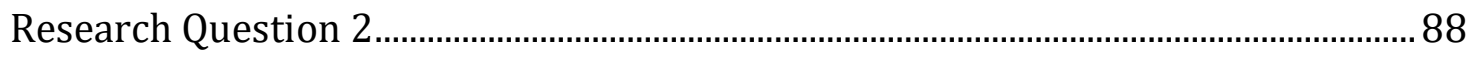

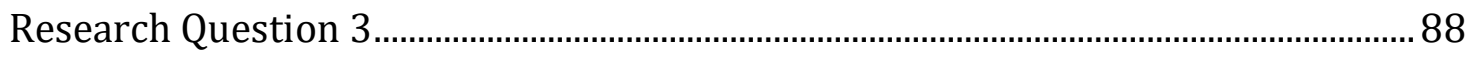

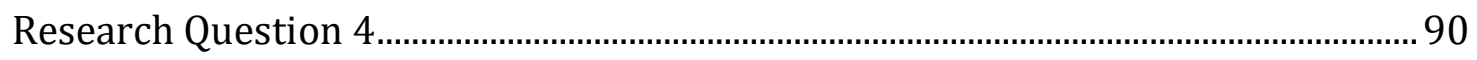

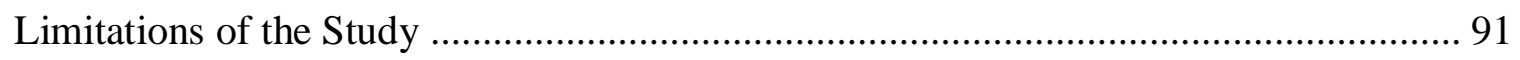

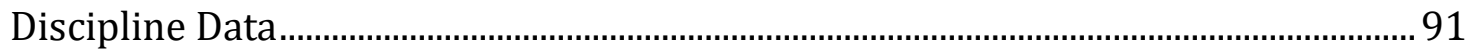

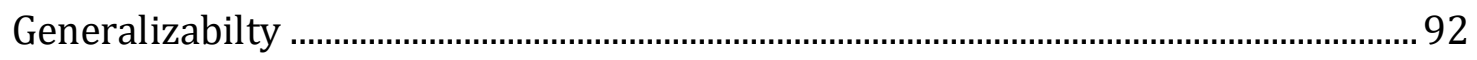

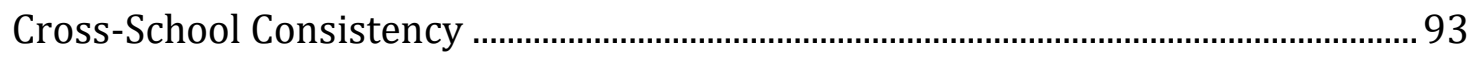

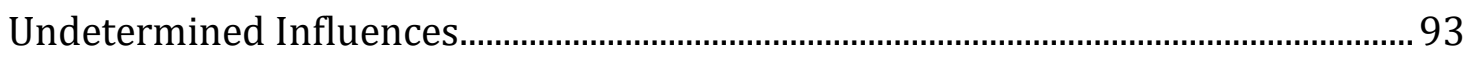

Implications for Policy Makers and Practioners ................................................... 94

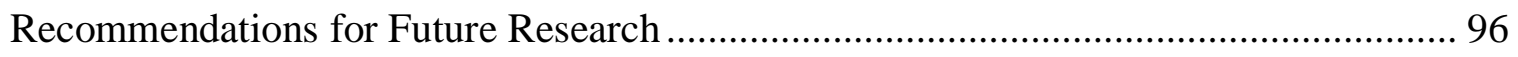

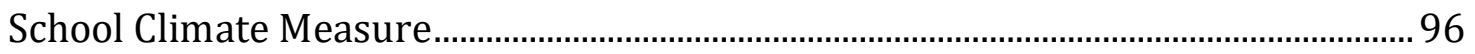

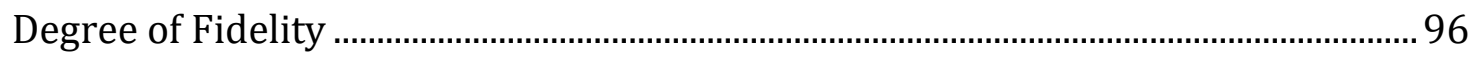

Beliefs Regarding Mathematics Achievement and Gender......................................... 97

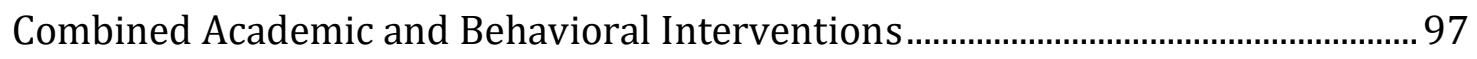

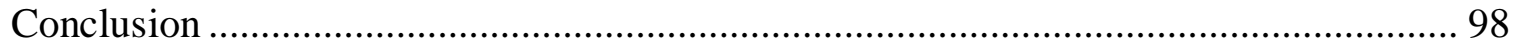

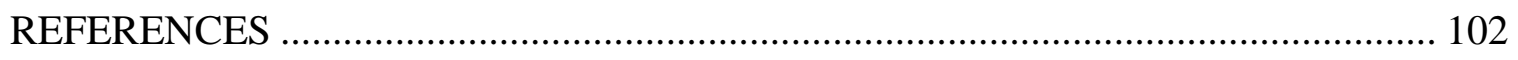

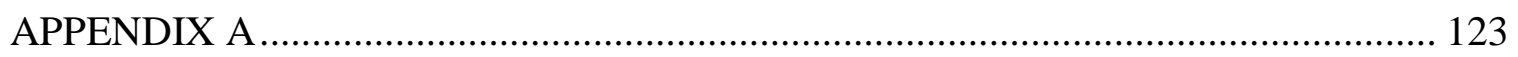

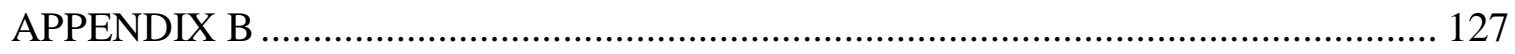

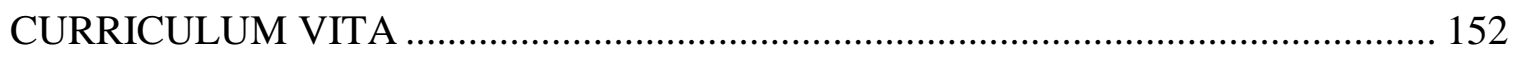




\section{LIST OF TABLES}

TABLE

PAGE

1. Inter-rater Scoring Agreement and Reliability ................................................... 59

2. Description of the Study Variables for Overall Academic Achievement .................... 65

3. Description of the Study Variables for Male Academic Achievement ........................ 65

4. Description of the Study Variables for Female Academic Achievement .................... 66

5. Description of the Study Variables for Academic Achievement by SES .................... 66

6. Descriptive Statistics for Number of Students Tested ........................................... 73

7. Descriptive Statistics for Percentages of Students Designated as Proficient or

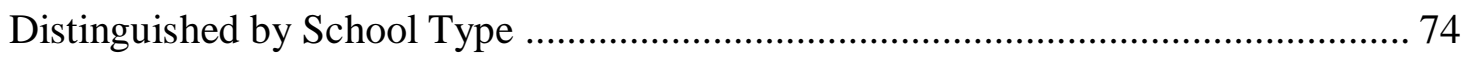

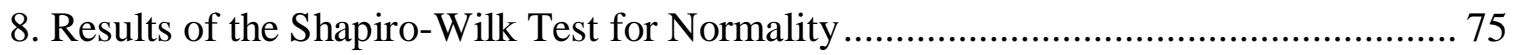

9. Mann-Whitney U Test for Total Percentage Proficient or Distinguished by School

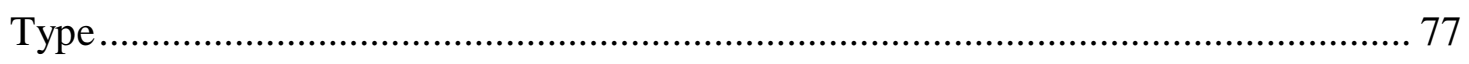

10. Independent Sample t-test for Male Proficient or Distinguished by School Type ..... 78

11. Mann-Whitney U Test for Female Proficient or Distinguished by School Type ....... 80

12. ANCOVA for Proficient or Distinguished by School Type While Controlling for SES

13. Marginal Means and SD for Proficient and Distinguished by School Type 81 


\section{LIST OF FIGURES}

FIGURE $\quad$ PAGE

1. Cycle of educational improvement driven by data, policy, and research. ................... 11

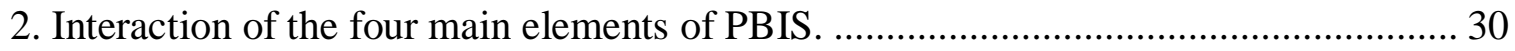

3. Three-tiered prevention model of PBIS ................................................................ 34

4. Bar graph of non-PBIS (0) versus PBIS (1) schools................................................ 73

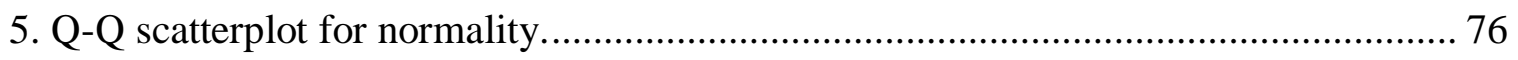

6. Boxplot scores of total percentages proficient or distinguished for non-PBIS and PBIS

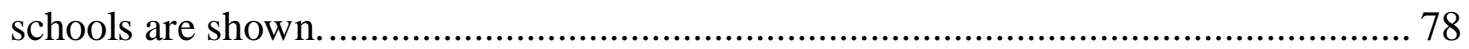

7. The mean of male percentages proficient or distinguished for non-PBIS and PBIS

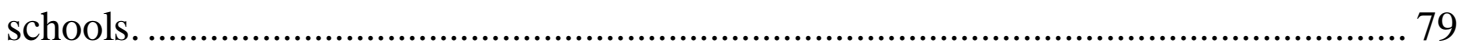

8. The mean of female percentages proficient or distinguished for non-PBIS and PBIS

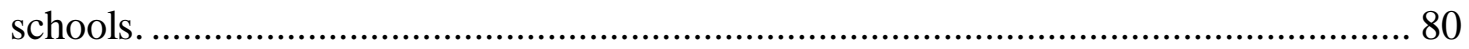




\section{CHAPTER I INTRODUCTION}

The extant literature has documented that a school environment plays a significant role in student achievement (Cohen, McCabe, Michelli, Pickeral, 2009; Hoy \& Hannum, 1997; Thapa, Cohen, Guffey, \& Higgins-D’Alessandro, 2013; Wang \& Holcombe, 2010), and accountability measures at the school, district, and state levels have served as the pressure points placing student achievement performance at the forefront of educational administrators and policy makers (Borkowski \& Sneed, 2006; Nichols, Glass, \& Berliner, 2012). This relationship among school environment, student achievement, and government accountability illustrates how a well-implemented intervention consists of many pieces within a system interacting to enhance student performance.

\section{Government Accountability}

To understand the landscape that undergirds the student achievement and school environment emphases, one might start with dissecting the role of governmental accountability measures and benchmark assessment measures. Notably, the critical voices of legislators often cite standardized test scores. For instance, one might recognize recent public calls for school improvements knowing that only $40 \%$ of fourthgrade students and $33 \%$ of eighth-grade students obtained a score of proficient or higher in mathematics on the National Assessment of Educational Progress in 2015 
(U.S. Department of Education, NAEP, 2015). Given that foundational learning during the elementary education years most often portends the lack of school success in future years the trajectory of academic outcomes for our students is frightening (Griswold, 2005). The U.S. educational system's shift downward has led to cries of concern. In 1983, the United States was the leader in quantity and quality of high school diplomas; however, that worldwide recognition has not been sustained. Thirty years later, our nation was ranked 36th in the Coleman Report (Sparks, 2016). Technological advances in the late 20th and early 21 st centuries, as well as economic globalization, have increased the need for a more educated workforce. Nonetheless, U.S. public education has fallen behind other countries in mathematics and science achievement starting in the 1970s (Alexander \& Pallas, 1984).

Government pressures for school accountability are not new to policy discussions on school improvement. Government efforts to assess and improve educational outcomes have been in place since accountability testing began with the passing of the Elementary and Secondary Education Act (ESEA) of 1965. Under this legislation, federal funds were allocated to disadvantaged students and those living in poverty, and schools were required to evaluate the effectiveness of their interventions using standardized tests to measure academic achievement. The belief was that if schools were provided more funding to compensate for the inherent academic challenges of students living in poverty, the achievement gap would be eliminated (Kirst \& Jung, 1991; Thomas \& Brady, 2005). However, after years of federal and state pressures and assistance under ESEA, the results demonstrated by national reports such as A Nation at Risk (National Commission on Excellence in Education, 1983) have painted a bleak picture of student achievement 
and highlighted discrepancies of socioeconomic status (SES). Put simply, critics characterized the idea of throwing money at the schools as ineffective and a bad policy decision.

In an effort to improve public education, U.S. Secretary of Education T. H. Bell initiated the National Commission of Excellence in Education to address the growing negative public perceptions of the quality of U.S. education in 1983. The convening of this commission resulted the development of the document, A Nation at Risk: The Imperative for Education Reform (National Commission on Excellence in Education, 1983), which created a fury of activity with its many incriminating findings. Key among those findings was the projection that for every 20 students born in 1983, six would not graduate from high school on time (i.e., by 2001). Of the 14 who would graduate, 10 would start college that fall, and only five would graduate from college by 2007 . Furthermore, the same report revealed $13 \%$ of 17 -year-olds would be classified as functionally illiterate. The report contained recommendations that schools (including colleges and universities) establish measurable standards that, coupled with higher expectations for academic achievement, would increase the academic rigor and improve academic outcomes throughout the nation's educational system.

Accountability for high achievement continues to be articulated through mandates set forth by state and federal policy makers, as exemplified by the reauthorization of the Elementary and Secondary Education Act, (i.e., No Child Left Behind Act (NCLB) of 2002 and Every Student Succeeds Act (ESSA) of 2016). For instance, NCLB required states to use high-stakes assessments as part of rigorous accountability systems (Borkowski \& Sneed, 2006). 
However, though most people agree that accountability for the outcomes of schooling is necessary, not everyone agrees on how to accomplish this task. Controversy exists among educators, researchers, and public opinion not only on what schools should be held accountable for, but also on how to measure those desired outcomes (Cohen et al., 2009).

Whereas school accountability is not new to education, it was not until the passage of NCLB that accountability in federal legislation included the requirement of reporting student achievement at the state, district, and school levels publicly for all students in all schools, which served as a punitive enforcement measure for those not meeting acceptable levels. Student achievement scores in reading, mathematics, and science produce a grade for the school (Lewis \& Haug, 2005). Unacceptable results thus reflect a failing school and not a failing student. This expectation for increased academic outcomes, paired with a specific timeline to accomplish this task, has resulted in a sense of urgency for school administrators and teachers to make programming decisions that promise results (Kelleher, 2003). Likewise, the reauthorization of ESEA through the Every Student Succeeds Act of 2016 continues to articulate accountability measures for positive student outcomes for all students.

\section{Assessment of Academic Outcomes}

Measuring student achievement in school is often done with test scores. Although four core subjects (reading, social studies, mathematics, and science) are commonly measured, mathematics has received the most attention by researchers and critics (Chval, Reys, Reys, Tarr, \& Chavez, 2006). There is a strong correlation between mathematics and educational attainment and to career opportunities (Choi \& Chang, 2011;Murnane, 
Willett, \& Levy, 1995; Watt, 2006). In addition, Clements and Sarama (2011) found that students in early childhood programs who were provided conceptual mathematics interventions performed better in language and emergent literacy than students who did not receive the same mathematics intervention. Thus, math reflects a critical learning component.

\section{Statement of the Problem}

National assessment scores for public school students coupled with systems of accountability that determine if schools are performing at an acceptable level have created pressure for school personnel to focus on producing high achievement scores for those areas measured in accountability systems (Nichols, Glass, \& Berliner, 2012). Paramount to accomplishing the task of increasing student achievement, educational leaders must know what practices will result in the outcomes expected. That is, they must know which interventions will support improved student achievement.

As one might assume, the relationship between a positive school environment and academic setting are significant to policy makers and educators, and the extant literature has revealed significant findings to that end. Cohen et al. (2009) found that a positive school climate promotes learning and is predictive of academic success. Gietz and McIntosh (2014) administered student satisfaction surveys in 969 elementary and 73 middle schools and compared the results of the Foundation Skills Assessment. They found that students' perception of their school environment was related to their academic success. While empirical evidence suggests that school improvement efforts should address climate issues to realize increased academic achievement, there is a gap between research and educational practice, as well as between research and education policy 
(Cohen et al., 2009). Thapa, et al. (2013) stated, " the field is evolving and . . calls for rigorous and empirically sound research that focuses on relating specific aspects and activities of interventions to changes in specific components of school climate" (p. 372).

Indeed, empirical research has shown that a positive school climate creates conditions that are associated with enhancing academic achievement. Accordingly, policy makers, researchers, and educators suggest that school personnel have the obligation and opportunity to adopt an intervention that fosters a positive school climate (Cohen, 2006). School leaders are faced with the challenge of deciding which programmatic interventions to adopt to achieve this outcome of having a positive school climate and its association with better academic achievement. Faced with many competing options that claim to be the panacea for academic challenges, some decisions are made without a clear understanding how the interventions will interplay with other factors of the overall school system. As a result, interventions frequently fail and are abandoned prior to full implementation.

The challenge for many educators is making effective program selections using a data-based process that prescriptively addresses student needs (Cramer, Little, \& McHatton, 2014; Means, Padilla, DeBarger, \& Bakia, 2009). At the same time, it is essential that practitioners know how implementation of a program in the context of the school community can be broken down into phases or a series of steps to achieve the desired outcomes (Durlak \& DuPre, 2008; Fixsen, Blase, Duda, Naoom, \& Van Dyke, 2010). Unfortunately, fidelity during the implementation of an intervention does not always occur. Fixsen, Blase, Metz, and Van Dyke (2013) found that decision makers typically spend the least amount of time in the foundational stage of "exploration and 
adoption" prior to program implementation. Additionally, school leaders are challenged with evaluating the efficacy of an intervention.

Implementation of educational interventions influences the intended academic outcomes. To overcome this concern, Adelman and Taylor (2003) recommended that an implementation plan be developed in the context of the specific school and classroom to communicate to implementers their role and expectations. Similarly, Fisher (1983) found during the initial implementation stage of installing an initiative that people experienced a variety of emotions resulting from fear associated with change. A well-designed implementation plan supports the abandonment of ineffective or redundant programs and can help to alleviate some of the challenges educators encounter when changing familiar practices. For instance, Romney, Israel, and Zlatevski (2014) discovered that providing readiness training to participants prior to the actual training for the Positive Parenting Program helped participants accept new practices. The authors also found this preparation step resulted in a cost savings of seven times less than the sites where no readiness training was conducted. Furthermore, the sites that received this readiness training achieved a high level of outcomes at a faster rate than their less trained counterparts. Taking these empirical lessons, educational leaders are challenged with responding to government accountability measures that schools face by understanding the effects of an educational intervention on school climate and its relationship to student achievement.

\section{Purpose of the Study}

The purpose of this study is to investigate an education intervention focused on helping improve the school environment as an indirect, but potentially a key relational, 
mechanism to enhance student achievement. Given that the primary goal of accountability systems is to increase academic achievement, educators must understand and respond to the connection between school climate and academic achievement; however, school climate is complex and comprised of many parts from within the school's entire system, making it necessary to approach school climate using systems thinking. Systems thinking is the ability to understand the interactions and relationships in complex and dynamic organizations (Senge, 2006). It allows leaders to view the whole school as a complex organization with many components (Shaked \& Schechter, 2013). Because of the complexity of the many systems within a school, implementation of new practices is often a slow and laborious endeavor. School personnel must understand that meaningful change requires common goals and that genuine change in sustainable practice will most likely occur in small increments over time (Fixsen, Naoom, Blase, Friedman, \& Wallace, 2005). Accordingly, this study examined the efficacy of positive behavior interventions and supports (PBIS) implementation into schools and its influence on student achievement in mathematics performance.

PBIS is a universal strategy that uses a systems-thinking approach in establishing a school environment that enhances the social, cultural, and behavioral supports necessary for students to achieve academic and social success (Dunlap \& Carr, 2007). The core features of PBIS represent research in behavioral science combined to empirically support practices that have shown promising results in improving school climate and achievement (Sugai \& Horner, 2006). When PBIS is implemented with fidelity, school personnel have the tools needed to analyze and change undesirable patterns of failure that occur within a school (Horner, Sugai, \& Vincent, 2005). Data 
collection and analysis are key components of the PBIS process. To allow the data to assist in directing the actions of those in the school, adult actions must be developed and instilled in a manner consistent with the intent of PBIS.

In his letter to chiefs of state departments of education, former U.S. Secretary of Education Arnie Duncan (see Appendix A) recommended PBIS to prevent and reduce the need for the use of restraint and seclusion for students with challenging behavior (A. Duncan, personal communication, July 31, 2009). In 2011, there were more than 9,000 schools in 40 states using PBIS with the goal of increasing student performance on academic and social skills (U.S. Department of Education, 2011). Schools implementing PBIS increased by the 2014-2015 school year to 20,384 (U.S. Department of Education, 2015), and 11 countries have started implementing PBIS.

Because of the extensive implementation of PBIS, addressing its effect as a school climate intervention and to examine effects on school achievement presents a viable and important inquiry. This study drew on data from schools in one state, Kentucky, to investigate the relationship PBIS had on student achievement. In Kentucky, more than 336 schools with 161,000 students and 10,700 teachers have implemented PBIS (Kentucky PBIS Network, 2009). Recent data from Kentucky schools implementing PBIS with fidelity showed they reduced suspension rates from $13.68 \%$ in the 2011-2012 school year to 6.75\% in the 2012-2013 school year (Kentucky PBIS Network, 2015). In light of this data, PBIS fidelity was also examined by assessing the degree to which implementation of PBIS enhances mathematics achievement at the elementary school level. 


\section{Significance of the Study}

The significance of this study is the understanding it brings of what happens to student achievement in mathematics when considering socioeconomic status and gender when PBIS is implemented with fidelity in Kentucky elementary schools. Practitioners and policy makers establish requirements and allocate resources that guide the development of state and local accountability systems. Since the inception of NCLB, public pressure to increase student achievement for all students is at the forefront. Many competing programs are available that purport to accomplish academic results; however, schools cannot afford to use their limited funds and time to implement ineffectual initiatives. Unlike many other initiatives, PBIS systematically examines a school's data so action planning is prescriptive and connects to other systems within the school context. Furthermore, the processes used to implement PBIS builds up their capacity of school personnel, which increases the probability the initiative will be sustained over time.

Research studies have indicated that socioeconomic status contributes to student achievement (Berkowitz, Moore, Astor, \& Benbenishty, 2016). A proxy to socioeconomic status is often manifested through data on students qualifying for free and reduced lunches. Given that, the percentage of students qualifying for free and reduced lunches based on income for Kentucky for the 2015-16 school year was 60.3\% (KDE School Report Card, 2016). The findings of the current study may provide insight into how the implementation of PBIS mediates the negative influence of poverty. Because PBIS implementation has presented data of improvedpositive school climate, and research suggests that there is a relationship between a positive school climate and student achievement, the assumption is that student achievement for all students will be 
enhanced when PBIS has been adopted at a school versus non-adoption of PBIS at a school (Mayer, 1998; Scott \& Nelson, 1999; Warren et al., 2006).

An example of such policy is the creation of NCLB and the requirements of an accountability system to measure outcomes. Subsequently, practitioners must make decisions to address school needs in meeting these new standards. Research on school improvement is imperative to ensure the results are realized to satisfy the requirements of accountability. Educators must be informed by the evidence behind an initiative and understand how to implement that initiative to achieve the results intended. Figure 1 illustrates the process that begins with national data motivating action by policy makers.

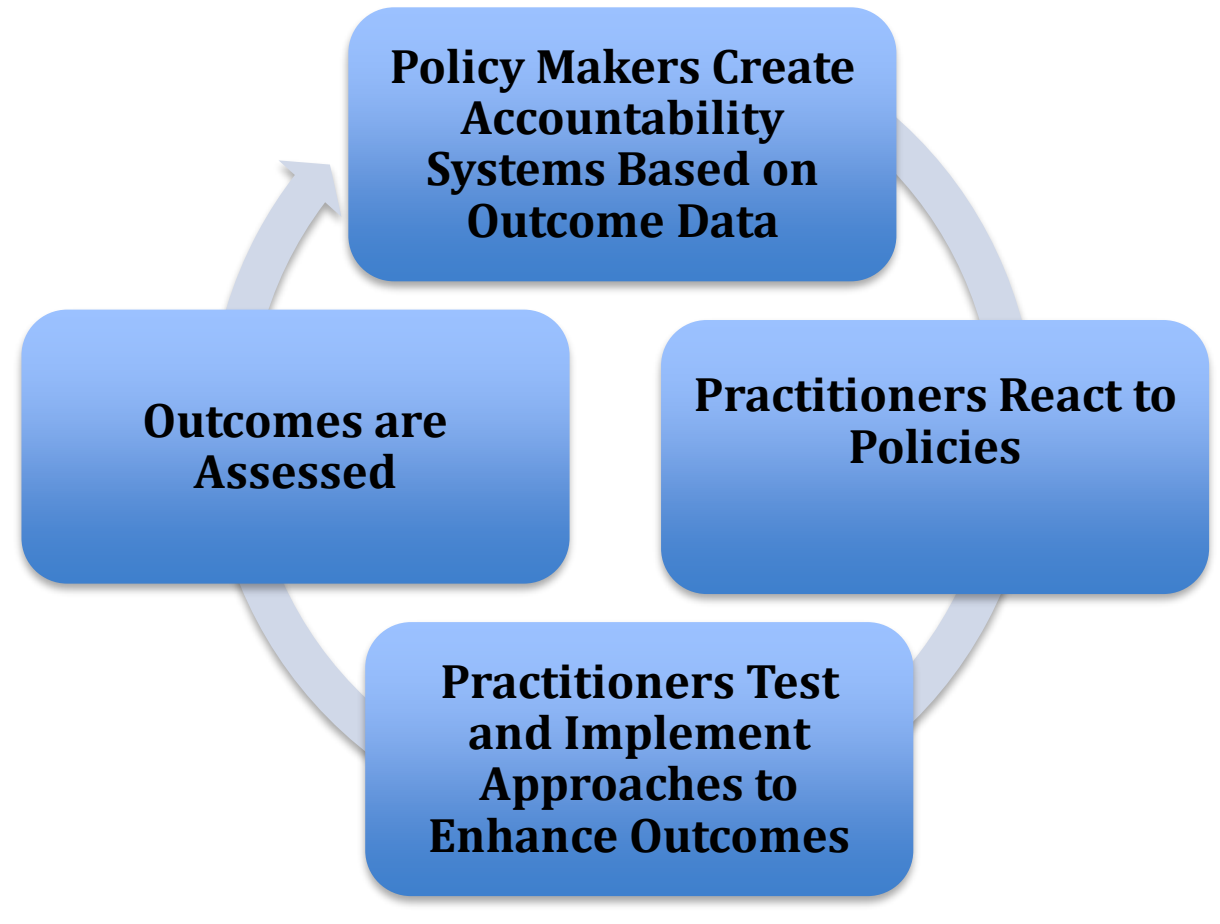

Figure 1. Cycle of educational improvement driven by data, policy, and research.

Whereas outcome data inform policy makers and practitioners alike, a deeper understanding is needed of the principles that support adopting an intervention and the 
relationship that intervention will have on academic achievement. Neal, Neal, Kornbluh, Mills, and Lawlor (2015) suggested the reason for the gap among policy makers, researchers, and practitioners is a lack of communication needed to make informed decisions.

Further examination of PBIS will reveal if implementing PBIS improves school climate, resulting in better academic outcomes. This includes concerns regarding the discrepancy between females and males in mathematics achievement and females' pursuing careers associated with mathematics and the lower performance of students of low socioeconomic status.

\section{Research Questions}

Only a few quantitative studies have assessed the influence of PBIS on academic achievement as measured by high-stakes assessment (Lassen et al., 2006). This study examines the relationship between PBIS and academic achievement, PBIS and academic achievement and gender, and PBIS and academic achievement when socioeconomic status is controlled.

The following research questions was used to guide this examination.

1. Is there a significant difference in the percentages of fifth graders at proficient or distinguished levels in mathematics between schools that implemented PBIS and schools that did not implement PBIS?

2. Is there a significant difference in the percentages of male fifth graders at the proficient and distinguished performance levels in mathematics between nonPBIS and PBIS schools? 
3. Is there a significant difference in the percentages of female fifth graders at the proficient and distinguished performance levels in mathematics between nonPBIS and PBIS schools?

4. Is there a significant difference in the percentages of fifth graders at proficient and distinguished levels in mathematics between schools that implemented PBIS and schools that did not implement PBIS when controlling for the schools' socioeconomic status?

\section{Scope of the Study}

The Kentucky Department of Education (KDE) archives district- and school-level assessment data on high-stakes accountability testing, which will be accessed for this study. Additionally, elementary schools that participated in a State Personnel Development Improvement Grant awarded to KDE for the implementation of PBIS selfreported fidelity of implementation data from the benchmarks of quality (BoQ) collected as a part of their PBIS implementation. Mathematics achievement data from elementary schools that implemented PBIS with fidelity and those that did not implement PBIS at all will be compiled to establish comparison groups to answer the research questions of this study. The specific study design will be discussed in further detail in Chapter 3.

A limitation of this study was that while the comparison schools did not implement PBIS, they may or may not have implemented other whole-school initiatives that potentially influence school climate to benefit mathematic achievement. This challenge may be addressed by increasing the sample size. A second limiting factor was the assumptions of PBIS execution. For instance, it is assumed that when a positive school climate is established and the conditions for learning are optimal, high-quality 
instruction is occurring that will result in increased math scores. Likewise, this assumption interprets fidelity based on self-reported data as true and meeting the required benchmarks of quality. While data were not available regarding the quality of instruction provided and the the benchmarks of quality reports were not tested for reliability due to limited data access, the researcher had reasonable justifications to proceed with certain assumptions, such as the sample size of schools that implemented PBIS was large enough to mediate those circumstances when poor quality instruction was provided or other intervening variables.

\section{Definitions of Terms}

Academic achievement: Mathematics scores obtained by a student's performance on the Kentucky's Unbridled Learning high-stakes assessment in grade five.

Benchmarks of quality (BoQ): A research quality tool used to annually assess universal schoolwide positive behavior supports to measure the extent PBIS that is being implemented as intended (Kincaid, Childs, \& George, 2005).

Fidelity: Adherence to the tenets of a model or program (Moncher \& Prinz, 1991).

Fidelity data: Data collected and analyzed to determine if a model or program has adhered to the components of implementation.

Fidelity of implementation: Content and instructional strategies used as they were designed and intended to be (National Center on Response to Intervention, 2010). Kentucky Performance Rating for Educational Progress (K-PREP): The assessment for grades 3-8 designed and used to assess students' academic progress in learning the content of Kentucky's standards. 
Non-PBIS schools: Elementary schools in Kentucky that have not implemented PBIS during the 2012-13, 2013-14, and 2014-15 school years.

Multi-tiered system of support: The practice of providing high-quality instruction and interventions matched to student need, monitoring progress frequently to make decisions about changes in instruction or goals, and applying child response data to important educational decisions (Batsche et al., 2005).

Positive behavioral interventions and supports (PBIS): A systems approach to establishing the social culture and individualized behavior supports needed for a school to be a safe and effective learning environment (Sugai \& Horner, 2009, p. 309).

PBIS schools: Elementary schools in Kentucky that have implemented PBIS at fidelity as determined by the BoQ during the 2012-13, 2013-14, and 2014-15 school years.

PBIS tier 1: The PBIS level that involves teaching the behavioral expectations to all students (Lewis \& Sugai, 2002).

PBIS tier 2: The PBIS level that provides instruction to students who have identified as not successful in meeting the behavioral expectations taught at tier 1 of PBIS (Gresham, 2005). Normally, $15 \%$ of students not successful at tier 1 experience success at the targeted tier 2 level of instructional discipline (OSEP, 2011).

PBIS tier 3: The PBIS level that provides intense individualized instruction for approximately $5 \%$ of students who have not been successful in meeting the behavioral expectations taught at tiers 1 and 2 of PBIS (Scotti, Evans, Meyer, \& Walker, 199; OSEP, 2011).

School climate: The culture of the school in terms of the quality and character of school life. School climate is based on patterns of students', parents' and school personnel's 
experience of school life and reflects norms, goals, values, interpersonal relationships, teaching and learning practices, and organizational structures (National School Climate Center, 2015).

School socioeconomic status (SES): The percentage of students meeting eligibility for free or reduced lunches based on the National School Lunch Program Guidelines established by the U.S. Department of Agriculture.

\section{Summary and Organization}

This study examines whether PBIS implemented with a high degree of fidelity enhances the school climate to the point where it has a positive influence on mathematics achievement. Mathematics is an academic filter that can predict student success. This is most obvious through a correlation between mathematics and educational attainment that leads to more promising career opportunities (Murnane et al., 1995). To examine this inquiry further, a review of the literature on school climate, student achievement, and PBIS will included in Chapter 2. Chapter 3 will describe the research method and design to address the proposed research questions. In Chapter 4, the findings will be presented. Chapter 5 will conclude with the analyses based on the findings, implications of those findings, and recommendations for future research. 


\section{CHAPTER II}

\section{REVIEW OF LITERATURE}

The study's focus is to examine the extent to which school climate influences student achievement. This study explores whether positive behavioral interventions and supports, as interventions to improve school climate, result in improved mathematics scores as a measure of achievement. To show the development of the concepts surrounding school climate and student achievement thus far, this chapter reviews the literature on school climate, academic achievement, and positive behavioral interventions and supports.

\section{School Climate}

The literature on school climate has consistently and clearly concluded that school climate influences learning environments and student behaviors and that both of these play a role in student learning. In a foundational piece on educational leadership, Perry (1908) suggested that leaders influence school climate that impacts student learning. Perry explained the principal's interaction with students, staff, and the public, as well as their role in the school's operations and student learning.

The literature expanded this idea in the late 1950s. Halpin (1958) posited that organizational climate influences school operations. While the literature from which he drew derived from research on industry, the military, and government, Halpin argued that 
the work he examined was a significant contribution to the study of organizational climate for social scientists to apply in schools. Exploring this relationship, Halpin and Croft (1963) developed the Organizational Climate Description Questionnaire (OCDQ), which served as the first recognized instrument used to measure school climate. The OCDQ was a descriptive 64-item Likert scale questionnaire that examined perceived open-to-closed climates between teacher-teacher and teacher-administrator in elementary schools.

In 1966, Halpin began applying this inquiry of organizational climate in studying how it relates to $\mathrm{K}-12$ schools. He asserted:

Anyone who visits more than a few schools notes quickly how schools differ from each other in their "feel." In one school, the teacher and the principal are zestful and exude confidence in what they are doing. They find pleasure in working with each other; this pleasure is transmitted to the students, who thus are given at least a fighting chance to discover that school can be a happy experience. In a second school, the brooding discontent of the teachers is palpable; the principal tries to hide his incompetence and his lack of a sense of direction behind a cloak of authority ... and the psychological sickness of such a facility spills over on the students who, in their own frustration, feed back to the teachers a mood of despair. (p. 131)

Halpin's description of these school discrepancies raised the question of whether school climate could account for these differences. According to Halpin, an open school climate is supportive, genuine, and engaged, whereas a closed school climate lacks authenticity 
and includes game playing and disengaged behavior. The development of the OCDQ provided practitioners the opportunity to systematically collect and analyze data. This enabled school personnel to intentionally alter practices to improve the climate for learning (Anderson, 1982). Andrews (1965) and Thomas (1976) found the overall scores from the OCDQ were not good predictors of student achievement; however, the individual subtests within the OCDQ did have predictive qualities regarding student achievement.

In subsequent years, the Effective Schools Movement promoted widespread examination of the differences between schools that met goals of student achievement and those schools that did not. As the research continued, it became clear that it was critical to understand school climate's relationship to student achievement (Anderson, 1982; Brookover et al., 1982; Brookover \& Lezotte 1979; Edmonds 1979; Purkey \& Smith, 1983). Earlier findings of Brookover and Lezotte concluded that each of the characteristics are related to one another in contributing toward an effective school, hence the word "correlates." Put simply, because the development of the OCDQ presented a foundational instrument to study school climate, school administrators and researchers started to recognize the constructs that formed components of an effective school. For example, in 1996, the Association of Effective Schools, Inc., identified characteristics previously cited in research that promote student achievement. These characteristics became known as the correlates of effective schools and include (a) a clear school mission, (b) high expectations for outcomes, (c) instructional leadership, (d) ongoing monitoring of student progress, (e) an opportunity to learn and time on task, (f) a safe and orderly environment, and (g) positive home-school relations. 


\section{School Climate Defined}

Although researchers and practitioners have continued to debate a definition of school climate (Homana, Barber, \& Torney-Purta, 2006), the common aspects of the definition of school climate include the physical and environmental factors, along with the human interaction factors of a school. Illustrating some of the variations in defining school climate, Cohen et al. (2009) suggested that school climate refers to the quality and character of school life. Kumpermine, Leadbeater, and Blatt (2001) referred to school climate as the number and quality of interactions between adults and students. Johnson, Johnson, and Zimmerman (1996) defined school climate as students' and teachers' perceptions of their school environment, or the school's personality. Manning and Saddlemire (1996) used feelings of trust and respect for students and teachers to define school climate. Collectively, each of these definitions focuses on an aspect of how to define school climate, yet none of these is independently comprehensive (Marshall, 2004). Furthermore, variations in the definition of school climate create a challenge for researchers when attempting to examine the relationship between school climate and academic achievement (Berkowitz et al., 2016).

One definition that has been recognized as empirically sound and properly comprehensive was developed by the National School Climate Center : "School climate refers to the quality and character of school life. Under this definition, school climate takes a systems perspective and presents a comprehensive set of considerations based on patterns of students', parents' and school personnel's experience of school life and reflects norms, goals, values, interpersonal relationships, teaching and learning practices, and organizational structures" (National School Climate Center, 2015). This definition 
includes the roles of multiple stakeholders such as students, parents, and educators, and it captures the environmental settings such as relationships, instruction, and structures. Given its comprehensiveness, for this paper, the NSCC definition will be used as the operative meaning for school climate. The benefit of such a comprehensive definition is that it ensures inclusion of multiple factors to examine and helps researchers isolate the significance of each of the factors when conducting an empirical study (Thapa et al., 2013).

\section{Assessing School Climate}

Defining school climate is a prerequisite to identifying those factors to be assessed (Anderson, 1982). That foundation lends itself to using the NSCC definition to operationalize the measures surrounding school climate. For instance, making improvements in a school's climate requires an accurate assessment to provide direction for those developing a plan for improvement (Cohen, 2006). Accordingly, many instruments used to evaluate school climate rely on the perceptions of the stakeholders. While perceptual data are sometimes argued as inherently flawed because they rely on subjective recounts and individual experiences from a single lens (Halpin \& Croft, 1963; Moos, 1979; Sarason, 1971), these data are critical when considering school climate because the individual experiences are what shape climate. Supporting that proposition, Goddard, Tschannen-Moran, and Hoy (2001) have posited that the perceptions of the staff and leadership regarding school climate appear to be linked to creating and sustaining effective learning environments. Similarly, according to Bandura (1993), teacher efficacy is a critical trait both directly and indirectly related to individuals' perception of their knowledge and skill to work effectively in the school 
environment. When a teacher's confidence increases, there is a corresponding increase in student achievement (Webb \& Ashton, 1986). In addition, students' positive perceptions of their school climate are associated with increases in academic achievement (Gietz \& McIntosh, 2014). In short, perceptions from all stakeholders play a role in school climate.

Instruments have been developed to assess school climate with directly measured aspects regarding a variety of stakeholders, such as surveys, interviews, and a review of data, such as attendance records and student discipline reports (Freiberg, 1999). Cohen (2006) shared an example from a school where a social and emotional education's comprehensive school climate inventory was administered. Results from the ranking by school staff and parents indicated that bullying was a minor challenge with the school; however, when the students completed the same instrument, they indicated bullying as a major issue. This study illustrated the benefits of examining perceptual data from multiple stakeholders.

\section{School Climate and Leadership}

More than 70 years after Perry (1908) found that principal leadership influences school climate and student achievement, researchers have continued to explore this line of inquiry. Edmonds (1979) concluded principal involvement and interest in instruction contribute to the school climate. Brookover and Lezotte (1979) also found that instructional leadership helped determine the school's tone. Similarly, Young (1980) found that increased instructional leadership by the principal resulted in improved school climate and increased social and academic growth. Consistently, these studies drew out key factors that illustrated that whenever leadership collaboratively established and 
supported a clear and shared organizational focus (Clonan, McDougal, Clark, \& Davidson, 2007; Handler et al., 2007; OSEP Center on PBIS, 2005; Sugai \& Horner, 2006), had high standards for and expectations of student learning (OSEP Center on PBIS, 2005), valued professional learning and maintained a supportive learning environment (Clonan et al., 2007), the school climate had the characteristics to be a highperforming school.

While much of the literature has identified the principal as being key to setting the tone of a school, the interactions among the principal, teachers, parents, and students are also significant (Wallace Foundation, 2006). Given the scope of responsibilities that the principal has to oversee, the principal cannot accomplish all leadership tasks. Appropriately distributing the responsibilities throughout school creates an environment where all members can own the success or failure of the students. Leadership's understanding of how the interactions of all stakeholders contribute to the overall school climate is essential in creating an effective learning environment that maximizes positive student outcomes (Louis, Leithwood, Wahlstrom, \& Anderson, 2010).

\section{School Climate and Academic Achievement}

With the public pressure to increase student achievement as measured by highstakes assessment and accountability systems since the passage of NCLB (2002), school practitioners must create climates that benefit learning for all students. Understandably, a school climate that reduces instructional time and lacks academic focus will result in the diminishing of student achievement (Lassen, Steele, \& Sailor, 2006). For instance, the average amount of instructional time a student loses for an office discipline referral is 20 minutes (Scott \& Barrett, 2004). This time does not include administrative tasks 
associated with managing this disciplinary office referral that could be used supporting instruction. Accordingly, intervention and prevention of behavioral and academic challenge are imperative, especially in the early years of a student's education. Deficits not remediated only worsen when academic and behavior challenges increase with age (McIntosh, Chard, Boland, \& Horner, 2006).

Establishing a positive school climate is a promising practice for creating the conditions for learning that lead to increased student achievement (Cohen et al., 2009). Nonetheless, schools are complex organizations with many moving components. Management of all the parts requires an understanding of systems and how they interact to influence climates, which requires a timely analysis of accurate data to inform decisions. Systematic implementation allows frequent examination of data regarding the effectiveness of interventions on the desired outcome for continuous improvement (Adelman \& Taylor, 2003).

Cohen et al. (2009) used a qualitative review of literature and policy and a survey of state educational leaders to show that a positive school climate promotes learning and supports academic success. A series of qualitative studies have shown that school climate is correlated with school achievement (see, e.g., Brookover \& Lezotte, 1979; Freiberg, 1999). For example, Durlak, Weissberg, Dymnicki, Taylor, and Schellinger (2011) found in a meta-analysis of 213 studies that that when school-based universal social and emotional learning programs were provided, students' academic achievement improved by 11 percentage points on state achievement tests.

Also, studies have documented connections between social emotional variables and academic performance. For example, to identify the most significant influences on 
learning, Wang, Haetel, and Walberg (1997) reviewed 179 handbook chapters and 91 research synthesis and surveyed 61 educational researchers. Of the 28 categories of influence reviewed, they were able to identify the top 11; of those categories, eight were related to social-emotional areas of development that created a school climate that resulted in greater academic outcomes. Extending the prior study, Battistich, Schaps, and Wilson (2004) examined the follow-up effects of a universal prevention program, the Child Development Project (CDP), which had been implemented at the elementary school level as a whole-school intervention program focused on developing students' social, ethical, and intellectual development (Battistich, Schaps, \& Wilson, 2004). The CDP emphasis is solely on prevention of undesirable behaviors across all students and does not include or prescribe any support to those students for whom prevention has been ineffective. The research group consisted of 12 schools from six school districts. Six schools participated in CDP, and six were comparison schools. While the number of schools was relatively low, the number of students, the unit of measure for Battistich et al. was 1,246. When these same groups attended middle school, student behavior and academic performance were examined and compared to students who did not participate in the CDP. Three of the six treatment schools were considered to have implemented CDP with less integrity than the three remaining treatment schools. However, the data from all six of the schools participating in CDP indicated a statistically significant $(p<$ .05) positive difference for the treatment schools in the areas of a sense of school as a community (e.g., school connectedness) and other related attitudes and motivations (e.g., academic performance as measured by grades and district achievement tests; Battistich et al., 2004). The researchers also found that this improved climate resulted in students' 
achieving at significantly higher rates on state achievement tests in the areas of reading and mathematics than comparison schools that did not participate in the CDP.

Building on these earlier studies, the literature has examine the relationship of school climate on aspects of student outcomes. Hoy and Hannum (1997) found a positive correlation between school climate and student achievement. The researchers sampled teachers from 86 middle schools with a series of tools designed to analyze school climate. These survey instruments contained six dimensions commonly affiliated with school health dimensions: academic emphasis, teacher affiliation, collegial leadership, resource support, principal influence, and institutional integrity. Although the degree to which each dimension influenced the academic outcomes varied, Hoy and Hannum concluded that a healthy school climate had a positive contribution to the outcomes of the eighthgrade state assessment.

Taking the school climate health concept further to examine organizational rules, Gottfredson, Gottfredson, Payne, and Gottfredson (2005) determined the school climate components of clarity of rules, fairness of rules, organizational focus, morale, planning, and administrative leadership were all features that reduce school disorder. Furthermore, they examined external factors of socioeconomic status (SES), size of student enrollment, and percentage of male students. Survey results from students indicated that schools where students perceived the rules as fair and clear and the discipline as consistently managed had less disorder, regardless of the external factors such as a low SES (Gottfredson et al., 2005). Schools can thus influence students' behavior and create environments that help to create the conditions for learning and mediate factors that typically account for low academic and behavioral outcomes. 
Conversely, Berkowitz et al. (2016) found through a synthesis of 80 studies the results were inconclusive regarding a positive school climate's mediating the relationship between a low SES and the challenges associated with academic performance. However, such discrepancies in the literature could be the result of the variation among researchers in determining the characteristics of a positive school climate, measures used to determine academic performance, and criteria used in determining the low SES population (Berkowitz et al., 2016). The literature has been clear that one of the strongest predictors of academic achievement is the students' SES (Sirin, 2005). Wang and Hocombe (2010) discovered the relationship between a low SES background and academic achievement can be mediated by establishing a positive school climate where students feel connected and engaged to the school.

Additionally, Choi and Chang (2011) suggested that gender plays a role, especially in mathematics. Females tend to perform lower than their male counterparts on standardized tests of mathematics. Furthermore, at the secondary level, females take fewer high-level math courses and are less likely to pursue careers associated with advanced mathematical skills (Watt, 2006). Researchers have attributed this phenomenon to factors that can be assigned into two broad categories: (a) mathematics attitude and (b) teachers' perception of the school climate. Because the attributes of a positive attitude toward mathematics, being male, being an English speaker, and having highly educated parents appear to enhance a student's trajectory for mathematics achievement, it is imperative that practitioners examine factors that may be mediated to support female students in achieving mathematical skills at a high level. Furthermore, 
female students must have equity of instruction and access to high-level mathematical instruction to support the career path of their choosing.

So it is necessary to examine student discipline and its relationship to enhanced academic achievement. Luiselli, Putnam, Handler, and Feinberg (2005) found that a whole-school positive behavior approach to address disciplinary problems in an urban elementary school reduced office referrals and suspensions and led to an increase in student achievement. It stands to reason that when students are spending more time in the classroom and disruptions are reduced, the result will be increased student achievement. Empirically supported, evidence-based interventions confirm this proactive approach and, when implemented with fidelity, sustain positive student behavior (Bradshaw et al., 2008).

Positive school climates promote behavioral outcomes while supporting effective instruction. In a randomized, waitlist-controlled effectiveness study, Horner and colleagues (2009) found that implementing PBIS with fidelity resulted in a school climate that supported academic outcomes, specifically third-grade state reading assessments. The school safety survey (a standardized instrument for measuring a risk factor score and protective factor score) was administered to both the control and treatment schools and reflected an improvement in perceived school safety and a reduction in office discipline referrals. In addition, the same schools implementing PBIS with fidelity attained a significantly higher proportion of students' meeting or exceeding the state reading standards (Horner et al., 2009). A causal relationship between the implementation of PBIS and academic achievement could not be established; however, a relationship can 
certainly be inferred because a positive environment promotes conditions that enhance learning (Horner et al., 2009).

\section{A Systems Perspective}

A systems approach looks at the overall school as the unit to be analyzed and how the collective body of individuals make up the overall school climate (Hoy et al., 1990). Shaked and Schechter (2013) suggested school leadership use a holistic framework to understand the interplay of the many parts that make up a school to simplify the inherent complexity. Though evidence-based practices affect behavior problems, often the practice is not sustained with fidelity during implementation, especially over an extended period of time. Those implementing a practice must understand the relationships of one school aspect on other aspects to prevent unintended consequences. Traditionally, discipline in schools has been determined by attention to specific children with problem behaviors using punishment rather than embracing a proactive systems approach.

Fidelity of implementation is fundamental to the research base of evidence-based instructional practices. Adding to implementing with fidelity is the need to a commitment of 3-5 years of implementation is essential to change practice (Sugai, 1996). Comprehensive initiatives such as PBIS are multifaceted, with many discrete components that make up the whole. Implementing one part of PBIS well and another part poorly is likely to diminish the overall outcomes. Implementation of an initiative in the context of a school is complex; the barriers that cause initiatives to fail such as a lack of initial program commitment, fiscal and human resources, and a lack of long-term planning to sustain short-term results as well as competing initiatives all have the potential to reduce program effectiveness (Sugai \& Horner 2006). 
The four elements of data, systems, practices, and outcomes reinforce one another in the implementation of PBIS, as illustrated in Figure 2 (Sugai \& Horner, 2006).

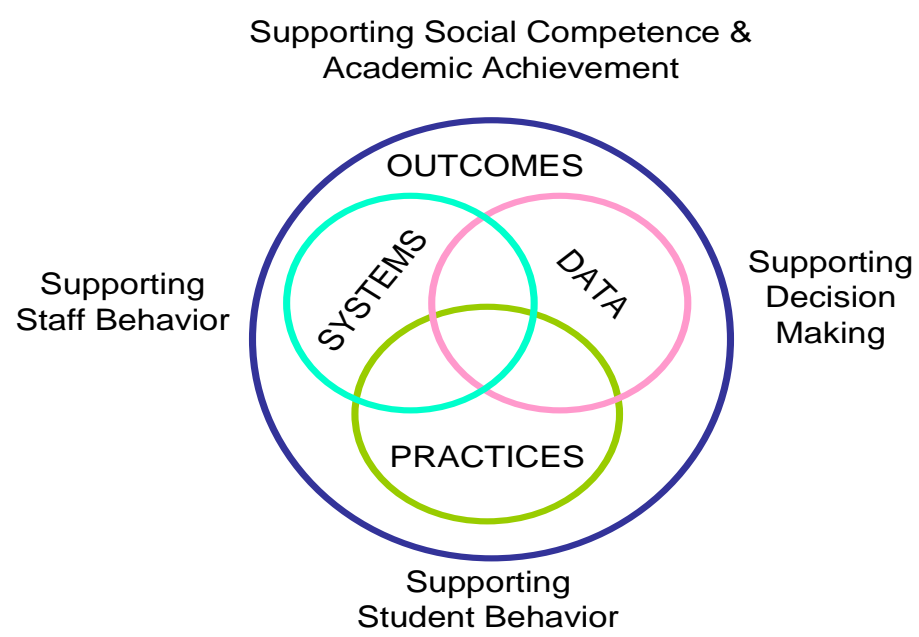

Figure 2. Interaction of the four main elements of PBIS.

PBIS is more likely to be sustained than other behavioral interventions used in schools because of the focus on systems that promote addressing the root cause of the behavioral concerns instead of the typical reactionary method of punishment, which only addresses the concern of challenging behavior (Sugai \& Horner, 2002). Fiscal and human resources, political and administrative support, and training and coaching that can be a hindrance to implementation of behavioral interventions are addressed in the systems approach, hence promoting the sustained implementation of PBIS practices (Carr \& Sidener, 2002). 


\section{Positive Behavioral Interventions and Supports}

PBIS is a systemic and school-wide approach to enhancing school climate by supporting an effective learning environment for all students (Sugai \& Horner, 2009). PBIS is neither a curriculum nor an intervention. Rather, it is a framework that includes (a) prediction and prevention of problems by providing proactive instruction of behavioral expectations, reinforcement of appropriate behavior, and monitoring and correction of problem behavior; (b) collection and use of data for decision making; and (c) application of more intensive and individualized support for students who do not respond to prevention measures (Lewis \& Sugai, 1999; Sugai \& Horner, 2002).

Multi-tiered systems of support such as response to intervention (RTI) and PBIS are designed to build capacity to facilitate success across a minimum of $95 \%$ of the student population (OSEP Center on PBIS, 2005). To do this, implementation must build capacity and expertise within the school regarding student behavior. This proper implementation involves ensuring strong commitment and support from staff, gauging staff interest to ensure readiness to commit to PBIS implementation, facilitating highfidelity implementation, and regularly monitoring implementation efforts.

At its core, PBIS promotes the prevention of problem behavior. Schools implementing PBIS establish a continuum of interventions designed to prevent the occurrence of predictable behavior problems by changing how adults interact with both students and the school environment (e.g., rules, routines, arrangements). Prevention and teaching components are critical across all systems of implementation when identifying interventions (Sugai \& Horner, 2009) through the use of explicit instruction of expectations to promote student understanding. In addition, PBIS focuses on schoolwide, 
nonclassroom, classroom, and individual student systems (Lewis \& Sugai, 1999). Explicit instruction is provided in a variety of contexts across the school and is differentiated for small groups and individual students.

As a layered approach, tier 1 instruction in PBIS is significant in that it changes the school's disciplinary practices from a reactive to a proactive approach. At this tier 1 level, all students receive instruction regarding the rules, routines, and physical arrangements established and taught by school staff. Students must have the opportunity to learn and respond to tier 1 instruction before staff can analyze student data to identify the students who may need more intense interventions.

Because systems to collect and analyze data are a part of PBIS implementation, school personnel are judiciously informed of the need to address specific student needs. Targeting the onset of behavior challenges allows school personnel to intervene at the lowest level of intensity, which often prevents more complex student behavior challenges (Sugai \& Horner, 2009).

Muscott, Mann, and LeBrun (2008) determined the effect of tier 1 PBIS procedures on discipline and academic achievement. After 1 year of implementation, 15 out of 28 schools obtained a fidelity measure of $80 \%$ on the schoolwide evaluation tool (SET). School data showed decreases in office discipline referrals of $28 \%$, out-ofschools suspensions of $19 \%$, and in-school suspensions of $31 \%$. The treatment schools saw an increase in math proficiency scores as measured by New Hampshire's state accountability measure for mathematics.

Numerous studies have emphasized the importance of establishing a learning environment that promotes learning (Berkowitz et al., 2016; Cohen et al., 2009; 
Gottfredson et al., 2005; Hoy \& Hannum, 1997; Shaked \& Schechter, 2013). PBIS is well documented as a process to create a learning environment that enhances instruction (Bradshaw et al., 2010; Horner et al., 2009). Researchers have also emphasized the importance of fidelity in the implementation of PBIS (Barrett, Bradshaw, \& LewisPalmer, 2008; Bradshaw, Debnam, Koth, \& Leaf, 2009). A salient point from each of the studies reviewed indicates more research is needed to determine the relationships among PBIS, implementation fidelity, school climate, and increases in academic achievement.

\section{Multi-Tiered Model}

Walker et al. (1996) described how the schools' focus should be on the systematic use of prevention and intervention strategies using a multi-tiered model. This includes prevention, followed by systemic behavior screening to identify those in need of more intensive supports. Further, formative assessment leads to the identification of students who require increasingly individualized intervention strategies. This system of practices is intended to promote a continuum of alternative school placements to address specific student needs, thereby reducing the use of suspension and expulsion as methods of dealing with inappropriate behavior.

Similarly, Sugai and Horner (2002) described the need for an integrated approach that provides behavior support at the tier 1 (i.e., schoolwide) level for all students, small group interventions at tier 2 for students at-risk of larger failures, and highly individualized interventions at tier 3 for students who have not responded positively to interventions at the previous levels of intervention. The three-tiered model provides a continuum of interventions for all students and differentiates the level of support based on the need for intervention (Sugai \& Horner, 2002). PBIS is designed to support the 
continuous analysis and use of data to make decisions, to support attention to systems, and to support the review of practices to achieve outcomes. Data can be used to identify trends that enhance the ability to predict under what conditions behavior infractions will occur. This model is represented graphically in Figure 2.

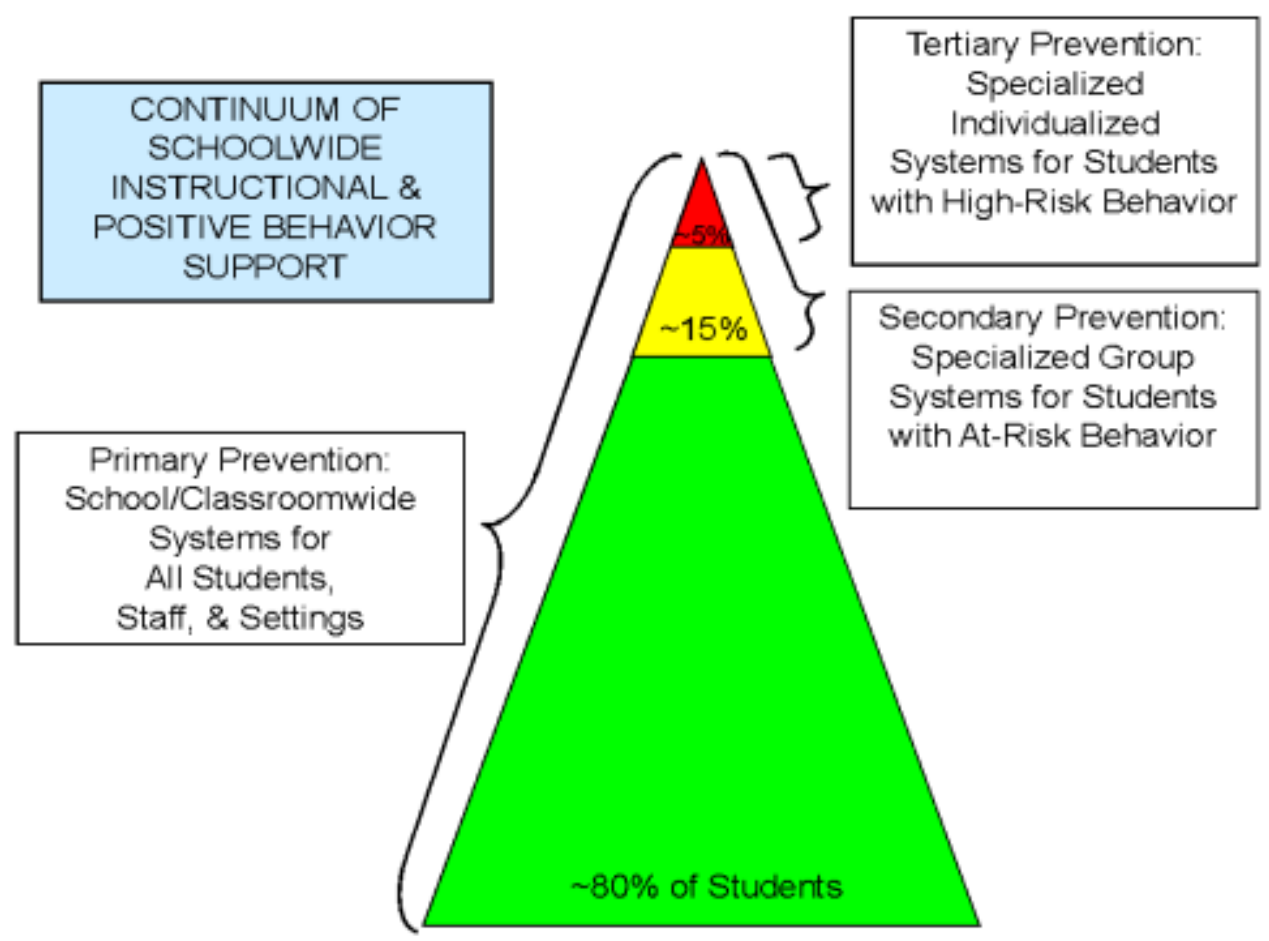

Figure 3. Three-tiered prevention model of PBIS.

Tier 1. According to Sugai and Horner (2002), tier 1 of PBS involves teaching behavioral expectations to all students to prevent and reduce incidents of problem behavior. If tier 1 interventions are implemented with fidelity, fewer students will need a more intense level of intervention at tiers two or three (Gresham, 2005).

Because the effectiveness of PBIS in applying the framework of positive behavioral interventions depends on how well each proceeding tier is implemented, the 
implementation of tier 1 is paramount. Lewis and Sugai (1999) identified the following key features that lay the foundation:

1. The majority of staff ( $80 \%$ or more) agrees to implement PBIS. Learning new practices can become challenging; when difficulties arise, abandonment of the new practice can be an option if the commitment is not made from inception.

2. School personnel, students, and community members develop a set of schoolwide expectations that define appropriate behaviors for all. Examples of a school's expectations are to be respectful, be responsible, be a team player, and be willing to learn. Under each of the broad categories, the specific behaviors are further defined in the respective context (classroom, nonclassroom).

3. Schoolwide expectations are taught to students and are reviewed on a regular basis. Behavior is taught in context to enhance learning. For example, students go to the playground while learning how to demonstrate schoolwide expectations on the playground. School personnel develop schedules for the teaching and achieving of expectations.

4. Schoolwide systems of reinforcement and recognition are developed and implemented with consistency.

5. Students are taught the types of behaviors considered to be rule violations, along with the consequences for not following the rules. Staff members agree on classifying rule violation into the categories of minor and major rule violations to promote consistency schoolwide.

6. A system to compile and analyze data is developed to continuously guide PBIS implementation. 
At the tier 1 level of PBIS, expectations are taught and monitored across all school settings. Research suggests that systematically teaching behavioral expectations and providing positive feedback for students' appropriate behavior create a positive and more effective method of establishing an environment conducive to teaching and learning than simply waiting for and responding to student misbehavior (Sugai \& Horner, 1999). The routine review and reteaching of rules are sufficient to prevent inappropriate behavior across the majority of students (Sugai \& Horner, 2009). However, according to Turnbull et al. (2002), even with primary interventions in place, approximately $20 \%$ of students will need further support beyond the tier 1 level. Tier 1 of PBIS emphasizes the prevention of problem behavior and is to be used with all students, in all settings, and by all staff (Lewis \& Sugai, 1999). This includes a conception of the school as a whole, with nonclassroom and classroom areas seen as separate systems within the total school and for individual students.

The key focus of schoolwide PBIS is to provide all students with direct behavior instruction, supervision, and support. Schools develop, teach, and reinforce a manageable number (three to five) of positively stated schoolwide expectations in the context of different settings throughout the school. Direct instruction of the school-based social skills and reinforcement systems that articulate appropriate behavior are essential to schoolwide systems (Lewis \& Sugai, 1999). Teaching expectations and rewarding appropriate behavior reduces problem behaviors and helps prevent new problems from developing. When the desired behaviors are instructed at tier 1 and implemented with fidelity, a minimum of $80 \%$ of all students will display appropriate behavior (OSEP Center on PBIS, 2005). 
Brophy (1986) suggested in a seminal literature review to explore whether teacher expectations for academic success and effective classroom management are causally related to increased student achievement. Additionally, Linney and Seidman (1989) reported a negative relationship between teacher criticism and student achievement. PBIS implementation promotes both effective classroom systems for appropriate behavior and emphasizes academic achievement.

PBIS implementation includes classroom behavior management strategies that are consistent with schoolwide expectations (Lewis \& Sugai, 1999). The teacher identifies what classroom rules relate to the schoolwide expectations for behavior. Routines regarding behaviors such as starting the school day, turning in work, transitioning from one activity to another, getting assistance, or completing assignments after an absence are all part of the direct instruction within the classroom system (Office of Special Education Programs, 2005). As a part of the PBIS design, classroom behaviors are taught during the first few weeks of school until a large majority of students show they have learned the behaviors and routines, and reteaching occurs when data indicate a need (Colvin \& Lazar, 1997; Cotton, 1990). Explicit instruction and practice are provided so that teachers can correct behavioral mistakes and reinforce appropriate actions. Students who do not respond satisfactory at tier 1 may need additional support that can best be provided at tiers 2 or 3 (Lewis \& Sugai, 1999).

Studies have also indicated that PBIS demonstrates positive change in nonclassroom settings too. Nelson, Colvin, and Smith (1996) found that $50 \%$ of all problem behaviors occur in nonclassroom settings. These are those areas outside of the classroom where students gather, such as the cafeteria, playground, hallways, restrooms, 
and large group assembly areas (Lewis \& Sugai, 1999). Rules and expectations for nonclassroom areas should be taught in their respective context because these areas typically lack routines and include larger numbers of students than found in the classroom. In addition, rules and expectations taught in the classroom context rarely generalize to the other settings (McIntosh \& Turri, 2014). Lewis and Sugai (1999) recommended that nonclassroom area teaching and supervision practices be centered around (a) organizing features of the physical environment, (b) establishing predictable routines, (c) teaching behaviors appropriate to the setting, and (d) ensuring staff members use supervision methods such as movement, proximity, visual scanning, and high rates of positive interactions. Lewis, Colvin, and Sugai (2000) found that the use of active supervision and positive reinforcement in nonclassroom areas yielded a decrease in problem behaviors. However, their data on social skill instruction alone revealed no positive difference in student behavior. Lewis, Powers, Kelk, and Newcomer (2002) found the use of PBIS to improve student behavior in nonclassroom settings, specifically during recess. Furthermore, the more frequently staff observed and acknowledged appropriate student behavior, the greater the reduction in inappropriate behavior.

Tier 2. Gresham (2005) found that students who had not been successful at the tier 1 of PBIS frequently experienced success at tier 2. However, more students at the secondary level of PBIS experienced success and returned to the tier 1 than students who need additional supports at tier 3. Scott (2003) recommended that an intervention team be in place to review student data to orchestrate the movement of students from one tier of PBIS to another. Expertise of the team members in the area of behavioral intervention, 
especially conducting functional behavioral assessments, are to inform the development and implementation of a student's interventions (Scott \& Nelson, 1999).

Important considerations exist when moving tiers. Lewis and Sugai (1999) proposed that once a student moves from tier 1, (a) a functional assessment be conducted, (b) family involvement be included, and (c) training opportunities for families on behavior strategies be provided. As the level of support increases for a student who has moved into tiers 2 or 3 , so does the need to increase the collection and use of data to provide accurate and meaningful feedback. Medley, Little, and Akin-Little (2008) found that student support plans developed by personnel in PBIS schools were more technically adequate than those developed in non-PBIS schools, therefore enhancing students' probability of success.

Lewis, Sugai, and Larson (1999) described tier 2 of PBIS as important to the continuum of support of PBIS, and typical school personnel can provide targeted interventions at this level with positive results for approximately $67 \%$ of students. Tier 2 interventions are an integrated component of PBIS. There are five features distinguishing tier 2 from tier 1 . First, in tier 2, an intervention team coordinates the implementation of the interventions among small groups of identified students. This may include what intervention is to be used, who implements the intervention, and when and where the intervention is to be implemented. The goal at this tier is to reduce targeted behavior problems and increase desired behavior (Turnbull et al., 2002). The second distinguishing feature of tier 2 is developing screening processes to identify the students who have not been successful at tier 1 and in need of further intervention. Third, tier 2 interventions continue to be tied back to the positive expectations established in Tier 1. In this way, tier 
2 is simply a more intensive approach to prevention rather than a separate system (Sugai \& Horner, 2009). The fourth feature of tier 2 involves the development of methods to facilitate regular communication with students, staff, parents, and administration to increase opportunities for students to receive feedback on their behavior. The fifth feature is the use of an array of positive intervention strategies to reinforce desired student behavior (Sugai \& Horner, 2009).

Hawken (2009) suggested that a critical aspect of the secondary tier is the timely implementation of an intervention, as soon as within one week of occurrence. Tier 2 interventions can be delivered one-on-one or in a small group setting and are prescribed by the intervention team based upon the unique needs of the students. Deciding a student needs targeted intervention requires the collection and analysis of data.

Classroom teachers may also refer a student to the intervention team that has not been identified by the screening process. In this circumstance, the referring teacher provides information about strategies implemented to address the student's needs and the response of the student. Upon the review of the student information, the intervention team may recommend revising strategies, implementing new strategies, or moving the student into a Tier 2 intervention. Decision making by the team allows the collection of relevant qualitative and quantitative data so effective behavioral interventions can be developed, either at the Tier 1 or Tier 2 level (Scott, 2003).

Tier 3. Students who have not achieved the desired behavioral results at tiers 1 and 2 are to receive intensified and individualized attention by a designated team at tier 3 , at which interventions are highly individualized (Scotti et al., 1991). This is typically necessary for approximately $5 \%$ of the student population and is the most complex level 
of intervention (OSEP Center on PBIS, 2005). Formal assessments and diagnostics such as a functional behavior assessment are used to develop prescriptive individualized strategies that are often used to develop a behavior intervention plan.

Students at tier 3 displaying significant behavioral issues are more likely to demonstrate academic failure, and criminal involvement and are at risk of dropping out of school (Rylance, 1997). A comprehensive and intense school-based mental health support system that involves wraparound services is needed. This may include multiple agencies providing support to a student (e.g., community health, child and family welfare, law enforcement). Communication and collaboration among agencies and an increase in family involvement are needed to maximize the influence of interventions at this intense tier of PBIS (Eber, Sugai, Smith, \& Scott, 2002). Furthermore, communication among all the stakeholder increases the possibility that all implementers will maintain consistency when providing interventions.

\section{Implementing PBIS}

Regardless of the evidence that supports the effectiveness of an intervention, if the intervention is not implemented as intended, the results are uncertain. Sugai and Horner (2009) identified the following components for successful implementation of PBIS: (a) getting buy-in from staff, (b) providing staff training to promote implementation, (c) creating a leadership team, and (d) using data to make decisions. Staff buy-in and agreement to support PBIS efforts are critical steps in developing sustainable systems. Sugai and Horner (2002) recommended that a minimum of $80 \%$ of school staff support implementation efforts at the adoption stage of PBIS. Leadership of a school should strategically use the processes to gain staff buy-in. An analysis of a 
school's data by staff can be used to identify the need to address student behavior. Although a school can still be successful with less than $80 \%$ buy-in, a plan should be developed to increase buy-in over time (Handler et al., 2007). Leadership should continuously provide opportunities for staff to review and analyze behavioral data so staff can realize the positive outcomes as the result of implementing PBIS.

While training is necessary to implement evidenced-based practices, Joyce and Shower (2002) discovered the traditional "sit and get" teacher training had minimum influence on changing teacher practice. Yoon, Duncan, Lee, Scarloss, and Shapley (2007) found that improvements in student achievement through professional development seemed linear. First, teachers undergo professional training, teacher knowledge and skills increase, classroom teaching is influenced, the teacher practices what has been learned, and then student achievement occurs. As each step occurs, they all move back and forth, interacting with one another and the standards to be instructed. The prescribed training to implement PBIS aligns with the characteristics of effective implementation to accomplish the desired outcomes (Guskey \& Yoon, 2009). Because PBIS is a systems change process to improve student behavior by improving the learning environment, managing all components of the operation is complicated. Training guides teachers to implement evidenced-based practices within the respective contexts of the school community and increases teachers' self-efficacy (Sugai \& Horner, 2006). Kelm and McIntosh (2012) found that when teachers perceived they had the knowledge to positively prevent and intervene with behavioral issues, fewer behavior problems manifested, and when problems did occur, the negative influence on achievement was reduced. 
Kealey, Peterson, Gaul, and Dinh (2000) determined that providing explicit teacher motivation practices as a part of teacher training resulted in a significant increase in program implementation. Professional training to implement PBIS involves different training procedures from those of traditional teacher training such as ongoing professional development and coaching. Supports that enhance PBIS implementation include teacher training, regular communication with staff, getting staff feedback on what works and does not work, and recognizing and reinforcing staff members in their efforts.

Developing a common vision and language as a part of the staff training strengthens implementation and improves the overall organizational health within a school (Sugai \& Horner, 2002). Developing a common vision and language in the implementation of PBIS addresses three critical components: (a) developing a clear statement of purpose for PBIS plans, (b) defining a small number of clearly defined behavioral expectations, and (c) creating procedures to teach and reinforce the defined behavioral expectations (Gottfredson, 1987; Gottfredson et al., 1996; Mayer, Butterworth, Nafpaktitis, \& Sulzer-Azaroff, 1983; Sugai \& Horner, 2002).

Teaming is another key component of sustainable systems. Cohen (2006) identified three essential components of effective PBIS implementation: administrator commitment, functioning of the leadership team, and staff buy-in. Accordingly, Bradshaw et al. (2008) found that the school principal is crucial in implementing PBIS and establishing the overall climate of the school. The school principal provides the foundation needed to implement a comprehensive initiative by effective administrative practices that support staff. Effective principals model the behavior they want others to 
display. They are visible and move about the school, interact with students and teachers in a positive manner, and are present in areas of the campus where student behavioral problems may occur.

Likewise, Handler et al. (2007) found that strong involvement of administrators while implementing PBIS produced the greatest desired outcomes. Principals must be knowledgeable about PBIS, understand PBIS implementation in the context of other initiatives, be willing to be engaged in the PBIS leadership team functions, and hold staff accountable for their respective roles (Newton, Horner, Algozzine, Todd, \& Algozzine, 2009).

Leadership responsibilities extend beyond the principal to that of key members assigned to the leadership team. Sugai and Horner (2002) emphasized the role of the leadership team in effectively implementing PBIS. An effective leadership team reviews the data needed to identify and address precisely what is needed in implementing PBIS with fidelity. The leadership team should be selected based on the expertise of the individuals and the roles they represent. George, Kincaid, and Pollard-Sage (2009) recommended staff from administration, general and special education, guidance, and support services (e.g., school psychologist). At the same time, it is important to determine personnel's expertise and consider the capacity of the school when designing a team to support the implementation of a comprehensive initiative. The tasks of the leadership team will require a substantial time commitment — approximately 40-50 hours of planning and training - upon initial year 1 implementation (Handler et al., 2007). Because the leadership team is the foundation of the overall PBIS implementation 
process, the time commitment is necessary to ensure a high level of expertise across the leadership team members.

Scott and Martinek (2006) suggested that the leadership team seeks the expertise of a PBIS coach. This individual has a deep knowledge of PBIS from the theoretical basis to implementation. The PBIS coach's role includes providing technical assistance and support to the leadership team, providing additional training to staff as needed, and supporting the use of fidelity measures (George et al., 2009). The use of coaching to support staff in the initial implementation of PBIS increases teacher efficacy and fidelity of implementation (Adelman \& Taylor, 2003). PBIS coaches who provide verbal prompts during PBIS implementation increase the quality of data collection (Scott \& Martinek, 2006). Fixsen et al. (2005) found that instructional coaches' providing feedback to implementers promotes the integrity of implementation of a specific initiative.

In a key finding relating to the sustainability of PBIS systems, Newton et al. (2009) stated that leadership teams are more likely to be effective at making decisions with data if the core social and academic outcomes are clearly articulated and measured. According to Safran and Oswald (2003) and Sugai and Horner (2002), the leadership team must develop a system to collect, review, and analyze behavioral data. Office discipline referrals, in-school suspensions, out-of-school suspensions, detentions, time-outs, and expulsions are all the types of behavior that degrade the learning environment. Implementing PBIS to have the greatest influence on the classroom and nonclassroom climates requires the leadership team to make decisions regarding the successes of PBIS and to identify additional necessary interventions (Simonsen \& Sugai, 
2007). The leadership team can also make more informed decisions when it has data reflecting the fidelity of PBIS implementation to determine if implementation changes are needed.

Multiple instruments have been developed to provide useful information regarding the fidelity of PBIS implementation (Lewis \& Sugai, 1999; Sugai \& Horner, 2002). Continuous improvement through the ongoing evaluation of fidelity of implementation is a key feature of PBIS, and the leadership team uses this data routinely to create or revise plans for improvement and sustainability. Sugai and Horner (2002) suggested that the PBIS action plan contain specific descriptions of tasks to be completed, as well as staff and administrative responsibilities, timeline for completion, resources needed, and how each task will be monitored.

Sugai (2007) reported that schools are continuing to increase their use of school data to guide decision making about PBIS implementation. Fundamentally, the design of PBIS promotes the use of data to prescriptively address whole group and individual student needs. Consequently, implementers are motivated to continue the use of data that results from PBIS implementation for the following reasons: (a) learning that student outcomes are improved when they increase their use of data-based decision making, (b) increasingly using decision making practices that decrease the effort and complexity of data management, and (c) discovering that when they actively use data to make decisions, intervention features are more contextually relevant and they are more likely to find improvements in student behavior and teacher effectiveness. 


\section{Fidelity of PBIS Implementation}

Implementation quality (i.e., fidelity) is defined as the degree to which an intervention is conducted as originally intended (Moncher \& Prinz, 1991). This definition is based on the assumption that the intervention is identified and systems are put in place to evaluate the integrity at the onset of the implementation. Implicit training of how to implement an intervention and knowledge of the instruments to be used for evaluating implementation increase the likelihood fidelity will be maintained (Kealey et al., 2000).

According to Gresham, Gansle, and Noell (1993), a lack of data regarding fidelity of implementation may compromise the evaluation of the validity of the intervention. Regardless of the potential effectiveness of an intervention, when integrity is lacking, it is difficult to determine a causal relationship. Whereas some schools have shown positive outcomes when PBIS was implemented, others have achieved minimal or no improvements in behavioral outcomes (Muscott et al., 2008; Sadler \& Sugai, 2009). Evaluating the fidelity of implementation of an intervention is paramount to inform decisions to continue or abandon an intervention.

Childs, Kincaid, and George (2010) suggested that when implementing PBIS, multiple sources of data should be used to evaluate fidelity of implementation. While multiple measures certainly strengthen the PBIS leadership team's ability to make informed decisions to support implementation, the amount of time to administer the measure(s) of fidelity must be a consideration, along with the feasibility with the school's resources. If an instrument requires an inordinate amount of time to administer, the likelihood of sustainability is jeopardized (Sugai \& Horner, 2009). 
The continuum of interventions is typically arranged within the three-tiered model of universal, secondary, and tertiary prevention. Implementation of the secondary and tertiary levels of PBIS depend on the effective implementation of the universal level of PBIS. Researchers have developed instruments to evaluate fidelity of PBIS implementation, which are the team implementation checklist, PBIS self-assessment survey, schoolwide evaluation tool, and benchmarks of quality. The schoolwide evaluation tool and benchmarks of quality are the most widely researched instruments to measure fidelity.

\section{Student Achievement and PBIS}

PBIS is intended to improve the overall effectiveness of schools' learning environments by increasing the amount of instructional time and academic engagement in the classroom (Horner et al., 2009). Because instructional time is correlated with academic achievement, the school climate must maximize instructional time. Scott and Barrett (2004) found the typical office discipline referral for inappropriate behavior resulted in a minimum of 20 minutes of lost instruction for the student referred.

Furthermore, the process to refer a student to the office for a discipline infraction often impedes the instructional delivery for other students in the classroom (Scott \& Barrett, 2004).

The literature consistently reports that challenging behavior has a negative influence on student achievement. Horner et al. (2009) examined the academic achievement of third-grade students on state reading standards. Results of this randomized, waitlist-controlled study reflected higher academic achievement than those in a control group; however, the researchers suggested additional studies should be 
conducted to learn more about the relationship PBIS implementation has with academic achievement.

Luiselli, Putnam, Handler, and Feinber (2005) also found that standardized test scores in an elementary school increased from 18 percentage points in math achievement and 25 percentage points in reading achievement after the implementation of PBIS. Office discipline referrals and out-of-school suspensions were reduced in their study each year of the 3 years of implementation; therefore, the assumption that students were engaged in classroom instruction was made. In addition, teachers reported PBIS implementation was effective and contributed to better classroom learning (Luiselli et al., (2005).

In a 5-year randomized controlled effectiveness trial of PBIS, Bradshaw, Mitchell, and Leaf (2010) found no significant differences in math or reading achievement scores of students in grades three and five between the control group and the experimental group. Though improvement in test scores tended to be higher for schools implementing PBIS, the increases were not significant.

The literature is less clear on PBIS and the influence on academic achievement when a statewide PBIS initiative is examined. Muscott et al. (2008) discovered largescale implementation of PBIS in New Hampshire schools improved math achievement. However, the authors did not include non-PBIS schools as a comparison group to determine whether increases in math occurred regardless of PBIS implementation. Furthermore, less than half of the schools showed an increase in reading achievement. Fidelity of implementation was achieved by the sample schools, as measured by the SET for each of 2 two years of achievement data. This study did not 
inspect differences between students of different socioeconomic backgrounds or gender, which might have provided a more in-depth analysis of how PBIS interacted with the academic results among these variables (Muscott et al., 2008).

\section{Research Questions}

The following research questions will be used in this study to examine the relationships between PBIS and mathematics achievement in elementary schools.

1. Is there a significant difference in the percentages of fifth graders at the combined proficient and distinguished performance levels in mathematics between schools that implemented PBIS and schools that did not implement PBIS?

2. Is there a significant difference in the percentages of male fifth graders at the combined proficient and distinguished performance levels in mathematics between non-PBIS and PBIS schools?

3. Is there a significant difference in the percentages of female fifth graders at the combined proficient and distinguished performance levels in mathematics between non-PBIS and PBIS schools?

4. Is there a significant difference in the percentages of fifth graders scoring proficient and distinguished performance levels in mathematics between schools that implemented PBIS and schools that did not implement PBIS controlling for the schools' socioeconomic status?

\section{Conclusion}

U.S. schools are faced with increasing demands to produce academic outcomes for all students. It is therefore incumbent upon schools to use educational means to enhance the school environment, which, as suggested in the extant literature, indirectly 
helps improve academic goals to be. Often when achievement scores are less than desired, professional development to address the instructional skills and knowledge of teachers in the respective content area are confronted to tackle the deficit. While highquality instruction in content areas is essential, the influence on student achievement will be minimal if such instruction is implemented in an environment that does not support learning for all students. As has been suggested, for educators to be effective regarding the interventions adopted to achieve the desired results, the learning climate should be addressed.

This review of the literature established that a healthy school climate creates conditions that enhance student learning (Cohen et al., 2009; Hoy et al., 1990). Relationships among all shareholders (e.g., school personnel, parents, students) determine the norms and values of the school (Thapa et al., 2013).

Also, schools are complex organizations comprised of many parts. School leaders must attend to all of these components, moving them forward in unison to achieve the maximum positive influence on student outcomes. Using a systems-thinking approach facilitates the comprehensive management of all aspects of a school, including demographic obstacles to academic success (Senge, 2006). PBIS is a systems-based framework for creating a positive school-wide climate through positive and proactive behavioral interventions. Essential to the PBIS framework are the formal collection and analysis of data. School data are used to make plans that prescriptively address the behavioral needs of all students in all settings. In any school, consistent and unified teaching of expectations, coupled with acknowledgement for positive behavior, represents the foundation of an effective system for facilitating students' behavioral 
success. Without a framework for considering these tasks, however, the foundation may be ill-equipped to support the school's goals. The PBIS framework facilitates identification of the school's individual problems to be addressed, specific behaviors to be taught, and consistency with which behaviors are acknowledged in an agreed upon manner. Because decisions are made based on the analysis of data, fidelity of implementation is critical to accurately inform the development of the plans of actions from data analysis.

This review of the literature examined research regarding school climate, its relationship to academic achievement, PBIS and the association to school climate and academic achievement, SES and academic achievement, and gender on academic achievement (specifically mathematics). Whereas this review of the literature is helpful in understanding factors related to school achievement, more information is needed to enhance the ability of policy makers and practitioners to be intentional in their decisions related to learning and understanding how PBIS influences achievement.

Previous studies have not focused specifically on the high-fidelity implementation of PBIS in elementary schools from a state perspective seeking to understand its relationship to academic achievement (Bradshaw et al., 2010). Furthermore, comparing academic achievement in schools that did not implement PBIS and exploring the gender differences while controlling for low socioeconomic status, have the potential to address variables that present challenges in achieving desired academic outcomes. 


\section{CHAPTER III}

\section{METHODOLOGY}

The purpose of this study was to examine the relationship positive behavioral interventions and supports (PBIS) has on students' mathematics achievement in elementary schools as measured by the Kentucky Performance Rating for Educational Progress (KPREP). Empirical research has demonstrated that a positive school climate promotes academic achievement (Hoy et al., 1990). PBIS, when implemented with fidelity, purports to positively alter school climate, thereby supporting teaching and learning (Horner, 2005; Bradshaw et al., 2008). Because mathematics achievement is a predictor of future academic attainment and career success (Murnane et al., 1995), and previous studies suggested that implementation of PBIS tends to promote academic achievement, it is helpful to investigate the effects of PBIS implementation on mathematics achievement to help school leaders determine if this framework can be used to advance mathematics achievement for all students.

This study explored whether implementing PBIS supports the school's goals in meeting all student needs for academic achievement, specifically populations that have historically shown a discrepancy in achievement levels. Typically, students of low socioeconomic status (SES) obtain lower academic achievement results than students who are not of low SES (Berkowitz et al., 2016). In addition, gender gaps in mathematics achievement vary depending on the measure used to determine achievement. Females tend 
to do better on classroom assessments that lead to classroom grades while males usually perform better on standardized mathematics tests. Cimpian (2016) discovered that as early as preschool, teacher perceptions of the mathematical ability for males is higher than that for females. Learning experiences in these early years influence are related to later learning and possibly influence female students' decisions to not pursue science, technology, engineering, and mathematics career choices (Eccies \& Wang, 2015). Given these considerations, this study also examined whether implementation of PBIS, in light of SES and gender, lead to statically significant differences in mathematics achievement outcomes.

\section{Instrumentation}

Secondary data from two instruments, K-PREP and benchmarks of quality (BoQ), were used in this study. K-PREP provides the data to determine the academic achievement in mathematics. BoQ presents data identifying whether an elementary school as the treatment group implemented PBIS with fidelity.

K-PREP. The K-PREP is a high-stakes accountability assessment administered in grades 3-8 throughout Kentucky's public schools within the last 14 instructional days of the school calendar. This instrument measures items from the common core standards that Kentucky adopted in reading, mathematics, and writing, and the core content for science and social studies adopted from the previous curriculum framework.

The K-PREP includes test items that have been norm-referenced, allowing Kentucky to obtain a national percentile score to compare Kentucky students' performance to students nationally. In the K-Prep, mathematics in fifth grade is the content area and grade level used for this study. The mathematics test at fifth grade assesses knowledge in the domains of (a) operations and algebraic thinking, (b) number and operations in base ten, (c) number and 
operations-fractions, (d) measurement and data, and (d) geometry (Kentucky Department of Education, 2015a).

The No Child Left Behind Act (NCLB) of 2002, and the subsequent reauthorization of this federal law, Every Student Succeeds Act (ESSA) of 2016, hold schools accountable for their students' achieving a proficient or higher level assessment and public reporting of test results to multiple audiences in specific ways. These results are compiled to produce an individual student report, a school-level report, a district-level report, and a state-level report. Because PBIS is implemented at the school level, the K-PREP scores at the school level reflect a key comparison to match the proper unit of analysis with the PBIS treatment group.

Further, as noted earlier, both NCLB and ESSA report student achievement scores as meeting proficiency or higher without any additional distinction, but Kentucky's assessment system adds the performance level of distinguished (ESSA, 2016). However, to create a standardized approach to analyzing the data so they may be applied to other studies looking at other state data for future comparisons, this study combines the percentage of proficient and distinguished student performance levels. In complying with ESSA (2016), test data are compiled by all students and then further disaggregated by special populations. For the purposes of this study, the populations' divided gender and SES were examined.

More specifically, performance levels were determined by converting the raw scores to scale scores. Scaling procedures included using the Rasch measurement model for multiple-choice test items and the partial credit model for constructed response test items. Step parameters were developed to identify the various points possible on the item as related to the item's overall difficulty. These parameters were produced on the frequently used theta scale, which has a mean of 0 and a standard deviation of 1 . Creation of the theta scoring 
tables allowed the linear reporting of a raw score to a scale score from 100-300. Content experts, with technical assistance from KDE and Pearson, facilitated the process of establishing cut scores to establish the performance levels of novice, apprentice, proficient, and distinguished. Cut scores for the performance level of proficient and distinguished for fifth grade mathematics for the 2014-2015 school year on the K-PREP are proficient (210228) and distinguished (229-300) (Kentucky Department of Education, 2015b). Students with a scale score below the proficient cut score are considered to be below the goal of the assessment and accountability system for Kentucky students. This study used the percentages of students at or above the proficient performance level as the school scores. Descriptive statistics for fifth-grade mathematics include a scale score mean of 212.40 with a standard deviation of 20.2 (KDE, 2015b).

K-PREP reliability. K-PREP reliability was examined prior to using these achievement scores as data sources. Reliability is the degree to which measures produce consistent, stable indicators of the level of the variable (Slaven, 2007). Regarding student achievement, when a score is reported for a student, there is an expectation that if the student had taken a different but equivalent version of the test, a similar score would have been obtained. If an achievement test does not measure student ability and knowledge consistently, it has no value in accomplishing the desired purpose (KDE, 2015a). Furthermore, the ability to measure consistently is a prerequisite to making appropriate interpretations of the scores on the measure (Dillman, 2000).

Test-retest reliability estimation is not used with the K-PREP because Kentucky's high-stakes accountability test mandates that students never take the same test twice. Testretest would require a gap in time between administrations of the K-PREP, and student 
growth may occur as the result of continued instruction. Additional testing would also take time from instruction (KDE, 2015a).

Alternative forms reliability is another method used to estimate test reliability when two comparable forms of the test are administered to the same students. Accurately measuring the two forms' coefficient depends on the degree of equivalency between the two versions of the test. The alternative form reliability method is not used for assessing the reliability of the K-PREP because Kentucky policy is that no student is to take more than one form of the high-stakes assessment (KDE, 2015a).

The internal consistency reliability estimation approach requires the test to be administered only one time, which it is advantageous to reliability methods requiring multiple administration. Therefore, internal consistency reliability is used to determine the reliability of the K-PREP test. Cronbach's (1951) coefficient alpha, frequently referred to as the coefficient alpha, is the most frequently internal consistency reliability estimate. The coefficient alpha is based on the assumption that the inter-item covariance constitutes truescore variance and that the average true score variance of items is greater than, or equal to, the average inter-item covariance (Cronbach, 1951). Coefficient alpha estimates for each overall test and by item type are provided for each grade and subject on the K-PREP test (KDE, 2015a). The coefficient alpha for all students in grade five mathematics are the multiple choice items $(\alpha=0.90)$, constructed response ( $\alpha=0.66)$, and an overall $(\alpha=0.91)$ reflecting strong internal consistency of the test items. The standard error of measurement, which provides an estimate of how much error there is likely to be in an individual's score, is calculated for each subject and grade level of the K-PREP. The standard error of 
measurement for K-PREP fifth-grade mathematics of (5.92) is an estimate of how much error there is likely to in an individual's score (KDE, 2015b).

K-PREP validity. K-PREP validity was also examined. Validity is the degree a test actually measures the concepts it is supposed to measure (Slaven, 2007). Evaluating the validity of the K-PREP test is a complex process that involves multiple steps prior to and after the administration of the test. The development of the Kentucky Performance Rating for Educational Progress, 2014-15 Technical Manual, and the accompanying Kentucky Performance Rating for Educational Progress, 2014-15 Year Book, was led by the Pearson Assessment. The overall process for validating the K-PREP involved input from a variety of stakeholder groups and professional organizations. The Kentucky Department of Education (KDE), Kentucky educators, the School Curriculum, Assessment, and Accountability Council, and the National Technical Advisory Panel on Assessment and Accountability (NTAPAA) each served specific roles in the development and review the K-PREP (KDE, 2015a).

The validity of the argument-based approach, which is an explicit scientific justification of the degree to which evidence and theory support the proposed interpretations of the test, is used for the validation of the K-PREP (Kane, 2013). The stages of scoring, generalization, extrapolation, and implication are important features used by the evaluators. Scoring validity for this study included the scoring of performance items and model fit and scaling. Results for the inter-rater agreement for fifth grade mathematics for constructedresponse items on the K-PREP are in Table 1. 
Table 1

Interrater Scoring Agreement and Reliability

\begin{tabular}{lcc}
\hline \multicolumn{1}{c}{ Domain } & Agreement & Reliability \\
\hline Operations and Algebraic Thinking & 94 & 83 \\
Number and Operations in Base Ten & 91 & 80 \\
Number and Operations-Fractions & 90 & 83 \\
Measurement and Data, Geometry & 90 & 82 \\
\hline
\end{tabular}

Note. Metrics are based on fifth-grade mathematics from administration of the K-PREP for 2014-15.

Another area of importance when examining the K-PREP as a test instrument is item response theory (IRT). IRT assigns the level of difficulty of items on the test and is used for the K-PREP design. When the level of difficulty has been established, equating test items allows items to be interchangeable across various forms of the test. Scaling, as previous noted, is used to convert scores into meaningful units of comparison. K-PREP addressed the generalization stage of the validity argument using evidence of content validity and evidence of control of measurement error. Because the K-PREP is based on specific content standards, constructing items to measure the intended achievement are well defined. Committees of content experts convene with item-development experts, KDE staff, and assessment experts to review test items and the results of field-tested items. An items is revised or omitted when evidence supports that the defined content is not assessed by the item. Content review committee meetings are highly structured with a defined purpose to further support the K-PREP validity. Reliability and the coefficient alpha were discussed above in the context of reliability as well as the conditional standard error measures for each scale score in fifth-grade mathematics and the coefficient alpha reliabilities for raw scores 
(KDE, 2015a). Extrapolation to support validity implies the sample of content assessed on the test can infer the students' knowledge of the overall common core standards for the subject and grade. While it is not practical to assess every concept, the test should be designed to assess as many concepts as feasible to extrapolate the achievement results. The peer review process conducted by the U.S. Department of Education satisfied the federal requirements of NCLB (KDE, 2015a, 2015b). In short, the K-PREP meets the conventional standards as a sound test instrument.

Benchmarks of Quality. The BoQ is used in this study to discriminate between schools in the treatment group and schools not in the treatment group. BoQ is a researchvalidated measure that assesses the development and implementation of PBIS across the elements critical to the effective implementation, including (a) the PBIS team, (b) faculty commitment, (c) effective procedures for dealing with discipline, (d) data entry and analysis plan established, (e) expectations and rules developed, (f) reward/recognition program established, (g) lesson plans developed for teaching expectations and rules, (h) implementation plan, (i) crisis plan, and (j) evaluation (see Appendix B). Under the 10 critical elements, there are 53 corresponding benchmarks to be rated at least annually. Developers of the BoQ recommended using the scoring guide to rate the status on PBIS implementation close to the end of the school year, March, April, or May. Members of the leadership team rate, based on self-reported data, each of the 53 benchmarks from 0 to 3 and submit the BoQ score form to the PBIS coach. Next, the PBIS leadership team discusses the individual ratings of the team members to achieve consensus on a final score. BoQ include a scoring guide with a rubric for each of the benchmarks (see Appendix B). Because BoQ contain 10 discrete critical elements, ratings can be used to evaluate strengths and to identify 
areas of need. BoQ are the preferred instrument to measure the fidelity of implementation at the schoolwide level (Bradshaw et al., 2009). Nonetheless, the BoQ is ultimately derived from self-reported data.

Prior to the development of BoQ, the most widely used instrument to measure the fidelity of implementation of PBIS was the schoolwide evaluation tool (Horner et al., 2004). Similar to BoQ, the SET is a research-validated measure that assesses the development and implementation of key features of tier 1 PBIS (Bradshaw et al., 2009). Although the SET meets and exceeds the psychometric properties used for measurement in research, the SET also requires an external evaluator who has received extensive training to administer. Consequently, the added expense of an external evaluator, in addition to the lengthy administration time involved in administering the SET, may be barriers to measuring the fidelity of implementation (Cohen, Kincaid, \& Childs, 2007; Horner et al., 2010).

Additionally, researchers predict that the more time-consuming and expensive an instrument is in measuring PBIS fidelity of implementation, the less likely the activity of measuring fidelity will be sustained over time (Kincaid et al., 2005).

Researchers have provided evidence supporting the validity and reliability of scores obtained using the BoQ. For example, Cohen et al. (2007) and Childs et al. (2010) established BoQ have strong psychometric properties. Descriptive statistics for BoQ were collected from 105 schools that produced an $M=69.33(S D=19.70)$. Project personnel researching BoQ elected to use the score of 70 out of a possible 107 to indicate a school is implementing PBIS with fidelity. Because the SET has been determined to have good psychometric properties, the SET was administered within 2 weeks of the administration of BoQ to determine a correlation. Using the Pearson product-moment correlations to show the 
strength of the relationship between two variables, results indicated a correlation of $r=0.51$, $p<.05$ between the SET and BoQ. Internal consistency was calculated using Cronbach's coefficient alpha for all $\mathrm{BoQ}$ subscales and the total score. The results provided an overall $a$ $=0.96$, and the subscales ranged from $a=0.43$ to 0.87 , with only the first or the 10 subscales less than $a=0.70$. Interrater reliability was completed by two people at 34 schools completing the BoQ to determine a correlation between raters. Using the Pearson productmoment correlations, $r$, for the overall $\mathrm{BoQ}$ to examine the strength of the relationship between raters indicated a correlation of $r=0.87, p<.01$. Because the $r$ range of values were from +1 to -1 , and a value of 0 indicated no association, the results indicated a strong relationship between raters. Test-retest reliability is the ability of a measure to produce consistent results when administered at different points in time. Pearson-product-moments were calculated from two administration times of the BoQ to determine the test-retest reliability, and the results indicated a high correlation of $r=0.87, p<0.1$ between administrations (Cohen et al., 2007). Thus, when implemented with reliability, the BoQ offers a reliable measure.

Schools obtaining a raw score of 70 or greater were deemed to be implementing PBIS at a high degree of fidelity and qualified within the treatment group of this study. BoQ data used in this study were compiled by the Kentucky Center for Instructional Discipline (KYCID) personnel to measure fidelity of implementation for schools participating in the PBIS initiative.

\section{Unit of Analysis}

The treatment sample of this study consisted of 112 Kentucky public elementary schools that implemented PBIS schoolwide during the 2012-13, 2013-14, and 2014-15 
school years by participating in the KYCID initiative. Each treatment school obtained a fidelity score of 70 or greater on the BoQ for 3 consecutive years during the data collection timeframe of this study, which indicates a high level of fidelity of implementation. Schools at the elementary level have been selected based on the achievement literature that indicates PBIS effectiveness at this level reflects the greatest academic gains (Barrett et al., 2008; Bradshaw et al., 2010; Horner et al., 2009; Muscott et al., 2008). Academic achievement scores consisted of the combined proficient and distinguished scores for students in fifth grade on the K-PREP assessment. Fifth-grade achievement results were used because the majority of students in this group most likely attended the same school where PBIS had been implemented for 3 consecutive years. PBIS implemented at high fidelity over a 3-year period has a greater chance of benefitting school climate and achievement than 1 or 2 years of implementation (Bradshaw et al., 2010).

The following parameters were used to exclude schools from the control group:

- Elementary schools that participated in the KYCID initiative and did not achieve fidelity of implementation as measured by the BoQ

- Elementary schools participating in the University of Louisville's College of Education and Human Development Center for Instructional and Behavioral Research in Schools Project

- Elementary schools that had a student population in fifth grade at a school that were too few to use to calculate a statistically accurate score

- Elementary schools that do not include fifth grade in the student population. Using the exclusion criteria, 342 elementary schools remained in the control sample. 


\section{Design of the Study}

Drawing on existing data that differentiates school mathematics achievement data between PBIS implemented schools versus non-PBIS implemented schools, this study takes a causal-comparative research design approach with an inquiry that examines the school differences in mathematics achievement of fifth-grade school children in Kentucky. Using other terminology to describe the same research design, Johnson and Christensen (2000) classified this type of study as "explanatory nonexperimental research" (p.7 ). Whether referenced as a causal-comparative design or an explanatory nonexperimental research, this study explores differences based on variables of interest.

The dependent variable of this study is mathematics achievement for fifth grade at the school level. K-PREP scores that reflected the percentage of students obtaining a score at each performance level were compiled. Percentages of proficient and distinguished were combined and the score for each school was used for analysis. PBIS was the independent variable at two levels: PBIS implementation with high fidelity coded as 1 and no PBIS implementation as 0 . Table 2 describes the variables of interest for all students in the treatment and control schools. School-level achievement data were further disaggregated into the percentages of students scoring at each performance level within a gender. Accordingly, the variables examined within males at the schools studies are presented in Table 3, and the variables examined within females at the schools studies are presentd in Table 4. Further, when examining school-level performance by comparing low and not low SES proxies, the variables examines are presented in Table 5. Each of these variables examining academic achievement between PBIS and non-PBIS schools in mathematics are dependent variables in the study. SES was determined based on the student's qualifying for 
free or reduced lunch according to the National School Lunch Program (NSLP) guidelines.

Students meeting NSLP income requirements were deemed low SES whereas students not meeting these requirements were considered not-low SES.

Table 2

Description of the Study Variables for Overall Academic Achievement

\begin{tabular}{lcc}
\hline \multicolumn{1}{c}{ Description } & Type of Variables & Coding \\
\hline Mathematics achievement & Dependent variable & Continuous \\
& & \\
PBIS & Independent variable & $0=$ Control schools \\
& & $1=$ Treatment schools \\
\hline
\end{tabular}

Note. Mathematics achievement scores are the percentage of fifth-grade students in a school obtaining a performance level of proficient and distinguished on the 2014-15 administration of the K-PREP.

Table 3

Description of Study Variables for Male Academic Achievement

\begin{tabular}{lcc}
\hline \multicolumn{1}{c}{ Description } & Type of Variables & Coding \\
\hline Mathematics achievement & Dependent variable & Continuous \\
for males & & \\
& Independent variable & $0=$ Control schools \\
PBIS & & $1=$ Treatment Schools \\
\hline
\end{tabular}

Note. Mathematics achievement scores are the percentage of fifth-grade students in a school obtaining a performance level of proficient and distinguished on the 2014-15 administration of the K-PRE 
Table 4

Description of the Study Variables for Female Academic Achievement

\begin{tabular}{lcc}
\hline \multicolumn{1}{c}{ Description } & Type of Variables & Coding \\
\hline Mathematics achievement & Dependent variable & Continuous \\
for females & & \\
& Independent variable & $0=$ Control schools \\
PBIS & & $1=$ Treatment Schools \\
\hline
\end{tabular}

Note. Mathematics achievement scores are the percentage of fifth-grade students in a school obtaining a performance level of proficient and distinguished on the 2014-15 administration of the K-PREP.

Table 5

Description of Study Variables for Academic Achievement by SES

\begin{tabular}{lcc}
\hline \multicolumn{1}{c}{ Description } & Type of Variables & Coding \\
\hline Mathematics achievement for & Dependent variable & Continuous \\
Students from low SES & &
\end{tabular}

Mathematics achievement for Dependent variable Continuous students from not low SES

PBIS

$$
\begin{gathered}
0=\text { Control schools } \\
1=\text { Treatment schools }
\end{gathered}
$$

Note. Mathematics achievement scores are the percentage of fifth-grade students in a school obtaining a performance level of proficient and distinguished on the 2014-15 administration of the K-PREP. SES will be used as a covariate due to the relationship between academic achievement and SES.

\section{Procedures}

Elementary schools that participated in Kentucky Center for Instructional Discipline (KYCID) during the 2012-13, 2013-14, and 2014-15 school years and that obtained a high 
rate of fidelity of implementation on the BoQ (70 or greater) for each of the 3 consecutive years of implementation were selected as the treatment group for this study. Achievement data from the 2014-2015 school year were used to compare the successful outcomes between the treatment and control groups. These data were retrieved from the KDE website. BoQ data were retrieved from the data collected by KYCID. K-PREP percentage of students in the performance levels of proficient and distinguished for the school's fifth grade

mathematics were used as the measure for academic achievement. All schools were assigned a code to maintain the anonymity of the schools used in this study.

A comparison group of elementary schools in Kentucky that did not participate in PBIS implementation was identified. As with the treatment group, achievement measures for this control group in this study were the combined percentages of students who obtained the level of proficient and distinguished on fifth-grade mathematics. Achievement data for both the treatment and control group were retrieved from the achievement results available on the Kentucky Department of Education website.

\section{Research Questions and Hypotheses}

RQ1: Is there a significant difference in the percentage of fifth graders at the combined proficient and distinguished performance levels in mathematics between schools that implemented PBIS and schools that did not implement PBIS?

Hypothesis: The percentage of students obtaining proficient or distinguished on mathematics achievement for students in PBIS schools will be higher to a level of statistical significance than the percentage of students obtaining proficient or distinguished mathematics achievement in non-PBIS schools. 
Null: There will be no difference in the percentage of students obtaining proficient or distinguished on mathematics achievement scores for students in elementary schools where PBIS has been implemented as compared to elementary schools not implementing PBIS in the performance of all students.

An independent $t$-test will be used to compare the means of the control and treatment groups to determine if a statistical significance exists between the academic achievement of the groups. Assumptions for an independent $t$-test includes that there is one continuous dependent variable, the two samples are independent, and each population will follow normality. These data will be analyzed for each of the assumptions prior to conducting inferential tests. If the assumptions of the independent $t$-test are violated, nonparametric tests will be conducted.

RQ2: Is there a significant difference in the percentages of male fifth graders at the combined proficient and distinguished performance levels in mathematics between non-PBIS and PBIS schools?

Hypothesis: The percentage of students obtaining proficient or distinguished on mathematics achievement for male students in PBIS schools will be higher to a level of statistical significance than the mathematics achievement in non-PBIS schools.

Null: There will be no difference in the mathematics achievement scores for male students in elementary schools where PBIS has been implemented with fidelity from those in elementary schools not implementing PBIS.

RQ3: Is there a significant difference in the percentages of female fifth graders at the combined proficient and distinguished performance levels in mathematics between non-PBIS and PBIS schools? 
Hypothesis: The percentage of students obtaining proficient or distinguished on mathematics achievement for female students in PBIS schools will be higher to a level of statistical significance than the mathematics achievement in non-PBIS schools.

Null: There will be no difference in the mathematics achievement scores for female students in elementary schools where PBIS has been implemented with fidelity as compared to those in elementary schools not implementing PBIS.

To answer research questions 2 and 3 , an independent $t$-test was used to compare the means of the percentage of males and females who achieved proficiency in the control group and treatment group. An assumption of the independent $t$-test is that there is one continuous dependent variable, the two samples are independent, and each population will follow normality. These data were analyzed for each question to see if it fit each assumption prior to conducting inferential tests. If the assumptions of the independent $t$-test were violated, nonparametric tests was conducted.

RQ4: Is there a significant difference in the percentages of fifth graders who scored proficient and distinguished performance levels in mathematics between schools that implemented PBIS and schools that did not implement PBIS while controlling for the schools' SES?

Hypothesis: The percentage of students of low SES in PBIS schools scoring proficient or distinguished will be commensurate with the percentage of students of not low SES scoring proficient or distinguished in non-PBIS schools when controlling SES.

Null: There will be no difference in the mathematics achievement scores for students in elementary schools where PBIS has been implemented from elementary schools not implementing PBIS in the performance of all students when low SES was controlled. 
To answer question 4, analysis of covariance (ANCOVA) was used to compare the means of the control and treatment groups to see if any statistically significant difference existed in mathematics achievement after adjusting for SES within groups. Amatea and West-Olatunji (2007) and Berkowitz et al. (2016) found a relationship between a school's low SES and low academic achievement, which is the dependent variable of this study. Whereas ANCOVA does not eliminate bias, it helps to make the comparison between the treatment and control groups more equitable. Therefore, major assumptions of ANCOVA are that of normality and linearity, along with equal regression slopes. If one or more of the assumptions of ANCOVA are violated a different linear model, a nonlinear model may provide better results to address the research question. The influence of the assumption results will depend on the extent of the violation and will inform the next step in statistical testing.

\section{Summary}

Chapter 3 has presented the methodology, instruments, population, design of the study, procedures, and null hypotheses to be used in this quantitative, quasi-experimental study. In addition, null hypothesis and statistical tests used for each research question were identified. In Chapter 4 the results of each statistical test will be presented. 


\section{CHAPTER IV}

\section{RESULTS}

The purpose of this quantitative causal-comparative study was to investigate the relationship between positive behavioral interventions and supports (PBIS) on fifth-grade student mathematics achievement in elementary schools as measured by the Kentucky Performance Rating for Educational Progress (K-PREP). Prior research has indicated that a positive school climate may enhance student achievement, with PBIS altering school climate and supporting teaching and learning (Bradshaw et al., 2008; Horner, 2005; Hoy et al., 1990). Mathematics achievement was selected as the variable of interest for this study because it has been considered a predictor of future academic and career success (Murnane et al., 1995).

Data for a sample of elementary schools that participated in the KYCID during the 2012-13, 2013-14, and 2014-15 school years and that obtained a high rate of fidelity of implementation on the Benchmarks of Quality (BoQ; 70 or greater) for each of the 3 years of implementation were selected as the treatment group for this study. Mathematics achievement for these schools was compared to schools that did not participate in PBIS implementation. Mathematics achievement was operationalized as K-PREP percentage of students in the performance levels of proficient and distinguished for the school's fifth-grade mathematics performance.

\section{Research Questions}

The following research questions guided this study: 
RQ1: Is there a significant difference in the percentages of fifth graders at the combined proficient and distinguished performance levels in mathematics between schools that implemented PBIS and schools that did not implement PBIS?

RQ2: Is there a significant difference in the percentages of male fifth graders at the combined proficient and distinguished performance levels in mathematics between non-PBIS and PBIS schools?

RQ3: Is there a significant difference in the percentages of female fifth graders at the combined proficient and distinguished performance levels in mathematics between non-PBIS and PBIS schools?

RQ4: Is there a significant difference in the percentages of fifth graders who scored at proficient and distinguished performance levels in mathematics between schools that implemented PBIS and schools that did not implement PBIS, controlling for the schools' socioeconomic status?

To present the findings, this chapter is divided into four sections. First, a description of the sample of schools included in this study is provided. Second, descriptive statistics for the sample are presented. Third, the major analyses conducted to address the research questions is detailed, followed by a summary. Fourth, a conclusion providing a transition to chapter 5 closes this chapter.

\section{Schools}

The sample contained data for 454 Kentucky elementary schools. The majority of the sample consisted of schools that had not implemented PBIS $(n=342,75 \%)$. Figure 4 presents a bar graph of the school types in the sample where 0 represents the control group 
and 1 represents the treatment group. The average number of fifth-grade students tested at each school was $73.90(S D=32.01)$. An average of $37.80(S D=17.25)$ male students and an average of $36.11(S D=16.08)$ female students were tested at each school. An average of $44.70(S D=21.15)$ low SES students and 29.21 $(S D=21.98)$ not-low SES students were tested from each school. Table 6 presents descriptive statistics for the students tested at each school.

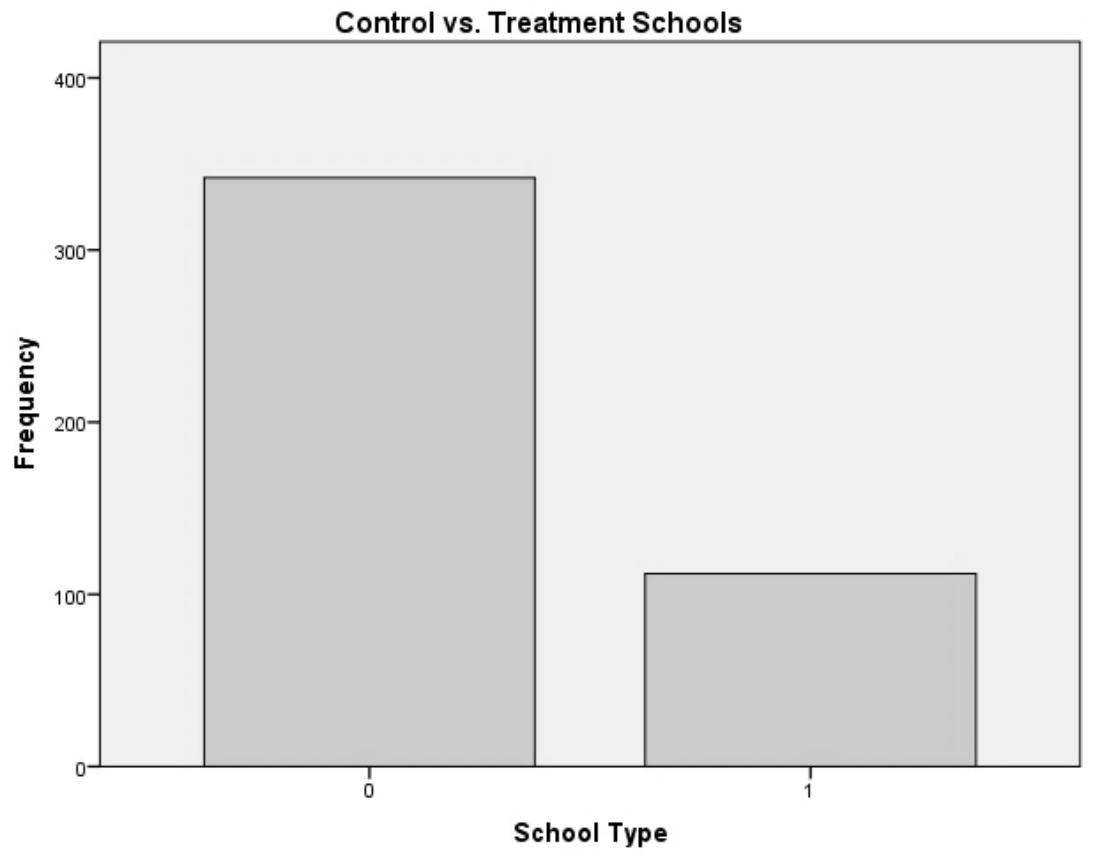

Figure 4. Bar graph of non-PBIS (0) versus PBIS (1) schools.

Table 6

Descriptive Statistics for Number of Students Tested

\begin{tabular}{lcccc}
\hline & Min & Max & $M$ & $S D$ \\
\hline Number Tested & 20.00 & 234.00 & 73.90 & 32.01 \\
Number Male Tested & 10.00 & 137.00 & 37.80 & 17.25 \\
Number Female Tested & 10.00 & 110.00 & 36.11 & 16.08 \\
Number Low SES & 10.00 & 184.00 & 44.70 & 21.15 \\
Number Not-low SES & 4.00 & 139.00 & 29.21 & 21.98 \\
\hline
\end{tabular}




\section{Descriptive Statistics}

Means, standard deviations and minimum and maximum values for the percentages of students designated as proficient or distinguished were calculated. Non-low SES students had the highest mean percentage of students designated as proficient or distinguished in mathematics $(M=69.88, S D=14.49)$. Low SES students had the lowest mean percentage of students designated as proficient or distinguished in mathematics $(M=48.7, S D=13.67)$. Table 7 presents the descriptive statistics for percentage of students designated as proficient or distinguished in mathematics.

Table 7

Descriptive Statistics for Percentages of Students Designated as Proficient or Distinguished

\begin{tabular}{lcccc}
\hline & Min & Max & $M$ & $S D$ \\
\hline Total & 16.10 & 85.70 & 57.14 & 13.28 \\
Male & 11.10 & 92.30 & 56.40 & 14.61 \\
Female & 15.40 & 100.00 & 57.99 & 14.89 \\
Low SES & 5.40 & 83.30 & 48.47 & 13.67 \\
Not-low SES & 14.10 & 100.00 & 69.88 & 14.49 \\
\hline
\end{tabular}

Major Analyses

To address research questions $1-3$, this researcher intended to conduct independent sample $t$-tests. To address research question 4, the researcher conducted an analysis of covariance (ANCOVA).

Prior to conducting the independent samples $t$-tests as the protocol to respond to questions 1-3, the researcher conducted Shapiro-Wilk tests to assess the assumption of normality and Levene's tests to assess the assumption of homogeneity of variance (Levene, 1960). The results of the normality test indicated that the assumption of normality was violated for total proficient or distinguished $(p=.008)$ and not-low SES $(p<.001)$. Because 
the assumption was violated for total proficient or distinguished, the researcher conducted a Mann-Whitney U test, the nonparametric alternative to the independent samples $t$-test.

Although the assumption was violated for not-low SES, the analysis can be considered robust to a violation of the assumption of normality with a sufficiently sized sample based on the implications of the central limit theorem when samples were $>50$ (Stevens, 2009). Table 8 presents the results of the Shapiro-Wilk test for normality.

Table 8

Results of the Shapiro-Wilk Test for Normality

\begin{tabular}{lccc}
\hline & Statistic & df & $p$ \\
\hline Total Proficient or Distinguished & .991 & 454 & 0.008 \\
Male Proficient or Distinguished & .994 & 454 & 0.056 \\
Female Proficient or Distinguished & .994 & 454 & 0.070 \\
Low SES Proficient or Distinguished & .997 & 454 & 0.495 \\
Not-low SES Proficient or Distinguished & .963 & 454 & $<0.001$ \\
\hline
\end{tabular}

For the ANCOVA, a Q-Q scatterplot (see Figure 5) that plotted the quantiles of the model residuals versus a Chi-square distribution was constructed to further assess normality (DeCarlo, 1997). Strong deviations in the plot were considered evidence of a violation of normality. There was no strong deviation; therefore, the researcher considered the assumption met. 


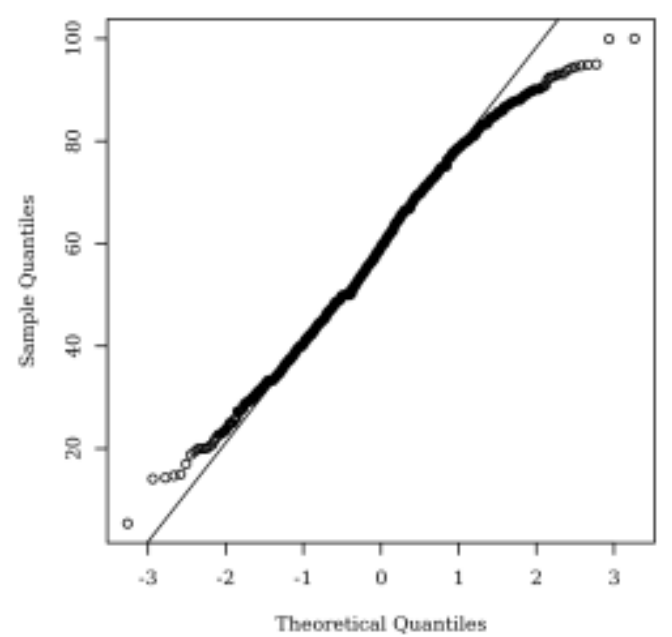

Figure 5. Q-Q scatterplot for normality.

Levene's test was conducted across gender groups to assess the quality of variances for the number of schools in which the percentage of proficient and distinguished math scores for both male and females followed assumptions of normality. For total proficient or distinguished, the result of Levene's test was significant, $F(1,452)=4.98, p=.026$. This finding indicated that the assumption of homogeneity of variance was violated for the groups. For male proficient or distinguished, the result of Levene's test was not significant, $F(1,452)$ $=2.33, p=.128$. This finding indicated that the assumption was met for the groups. For female proficient or distinguished, the result of Levene's test was significant, $F(1,452)=$ 4.57, $p=.033$. Finally, the result of Levene's test for SES was not significant, $F(1,906)=$ $2.68, p=.102$, indicating that the assumption of homogeneity of variance was met for SES.

Because the assumptions were violated for total proficient or distinguished and female proficient or distinguished, the researcher conducted the Mann-Whitney U test. The researcher selected the nonparametric alternative to the independent samples $t$-test because this analysis does not require that the same restrictive assumptions be met (Leech, Barrett, \& Morgan, 2012). In addition to being the nonparametric alternative to the independent 
samples $t$-test, the Mann-Whitney $\mathrm{U}$ test is appropriate for comparing differences among groups (Leech et al., 2012). Accordingly, the results from the Mann-Whitney U test as applied to research question 1 are explained below.

\section{Research Question 1}

A Mann-Whitney U test was conducted to assess significant differences in total percentage of students designated as proficient or distinguished between the PBIS and nonPBIS groups. The Mann-Whitney U test does not share the assumptions of the independent samples $t$-test related to normality (Conover \& Iman, 1981). The results of the MannWhitney $\mathrm{U}$ test were not significant at $U=18403.5, z=-0.62, p=.535$, which indicated that the percentages of students who were designated as proficient or distinguished were statistically similar between PBIS and non-PBIS schools. Consequently, the researcher failed to reject the null hypothesis. Table 9 presents the results of the Mann-Whitney U test. Figure 6 presents the boxplot scores of total percentages proficient or distinguished for nonPBIS and PBIS schools.

Table 9

Mann-Whitney U Test for Total Percentage Proficient or Distinguished by School Type

\begin{tabular}{lcccccc}
\hline & \multicolumn{2}{c}{ Mean Rank } & & & $p$ \\
\cline { 2 - 3 } Variable & Control & Treatment & & $z$ & \\
\hline $\begin{array}{l}\text { Total } \\
\text { Proficient or } \\
\text { Distinguished }\end{array}$ & 225.31 & 234.18 & & 18403.50 & -0.62 & .535 \\
\hline
\end{tabular}




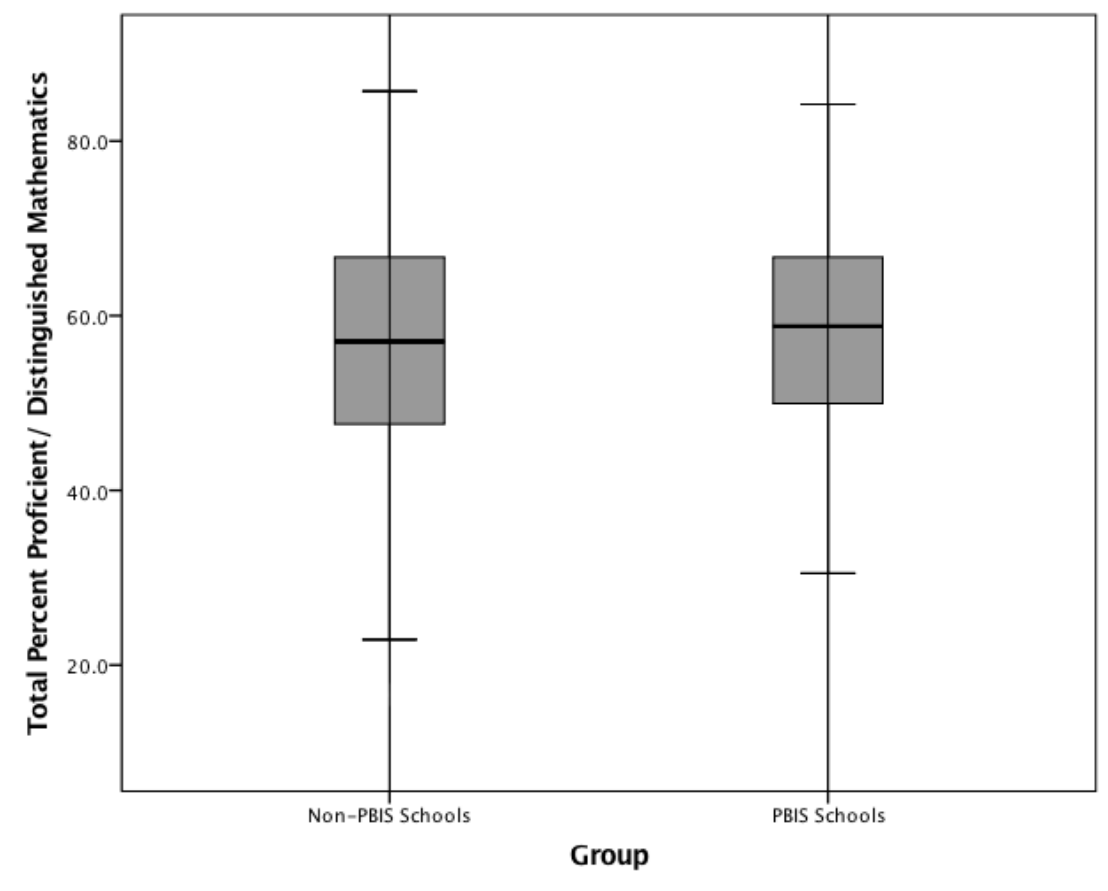

Figure 6. Boxplot scores of total percentages proficient or distinguished for non-PBIS and PBIS schools are shown.

\section{Research Question 2}

The independent samples $t$-test was not significant, $t(452)=-0.49, p=.626$, which indicated that the mean percentages of male students designated as proficient or distinguished were similar between PBIS and non-PBIS schools. The null hypothesis was not rejected. Table 10 presents the results of the independent samples $t$-test. Figure 7 presents the mean percentages of male students designated as proficient or distinguished in non-PBIS and PBIS groups.

Table 10

Independent Samples t-test for Male Proficient or Distinguished by School Type

\begin{tabular}{lccccccc}
\hline & \multicolumn{2}{c}{ Control } & \multicolumn{2}{c}{ Treatment } & & & \\
\cline { 2 - 5 } Variable & $M$ & $S D$ & $M$ & $S D$ & $t$ & $p$ & $d$ \\
\hline $\begin{array}{l}\text { Male Proficient or } \\
\text { Distinguished }\end{array}$ & 56.21 & 15.21 & 56.98 & 12.63 & -0.49 & \multirow{2}{*}{.626} & 0.06 \\
\hline
\end{tabular}




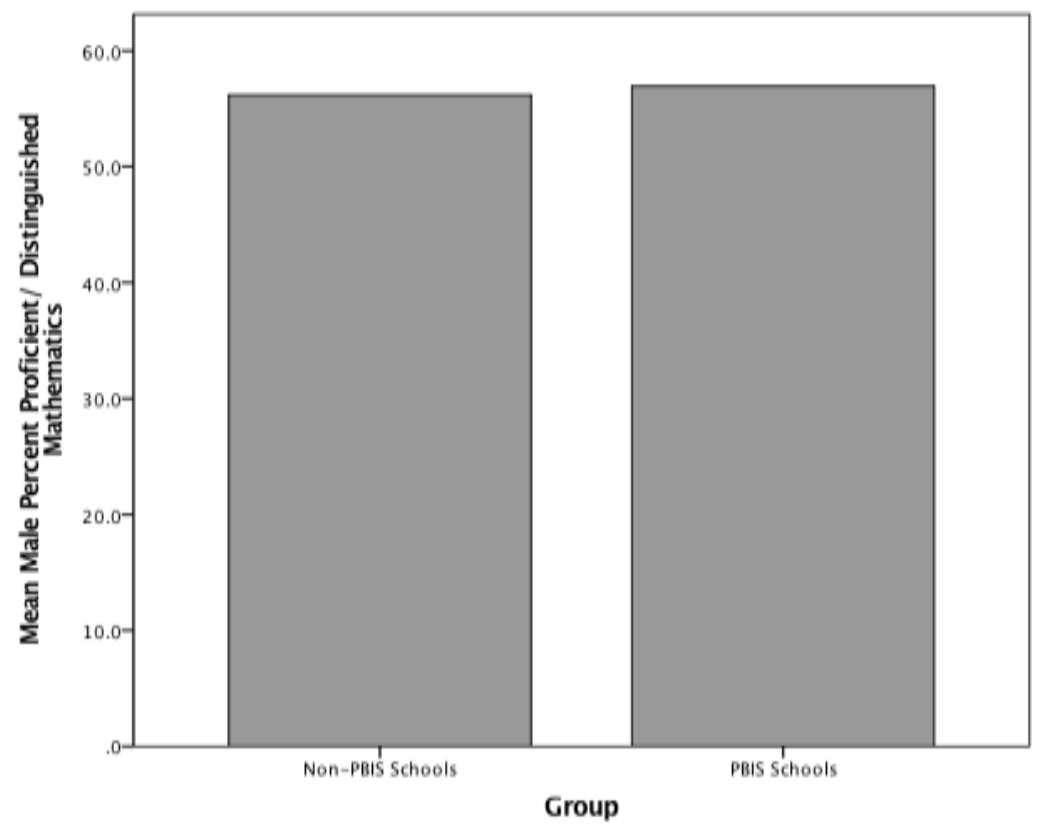

Figure 7. The mean of male percentages proficient or distinguished for non-PBIS and PBIS schools.

\section{Research Question 3}

The results of the Mann-Whitney $U$ test were not significant, $U=17827.5, z=-1.10$, $p=.272$, which indicated that the mean percentages of female students designated as proficient or distinguished were similar in PBIS and non-PBIS schools. The null hypothesis was not rejected. Table 11 presents the results of the Mann-Whitney U test. Figure 8 presents the mean percentages of female students designated as proficient or distinguished in non-PBIS and PBIS groups 
Table 11

Mann-Whitney U Test for Female Proficient or Distinguished by School Type

\begin{tabular}{|c|c|c|c|c|c|}
\hline \multirow[b]{2}{*}{ Variable } & \multicolumn{2}{|c|}{ Mean Rank } & \multirow[b]{2}{*}{$U$} & \multirow[b]{2}{*}{$z$} & \multirow[b]{2}{*}{$p$} \\
\hline & Control & Treatment & & & \\
\hline \multicolumn{6}{|l|}{ Female } \\
\hline $\begin{array}{l}\text { Proficient or } \\
\text { Distinguished }\end{array}$ & 223.63 & 239.33 & 17827.50 & -1.10 & 0.272 \\
\hline
\end{tabular}

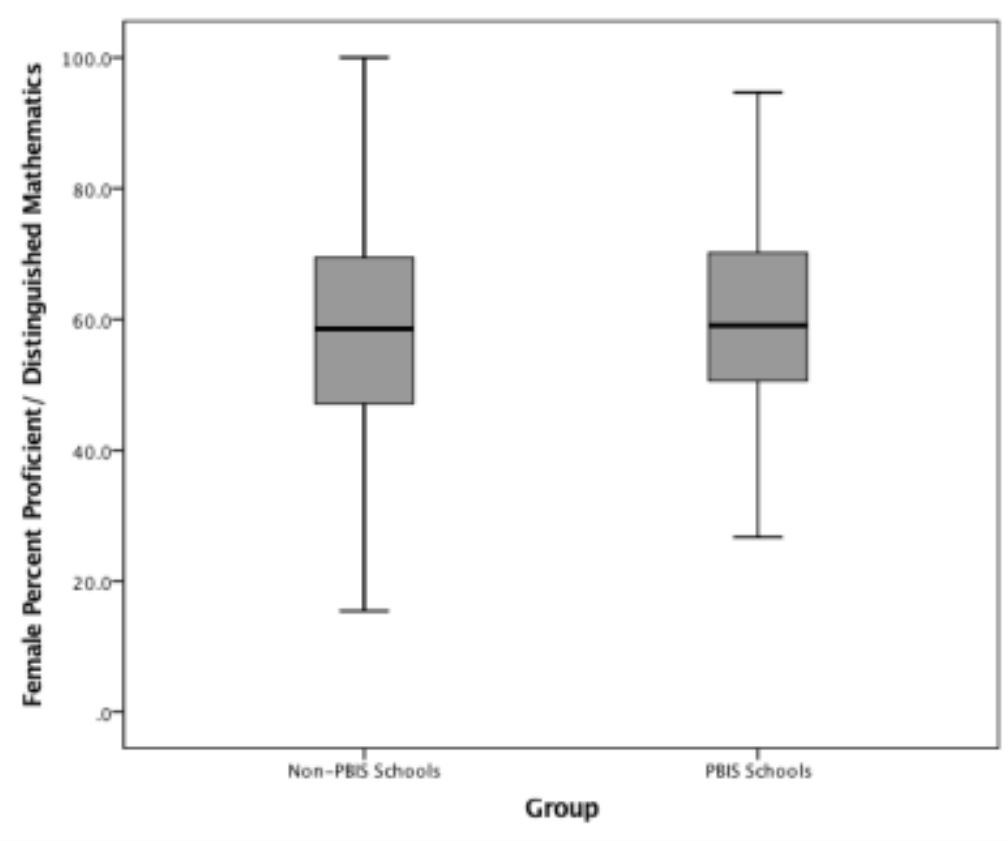

Figure 8. The mean of female percentages proficient or distinguished for non-PBIS and PBIS schools.

\section{Research Question 4}

The results of the ANCOVA were significant, $F(2,905)=261.85, p<0.001$ when examining the difference between students of low SES and students of not-low SES. The groups for the analysis were PBIS versus non-PBIS schools, and low SES versus not-low 
SES students. This finding indicated that there were not significant differences between PBIS and non-PBIS schools. Table 12 shows the results of the ANCOVA. The main effect of group (PBIS versus the control group as non-PBIS) was not significant at the $95 \%$ confidence level, $F(1,905)=0.15, p=.700$. This finding indicated that implementation of PBIS did not influence differences in the number of students designated as proficient or distinguished. Table 13 shows the means and standard deviations. There were no significant effects in the model. As a result, post hoc comparisons were not conducted.

Table 12

ANCOVA for Proficient or Distinguished by School Type While Controlling for SES

\begin{tabular}{lccccc}
\hline Term & $S S$ & $d f$ & $F$ & $p$ & $\eta^{2} \mathrm{p}$ \\
\hline School Type & 29.54 & 1 & 0.15 & .700 & 0.00 \\
SES & 104010.43 & 1 & 523.56 & $<.001$ & 0.37 \\
Residuals & 179788.54 & 905 & & & \\
\hline
\end{tabular}

Table 13

Marginal Means and SD for Proficient or Distinguished by School Type

\begin{tabular}{lcc}
\hline School Type & Marginal Means & $S D$ \\
\hline Non-PBIS & 59.07 & 14.09 \\
PBIS & 59.49 & 14.09 \\
\hline
\end{tabular}

\section{Summary of Findings}

Analysis of RQ1 was conducted using the Mann-Whitney U test as an alternative to the proposed independent samples $t$-test because the assumption of normality was violated. Results of this analysis suggest no significant difference between the percentage of fifth graders at the combined proficient and distinguished performance levels in mathematics at schools that implemented PBIS and schools that did not implement PBIS. Therefore, the null hypothesis was not rejected. 
An independent samples t-test was conducted to address RQ 2 in determining a significant difference in the percentages of male fifth graders at the combined proficient and distinguished performance levels in mathematics between non-PBIS schools and PBIS schools. Results indicated no significant difference in the performance level of male students between non-PBIS and PBIS schools. The null hypothesis was not rejected.

Because the assumption of homogeneity of variance was violated for the female population of schools that did implement PBIS, the Mann-Whitney U test was conducted to answer RQ3. Results of this analysis suggest no significant difference between the female percentage of fifth graders at the combined proficient and distinguished performance levels in mathematics between non-PBIS and PBIS schools. Therefore, the null hypothesis was not rejected.

ANCOVA was used to determine if the main effect of implementing PBIS, with SES as the covariate, presented a relationship of significant difference between non-PBIS and PBIS schools. The effect of non-PBIS versus PBIS schools was not significant at the $95 \%$ confidence level, $F(1,905)=0.15, p=.700$. Corresponding with the litature on the performance of students from low SES, Comparison between the performance of low SES and not-low SES was significant. Therefore, the null hypothesis was not rejected.

\section{Conclusion}

The major findings of this analysis indicated that for each research question posed, there was no significant difference in the percentage of students scoring at the performance level of combined proficient and distinguished in fifth grade on mathematics between schools implementing PBIS as compared to schools not implementing PBIS. In light of the major 
findings, the analysis of these findings along with the study's limitations and recommendations for future research are presented in the next chapter. 


\section{CHAPTER V \\ DISCUSSSION}

The purpose of this study was to investigate the relationship Positive Behavioral Interventions and Supports (PBIS) may have on mathematics achievement in elementary schools as measured by fifth graders' performance on the Kentucky Performance Rating of Educational Performance (K-PREP). If PBIS positively influences a school's learning climate, and a positive learning climate supports the conditions that improve teaching and learning, then PBIS may be a process that educators can implement to improve academic achievement to meet the goals of the school accountability systems established by policy makers at the federal and state levels of government.

Research question 1 presented an overall comparison of academic achievement (based on mathematics performance of fifth graders) between the non-PBIS and PBIS schools. Using a Mann-Whitney U test, the researcher assessed whether there was a significant differences in total percentage of students designated as proficient or distinguished between the PBIS and non-PBIS groups. Research question 2 tested the relationship between males in non-PBIS and PBIS schools. Using an independent samples $t$-test, this inquiry examined whether mean percentages of male students designated as proficient or distinguished were similar between PBIS and non-PBIS schools. Research question 3 examined the relationship of females between the nonPBIS and PBIS schools because the literature suggested a discrepancy in mathematical performance and career selection based on gender. Accordingly, this question examined 
whether the mean percentages of female students designated as proficient or distinguished were similar in PBIS and non-PBIS schools. Finally, because of the historical lower performance in academic achievement for students of low socioeconomic status (SES), research question 4 examined the academic performance between non-PBIS and PBIS schools while controlling for SES through an ANCOVA.

PBIS schools selected for this study implemented PBIS with fidelity as measured by the Benchmarks of Quality (BoQ) during the 2012-13, 2013-14, and 2014-15 school years. Training and ongoing coaching were provided by facilitators trained in PBIS implementation from Kentucky Center for Instructional Discipline (KYCID). Non-PBIS schools that had not attempted to implement PBIS during the same 3-year period of time were selected to compare the academic achievement in examining this relationship. Academic achievement in mathematics as measured by the state's high-stakes accountability test (K-PREP) was used to determine the level of academic achievement. Because the state and federal definition of student success is determined by the academic performance level of proficient or higher, the schools' combined percentage of students achieving proficient and distinguished was used as the metric for comparison between non-PBIS and PBIS schools. While the results of the analysis conducted failed to accept the alternative hypothesis of each research question, the findings of this current study will be discussed further in this chapter to contextualize these findings to prior research.

\section{Summary of Major Findings}

\section{Research Question 1}

Analysis of the first research question was conducted using the Mann-Whitney U test. Results of this analysis suggest no significant difference between the percentage of 
fifth graders at the combined proficient and distinguished performance levels in mathematics between schools that implemented PBIS and schools that did not implement PBIS, $U=18403.5, z=-0.62, p=.535$. This finding is distinguishable from prior research. Previous studies found an increase in academic achievement with schools that implemented PBIS with fidelity as measured by the state's high-stakes accountability test (Luiselli et al., 2005; Moscott et al., 2008). However, this current study included differences that set it apart from previous studies and addressed the recommendations by the researchers of these previous studies.

As recommended by Luiselli et al. (2005), this current study includes 3 years of PBIS implementation at a high level of implementation fidelity, based on the BoQs to be selected in the PBIS school sample for this current study. Furthermore, the previous study implemented the PBIS program in schools that had substantial behavioral challenges, whereas this current study included all schools that met the fidelity requirement to be a PBIS school sample. Non-PBIS schools were excluded only if they had attempted PBIS and did not meet fidelity. A system designed to address adverse behavior like PBIS may result in more substantial improvements in behavior that resulted in a greater increase in student achievement than a school that does not have the same level of unfavorable behavioral issues.

Studies that include a comparison between treatment and control groups, might provide a better analysis of the relationship of a treatment than those that examine a treatment group only. Muscott et al. (2008) examined the relationship PBIS had on schools using a small sample of 12 PBIS elementary schools, and did not include a comparison group of non-PBIS schools. Without having a sample of non-PBIS schools 
to compare the academic achievement performance of the treatment schools presents a challenge. Academic increases in the PBIS schools from the study conducted by Muscott and colleagues may have been greater, less than, or commensurate with the non-PBIS schools in their study. This present study included the achievement results of 112 elementary schools and a comparison group of 342 elementary schools. Both the increase in the number of schools included in a study and incorporating a comparison group was achieved by this current study, thereby addressing the recommendations of the previous study.

The type of test used to influence increased academic achievement may make a difference to PBIS implementation. For instance, in a randomized, wait-list controlled effectiveness study, Horner and colleagues (2009) found that implementing PBIS resulted in a school climate that supported academic achievement, specifically third-grade state reading assessments. However, schools in this study were unable to adequately document disciplinary procedures to the extent that fidelity in implementing PBIS was confirmed, and they used reading, not math, as the performance indicator. Horner et al. (2009) identified that measuring fidelity is key to accurately establish if there is a relationship between PBIS implementation that creates a climate resulting in increased academic performance, and recommended that future studies address this limitation. To address this recommendation for future research, this researcher selected schools based on 3 consecutive years of high PBIS implementation fidelity as measured by the BoQ.

In short, this study presents different findings from the prevailing literature; however, this study is somewhat distinguishable from the prior studies, including a high level of fidelity, comparison group, and subject matter used to determine academic 
performance. Furthermore, these differences were responsive to recommendations from previous studies regarding PBIS and academic achievement.

\section{Research Question 2}

Research question 2 examined differences between PBIS and non-PBIS schools based on the academic achievement of male students. An independent samples $t$-test was conducted to address the second research question in determining if there was a statistically significant difference in the percentages of male fifth grade students at the combined proficient and distinguished performance levels in mathematics between nonPBIS schools and PBIS schools. Results from this analysis indicated no significant difference in the percentage of student performance level based on male students between non-PBIS and PBIS schools, $t(452)=-0.49, p=.626$.

While efforts to ensure opportunities associated to mathematics for females is important, limitations of this data precluded a comparative analysis between two genders. Instead, the data lent themselves to an analysis within a gender group. Specifically, males within PBIS and non-PBIS schools did not display a statistically significant difference in academic achievement. Therefore, this finding suggests that PBIS may lead to no appreciable difference for males in mathematics achievement.

\section{Research Question 3}

Research question 3 examined differences between PBIS and non-PBIS schools based on the academic achievement of female students. Mann-Whitney U test was conducted to answer the research question. Results of this analysis imply no statistically significant difference between the female percentage of fifth graders at the combined proficient and distinguished performance levels in mathematics between non- 
PBIS and PBIS schools, $U=17827.5, z=-1.10, p=.272$.

Findings for research question 3 of this current study did not result in a statistically significant difference between females' mathematics achievement at PBIS schools and non-PBIS schools. Prior studies focused on mathematics achievement taking a gendered analysis comparing males and females (Choi \& Chang, 2011; Watt, 2006). However, the limitations of this study's data only permitted an analysis focused on one gender comparing the performance of mathematics achievement between PBIS and non-PBIS schools.

Gender based analysis are important. Griswold (2005) suggested that foundation learning at the elementary level most often determines the trajectory of educational outcomes in future years. Nonetheless, this study did not allow for such analysis, and it is quite possible that even with the analysis within one gender, female, fifth grade is too early to identify mathematics achievement deficits consistent with the extant literature, which rests primarily with findings at the secondary level. There is evidence from prior research that females have different experiences with math. Cimpian (2016) established that as early as kindergarten, teachers perceive that female students possess lower mathematical ability than male students. Existing literature and the analysis of this current study suggests that more research is needed to explore the beliefs educators have regarding the mathematical abilities of females to inform any incorrect notions pertaining to the ability of female students in learning mathematics. While important, this study presents a distinguishable outcome from prior studies indicating that math achievement scores are not significantly different when considering PBIS and non-PBIS schools. 


\section{Research Question 4}

For research question 4, an analysis of covariance (ANCOVA) was used to determine if the main effect of implementing PBIS, with SES as the covariate, presented a relationship of significance between non-PBIS and PBIS schools. Comparison between the performance of low SES and not-low SES was significant, $F(2,905)=261.85, p<$ .001. Although, the effect of non-PBIS versus PBIS schools was not significant at the $95 \%$ confidence level, $F(1,905)=0.15, p=.700$. In many studies, it is well documented that one of the strongest predictors of academic achievement is student SES (see, e.g., Sirin, 2005). Because a relationship has been well-established in the literature regarding SES and academic outcomes, SES was selected as a covariate to reduce the confounding effect.

Students qualifying for free and reduced lunch in Kentucky for the 2015-16 school year was $60.3 \%$ (KDE School Report Card, 2016). Given that, this researcher hypothesized the implementation of PBIS with fidelity would reduce the negative influence of poverty on academic achievement. This study's findings are consistent with prior research examining SES and academic achievement. For instance, Wang and Hocombe (2010) found the relationship between low achievement and low SES background can be reduced by establishing a positive school climate where students feel safe and connected to school. Gottfredson et al. (2005) established that schools that implemented instructional discipline procedures like those core components of PBIS lessened the low achievement associated with low SES. Luiselli et al. (2005) found that a whole school positive behavior approach to disciplinary problems reduced office referrals 
and suspensions, which resulted in an increase in time spent in instructional settings. Findings from these studies propose that PBIS, when implemented with fidelity, might enhance academic achievement in spite of low SES. Because PBIS has been shown promise in the previous studies by creating a positive school climate, and a positive school climate has been shown to provide the conditions for effective teaching and learning, the expectation was that students from low SES would achieve as well as students from not-low SES. While the results from this present study failed to demonstration a relationship between PBIS implementation and an increase in mathematics achievement, the fact remains that additional research is needed to examine school climate and the performance of students from low SES.

Analysis of each research question presented resulted in no significant difference in the percentage of students scoring at the performance levels of combined proficient and distinguished in fifth grade mathematics between schools implementing PBIS and schools not implementing PBIS. However, commensurate with prior studies, the academic achievement of students with low SES was significantly lower than students not of low SES (Siran, 2005). Previous studies have shown that PBIS improves school climate and a positive school climate supports teaching and learning (Wang \& Hocombe, 2010; Gottfredson et al., 2005). Even though the results of the analysis failed to reject the null hypothesis, this current study had limitations that can be addressed by recommendations for future studies discussed in the following sections of this chapter.

\section{Limitations of the Study}

\section{Discipline Data}

Several limitations exist with this current study. PBIS is intended to prevent and 
address inappropriate behavior by proactive instruction of appropriate behavioral expectations, reinforcement of appropriate behavior, and the monitoring and correction of inappropriate behavior (Sugai \& Horner, 2002). Therefore, PBIS should reduce time spent managing disciplinary infractions, resulting in students having more time in instructional settings. This current study examined the relationship PBIS had on academic achievement. Data regarding office discipline referrals, suspensions, and other disciplinary infractions may have provided deeper insight as to the influence PBIS had on discipline, and a possible relationship between discipline and school climate. In addition, this information may also contribute to the literature on how school climate interacts with academic achievement. Because disciplinary data from the sample populations were not available, this researcher made the assumption, based on previous research, there was a reduction in disciplinary infractions that resulted in more instructional time in the PBIS schools (Cohen et al., 2009; McIntosh et al., 2006; Scott \& Barrett, 2004). Furthermore, if PBIS implementation results in more instructional time for students in the PBIS schools, it is presumed that students were engaged in instruction consisting of equal quality as that in non-PBIS schools. This may, or may not, have been the case. Data regarding student engagement, teacher experience, or other indicators related to instructional quality, combined with PBIS fidelity of implementation data, may have provided understanding into the relationship between PBIS and academic achievement. Nonetheless, these data were not available at the school level to maintain a consistent unit of analysis for this study.

\section{Generalizabilty}

A second limitation of this study is the geographic boundaries of the sample 
population. Data measuring mathematics achievement were extrapolated from Kentucky's high-stakes accountability assessment (K-PREP) at the school level for fifth grade only. Furthermore, PBIS schools were those elementary schools that participated in the KYCID initiative to implement PBIS. Non-PBIS schools were selected from the remaining elementary schools in Kentucky that did not attempt to implement PBIS.

These Kentucky specific parameters prohibit the generalizability of the findings beyond Kentucky schools and KYCID trained PBIS implementation.

\section{Cross-School Consistency}

The third limitation of this study was that information was not available to this researcher to determine if the training provided to the schools implementing PBIS and completing the BoQ ratings was standardized among the trainers to ensure consistency with all PBIS schools. Therefore, the assumption was made that all KYCID trainers provided training in a consistent manner and provided an equal number of coaching visits to the PBIS schools. Furthermore, this current study postulated that all PBIS schools began implementation at the same time in their first year of implementation, and administered the end of the year BoQ rating at the same time of the year for each of the 3 school years that data were collected.

\section{Undetermined Influences}

The forth limitation of this study was a lack of information regarding other initiatives in both the non-PBIS and PBIS schools that could have been implemented at the same time period as PBIS. Executing multiple initiatives at the same time have the potential to skew mathematics achievement results. Schools could have implemented a program to enhance mathematics achievement in some of the schools, or had additional 
professional learning experiences focused on mathematics achievement. Schools may have focused more on remediating the skills of students at the novice and apprentice performance levels rather than the measured proficient and distinguished levels reported in this study.

\section{Implications for Policy Makers and Practioners}

This study began with the discussion about governmental pressure imposed through legislation that influences national, state, and local policy to improve student achievement as measured by high-stakes assessement and accountability. Because PBIS has been promoted as a means to support student outcomes, this study presents an argument for reasons why practitioners need information such as this current study to inform and guide their decisions when considering initiatives and other practices. Specificially, as this study concluded that there was no satistically significant difference in fifth grade mathematics achievement between schools with PBIS and schools that had not adopted PBIS, it highlights the potential implications arising from this study.

One possible implication arising from this study is that policy makers and practitioners may decide to suspend PBIS as a framework. Indeed, fiscal and human resources vary among schools and districts. Determining the most efficient and effective way to influence practices that may have a relationship to positive student outcomes is critical when managing school finances. While the PBIS schools in this current study participated in a state supported initiative to implement PBIS, which offset or reduced training costs, staff time and other investments in PBIS may be forgone in the future given that the findings were not significant. Also, PBIS requires a considerable amount of 
training and coaching to implement with fidelity. Costs associated with the implementation of PBIS were not examined by this current study.

Another possible implication arising from this study is that policy makers and practitioners may operate with greater caution before adopting a practice in fear that the initiative may be more a fad than an actual solution. Certainly, prior to a school adopting an initiative, it is imperative the school leadership know the problems of practice they desire to address specific to the school. While research has shown that PBIS may help establish a positive school climate, which supports the conditions for effective teaching and learning (Bradshaw, Koth, Bevans, Ialongo, \& Leaf, 2008; Horner, Sugai, \& Vincent, 2005; Hoy, Tarter, \& Bliss, 1990), PBIS was developed from the principles of applied behavior analysis, and intended to improve the behavioral outcomes of students. Thus, although PBIS may be the answer to student behavioral challenges, the relationship between improving school climate and improving academic achievement may be weak or tenuous. School level analysis may be a solution to evaluate future adoption of frameworks or initiatives.

A third possible implication arising from this study is that policy makers and practitioners may question implementation practices. For instance, determining the effectiveness of PBIS requires the practices to be implemented as intended. This current study selected PBIS schools that were determined to have implemented PBIS with fidelity, and there was no statistically significant difference observed in student achievement with compared to schools not implementing PBIS. However, data were not available to determine if improvements in student behavior occurred that may be associated with the three years of PBIS implementation. 


\section{Recommendations for Future Research}

\section{School Climate Measure}

In light of this study design and the findings, new questions have emerged. First, previous studies suggest that PBIS, when implemented with fidelity, contributes to a positive climate (Brookover \& Lezotte, 1979; Cohen et al., 2003; Durlak et al., 2011). To confirm or deny this assertion, future studies that examine the relationship between PBIS and school climate should include a measure to evaluate school climate before and after the implementation of PBIS. Including a measure of school climate may result in findings regarding how each component of PBIS interacts with the various aspects of school climate. Additional ontributions to the literature may provide practitioners with information on how to be intentional in efforts to improve school climate and prevent the adoption of a program that does not produce the desired outcomes.

\section{Degree of Fidelity}

According to Gresham et al. (1993), a lack of data regarding fidelity of implementation can compromise the evaluation of the validity of the intervention. Fidelity of implementation was measured by the BoQ, with a score of 70 or greater indicating high fidelity of PBIS implementation, and no statistically significant difference was found in academic achievement between non-PBIS and PBIS schools in this current study. Members of the leadership team in each school rate the 53 benchmarks from 0 to 3 and submit the BoQ score form to the PBIS coach. Next, the PBIS leadership team discusses the individual ratings of the team members to achieve consensus on a final score. While a rubric is provided to guide the scoring, the BoQ score for fidelity is self-

rated. Because fidelity is such an important feature in the implementation of PBIS, future 
studies could examine the possible relationship between PBIS schools based on the degree [emphasis added] of fidelity of implementation. The 112 PBIS schools in this study obtained a BoQ score ranging from 70-100. Perhaps schools obtaining a fidelity rating of 90 on the BoQ have higher academic achievement than a school that had a fidelity score of 70. A study looking at the degree of fidelity of implementation of PBIS might have implications for evaluating the influence various features of PBIS have on academic achievement.

\section{Beliefs Regarding Mathematics Achievement and Gender}

Prior studies suggested gender differences in mathematics, females selecting fewer higher level mathematics in high school and not pursuing careers related to mathematics. Furthermore, Cimpian (2016) discovered that as early as preschool, teacher perceptions of the mathematical abilities for males is higher than that of females. While significant mathematics achievement differences based on gender were not observed in the results of this current study, more research is needed. Implications of these findings suggest the cause of the discrepancy between male and females related to mathematics may require an examination of the beliefs of educators at a much earlier than when the observed differences at the secondary level and later career choices present. Efforts to enhance school climate should include the examination of the beliefs of practitioners to identify potential gender barriers to access and equity for all students.

\section{Combined Academic and Behavioral Interventions}

Sugai and Horner (2009) describe PBIS as a multi-tiered systems approach for establishing the social culture and individualized behavior supports needed for a school to be a safe and effective learning environment. This multi-tiered system is akin to response 
to intervention framework to address academic challenges. Research examining schools that implement an integrated approach with both PBIS and response to intervention might provide more information as to how PBIS, school climate, and academic achievement relate. (Implications, for

\section{Conclusion}

Assuming that academic achievement will improve automatically as the result of implementing PBIS and not considering how other variables can interfere with learning may lead to incorrect inferences about the relationship between PBIS and academic achievement. Learning mathematics content is complex and requires effective teaching and learning. Nonetheless, enhancing the environment by implementing a program such as PBIS may indirectly support the practice of effective teaching and learning to achieve increased academic outcomes.

This current study sought to investigate the relationship between PBIS and academic achievement in elementary schools. Prior studies have suggested that a positive school climate establishes the conditions that enhance academic achievement (Bradshaw et al., 2008; Durlak et al., 2011; Horner, 2005; Hoy et al., 1990). Researchers have identified PBIS when implemented with fidelity as a method to promote a positive school climate (Berkowitz et al., 2016; Gottfredson et al., 2005; Shaked \& Schechter, 2013). When students display inappropriate behavior in school, academic achievement is impeded for the student displaying such behavior and often for others.

PBIS is a system of behavior management that uses instruction through teaching, reteaching, modeling, recognizing, and rewarding of positive student behavior, which reduces unnecessary discipline and promotes a climate of safety and more effective 
learning (Positive Behavior, 2009). It was the assumption of this researcher that this current study would find schools that implemented PBIS with fidelity would realize better gains in academic achievement than schools that did not implement PBIS.

Cimpian (2006) recommended that more research be conducted regarding the fixed notion that female students lack the ability to learn mathematics, as reported by the kindergarten teachers. This current study investigated the fifth-grade mathematics performance of males and females to determine if a discrepancy exists. Findings indicated that fifth-grade mathematics achievement scores for females were not significantly different from fifth grade mathematics achievement scores for males. Watt (2006) found that self-perceptions and intrinsic values of female students related to mathematics were the major influences on the selection in secondary mathematics, which predicted mathematics-related career goals. These findings suggest that while significant differences between the achievement scores of males and females in this current study were not found, underlying problems regarding mathematics for females student remain a concern. It was the assumption of this researcher that the features of PBIS that intended to create an environment of respect and fairness might moderate the effect of the academic performance of females. Because findings in this current study did not show a discrepancy on mathematics performance based on gender, making inferences about a relationship is limited. Additional research is needed to learn more about the perceptions of both teachers and students to describe concerns related to gender and mathematics and intervene accordingly.

Corresponding with the literature, this study found a significant difference in the performance of students from low SES as compared to students from not-low SES. Even 
with federal research such as the Coleman Report and federal initiatives such as Elementary and Secondary Education Act (ESEA) and No Child Left Behind (NCLB), SES has continued to have a significant influence on fifth-grade mathematics performance in Kentucky schools based on this present study. More than 50 years of federal legislation, policy, and program implementation throughout the public school system has not changed this relationship between low SES and academic achievement. Because this cycle continues to influence academic achievement for students of low SES in public schools in Kentucky, learning more how practitioners can intervene is urgent.

Although the findings of this study reflected no significant difference between the non-PBIS and PBIS schools in academic achievement, there may be other mitigating factors. The reasons schools elected to implement PBIS or did not could have been an issue. A school in the control group could have decided not to adopt PBIS because other systematic processes were in place that promoted a positive learning climate.

Conversely, a school from the treatment group may have decided to implement PBIS because of the challenging behavior issues that impeded the learning environment at a particular school. The status of the learning environment and academic performance level of a school may have generated a directive from a principal's supervisor to implement PBIS. While PBIS requires the buy-in of $80 \%$ of the staff, authentic commitment may not exist if a specific approach is mandated and not self-selected, thereby reducing the influence of PBIS on creating a positive learning environment.

For PBIS to be an effective program, systematic processes need to be managed, studied, and refined based on accurate data. When a school is not accomplishing the desired outcomes, it can be expected that the systems of the PBIS approach that lead to 
an effective learning climate are not in place to create positive academic achievement. As a systems approach, PBIS requires all parts of the program to work in tandem with one another to produce positive results (Senge, 2006). More intense examinations of each school may reveal an aspect of PBIS that should be adjusted to achieve the results intended. While BoQ was used in the PBIS schools to determine fidelity of implementation, perhaps this instrument is not as sensitive to detecting all parts of the system essential to the maximum influence of PBIS.

Government pressure to produce high academic achievement for all students as measured by high-stakes accountability systems continues to be articulated through federal legislation (ESSA, 2016). Meeting the educational needs of all students is complex. Educators must continue to rely on research such as this current study to inform their decisions so efforts produce the outcomes intended. 


\section{REFERENCES}

Adams, T. (2000). The status of school discipline and violence. Annals for the American Academy of Political and Social Science. 567, 140-156.

Adelman, H. S., \& Taylor, L. (2003). On sustainability of project innovation as systemic change. Journal of Educational and Psychological Consultation, 14(1), 1-25.

Alexander, K., \& Pallas, A. (1984). Curriculum reform and school performance: An evaluation of the "new basics." American Journal of Education, 92, 391-420.

Alexander, K., \& Morgan, S. (2016). The Coleman Report at fifty: It's legacy and implications for future research on equality of opportunity. Journal of the Social Sciences. 2(5), 1-16.

Amatea, E. S., \& West-Olatunji, C.A. (2007). Joining the conversation about educating our poorest children: Emerging leadership roles for school counselors in highpoverty schools. Professional School Counseling. 11(2), 81-89.

Andrews, J. H. (1965). School organizational climate: Some validity studies. Canadian Education and Research. 5, 317-34.

Algozzine, B., \& Algozzine, K. (2009). Facilitating academic achievement through schoolwide positive behavior support. In W. Sailor, G. Dunlap, G. Sugai, \& R. Horner (Eds.), Handbook of Positive Behavior Support. New York: Springer, pp. $521-550$. 
Anderson, C. (1982). The search for school climate: A review of the research. Review of Educational Research, 52, 368-420. Doi:10.3102/00346543052003368

Baer, D. M., Wolf, M. M., \& Risley, T.R. (1968). Some current dimensions of applied behavioral analysis. Journal of Applied Behavior Analysis, 1, 91-97.

Bandura, A. (1993). Perceived self-efficacy in cognitive development and functioning. Educational Psychologist, 28, 117-248.

Barrett, S., Bradshaw, C. P., \& Lewis-Palmer, T. (2008). Maryland statewide PBIS initiative: Systems, evaluation, and next steps. Journal of Positive Behavior Interventions. $10,105-114$.

Batsche, G., Elliott, J., Graden, J.L., Grimes, J., Kovaleski, J. F., Prasse, D., Reschly, D.J., Schrag, J., \& Tilly III, W. D. (2005). Response to Intervention: Policy considerations and implementation. Alexandria, VA: National Association of State Directors of Special Education.

Battistich, V., Schaps, E., \& Wilson, N. (2004). Effects of an elementary school intervention on students' “connectedness" to school and social adjustment during middle school. Journal of Primary Prevention. 24, 243-262.

Berkowitz, R., Moore, H., Astor, R.A., \& Benbenishty, R. (2016). A research synthesis of the associations between socioeconomic background, inequality, school climate, and academic achievement. Review of Educational Research. Advance online publication. doi: 10.3102/0034654316669821

Borkowski, J., \& Sneed, M. (2006) Will NCLB Improve or harm public education? Harvard Educational Review: 76(4), 503-525.doi:http://dx.doi.org/10.17763/hear. 76.4.c897030171683u82 
Bradshaw, C. P., Debnam, K., Koth, C. W., \& Leaf, P. J. (2009). Preliminary validation of the implementation phases inventory for assessing fidelity of schoolwide positive behavior supports. Journal of Positive Behavior Interventions. 11, 145160.

Bradshaw, C. P., Mitchell, M. M., \& Leaf, P. J. (2010). Examining the effects of schoolwide positive behavioral interventions and support on student outcomes: Results from a randomized controlled effectiveness trial in elementary schools. Journal of Positive Behavior Interventions. 12, 133-148.

Bradshaw, C.P., Koth, C.W., Thornton, L.A. et al. (2009). Prevention Science. 10(2), $100-115$.

Bradshaw, C. P., Koth, C. W., Bevans, K. B., Ialongo, N., \& Leaf, P. J. (2008). The impact of school-wide positive behavioral interventions and supports (PBIS) on the organizational health of elementary schools. School Psychology Quarterly, 23(4), 462-473.

Brookmeyer, K.A., Fanti, K.A., \& Henrich, C.C. (2006). Schools, Parents, and Youth Violence: A Multilevel, Ecological Analysis. Journal of Clinical Child \& Adolescent Psychology. 35(4), 504-514.

Brookover, W.B., Beamer, L., Efthim, H., Hathaway, D., Lezotte, L., Miller, S., Passalacqua, J., \& Tornatzky, L. (1982). Creating effective schools: An in-service program for enhancing school learning climate and achievement. Holmes Beach, Fla: Learning Publications.

Brookover, W.B., \& Lezotte, L.W. (1979). Changes in school characteristics coincident with changes in student achievement. East Lansing: Michigan State University, 
East Lansing Institute for Research in Teaching. Retrieved from ERIC database. (ED181005).

Brophy, J. (1986). Teacher influences on student achievement. American Psychologist. 41, 1069-1077.

Carr, E. G., Dunlap, G., Horner, R. H., Koegel, R. L., Turnbull, A. P., Sailor, W., \& Fox, L. (2002). Positive behavior support: Evolution of an applied science. Journal of Positive Behavioral Interventions, 4, 4-16.

Carr, J. E., \& Sidener, T. M. (2002). In response: On the relation between applied behavior analysis and positive behavior support. The Behavior Analyst, 25(2), 245-253.

Childs, K. E., Kincaid, D., \& George, H. P. (2010). A model for statewide evaluation of a universal positive behavior support initiative. Journal of Positive Behavior Interventions, 12, 198-210.

Choi, N., \& Chang, M. (2011). Interplay among school climate, gender, attitude toward mathematics, and mathematics performance of middle school students. Middle Grades Research Journal, 6 (1), 15-28.

Chval, K.B., Reys, R., Reys, B.J., Tarr, J.E., \& Chavez, O. (2006). Pressures to improve student performance: a context that urges and impedes school-based research. Journal for Research in Mathematics Education, 37 (3), 158-166.

Cimpian, J.R., Lubienski, S.T., Timmer, J.D., Makowski, M.,B., \& Miller, E.K. (2016). Have gender gaps in math closed? Achievement, teacher perceptions, and learning behaviors across two ECLS-cohorts. AERA Open,.2, (4), 1-19. DOI:

$10.1177 / 2332858416673617$ 
Clements, D.H., \& Sarama, J. (2011a). Early childhood mathematics intervention. Science. 333, 968-970.

Clonan, S.M., McDougal, J.L., Clark, K., \& Davidson, S. (2007). Use of office discipline referrals in school-wide decision making: A practical example. Psychology in the Schools, $44(1)$.

Cohen, J., McCabe, L., Michelli, N. M., \& Pickeral, T. (2009). School climate: Research, policy, practice, and teacher education. Teachers Ccollege Record, 111(1), 180213.

Cohen, J. (2006). Social, emotional, ethical and academic education: Creating a climate for learning, participation in democracy and well-being. Harvard Educational Review, 76, (2) 201-237.

Cohen, R., Kincaid, D., \& Childs, K. (2007). Measuring school-wide positive behavior support implementation: Development and validation of the benchmarks of quality. Journal of Positive Behavior Interventions, 9, 203-213.

Coleman, J. S., Campbell, E.Q., Hobson, C. J., McPartland, Alexander M. Mood, Frederick D. Weinfeld, and Robert L. York. 1966. Equality of Educational Opportunity. Washington: U.S. Department of Health, Education, and Welfare, Office of Education.

Conover, W.J., \& Iman, R.L. (1981). Rank transformations as a bridge between parametric and on parametric statistics. The American Statistician. 35(3), 124129.

Cramer, E.D., Little, M.E., \& McHatton, P.A. (2014). Demystifying the data-based decision-making process. Action in Teacher Education, 36(5-6), 389-400. 
Cronbach, L.J. (1951). Coefficient alpha and the internal structure of tests. Psychometrika. 16,(3), 297-334.

DeCarlo, L. T. (1997). On the meaning and use of kurtosis. Psychological methods, 2(3), 292-307.

Dillman, D.A. (2000). Mail and Internet surveys: The tailored design method. New York: John Wiley \& Sons, Inc.

Dunlap, G., \& Carr, E. G. (2007). Positive behavior support and developmental disabilities: A summary and analysis of research. Handbook of Developmental Disabilities (pp. 469-482). New York: Guilford.

Dunlap G., Sailor, W., Horner, R.H., \& Sugai, G. (2009). Using a problem-solving model to enhance data-based decision making in schools. Handbook of Positive Behavior Support (pp. 375-394). New York: Springer.

Durlak, J. A. \& DuPre, E. P. (2008), Implementation matters: A review of research on the influence of implementation on program outcomes and the factors affecting implementation. American Journal of Community Psychology, 41: 327-350.

Durlak, J.A., Weissberg, R.P., Dymnicki, A.B., Taylor, R.D., \& Schellinger, K.B. (2011). The impact of enhancing students' social and emotional learning: A meta-analysis of school-based universal interventions. Child Development, 82(1), 405-432.

Eber, L., Sugai, G., Smith, C., \& Scott, T. (2002). Blending process and practice to maximize outcomes: Wraparound and positive behavioral interventions and supports in the schools. Journal of Emotional and Behavioral Disorders, 10, 171181. 
Eccles, J.S., \& Wang, M.T., (2015). What motivates females and males to pursue careers in mathematics and science? International Journal of Behavioral Development, 40(2), 100-106.

Edmonds, R. (1979). Effective schools for the urban poor. Educational Leadership, 37 (1), 15-23.

Every Student Succeeds Act, 2016. Pub. L. No. 107-110 Available online: http://www2.ed.gov/documents/essa-act-of-1965.pdf

Fisher, D. (1983). The going gets tough when we descend from the ivory tower. Analysis and Intervention in Developmental Disabilities, 3(2-3), 249-255.

Fixsen, D., Blase, K., Metz, A., \& Van Dyke, M. (2013). Statewide implementation of evidence-based programs. Exceptional Children, 79, 213-230.

Fixsen, D. L., Blase, K. A., Duda, M. A., Naoom, S. F., \& Van Dyke, M. (2010). Sustainability of evidence-based programs in education. Journal of EvidenceBased Practices, 11(1), 30-46.

Fixsen, D. L., Naoom, S. F., Blase, K. A., Friedman, R. M., Wallace, F. (2005). Implementation research: A synthesis of the literature (FMHI Publication No. 231). Tampa: University of South Florida, Louis de la Parte Florida Mental Health Institute, National Implementation Research Network.

Freiberg, H.J. (1999). School climate: Measuring, improving and sustaining healthy learning environments. Philadelphia: Falmer Press.

George, H. P., Kincaid, D., \& Pollard-Sage, J. (2009). Primary-tier interventions and supports. In W. Sailor, G. Dunlap, G. Sugai, \& R. Horner (Eds.), Handbook of Positive Behavior Support (pp. 375-394). New York: Springer. 
Gietz, C., \& McIntosh, K. (2014). Relations between student perceptions of their school environment and academic achievement. Canadian Journal of School Psychology, 29, $161-176$.

Goddard, R.D., Tschannen-Moran, M., \& Hoy, A. (2001). Multilevel examination of the distribution and effects of teacher trust in students and parents in urban elementary schools. The Elementary School Journal, 102 (1), 3-17.

Gottfredson, D. (1987). An evaluation of an organization development approach to reducing school disorder. Evaluation Review, 11, 739-763.

Gottfredson, D., Gottfredson, G., \& Skroban, S. (1996). A multimodal school based prevention demonstration. Journal of Adolescent Research, 11, 97-115.

Gottfredson, D., Karweit, N. L., \& Gottfredson, G. (1989). Reducing disorderly behavior in middle schools (Report No. 37). Baltimore, MD: Center for Research on Elementary and Middle Schools.

Gottfredson, G. D., Gottfredson, D.C., Payne, A.A., \& Gottfredson, N.C. (2005). School climate predictors of school disorder: Results from a national study of delinquency prevention in schools. Journal of Research in Crime and Delinquency, 42(4), 412-444.

Gresham, F. M. (2005). Response to intervention: An alternative means of identifying students as emotionally disturbed. Education and Treatment of Children, 28, 328344.

Gresham, F. M., Gansle, K. A., \& Noell, G. H. (1993). Treatment integrity in applied behavior analysis with children. Journal of Applied Behavior Analysis, 26, $257-$ 263. 
Griswold, P. A. (2005). Relating academic data from the elementary grades to state test results in high school: Implications for school improvement through professional development. Journal of Research in Childhood Education, 20, 65-74.

Guskey, T. R., \& Yoon, K. S. (2009). What works in professional development? Phi Delta Kappan, 90, 495-500.

Halpin, A.W. (1958). Administrative theory in education. London: Macmillan.

Halpin, A.W. (1966). Change and organizational climate. Journal of Educational Administration, 10 (1), 38- 81.

Halpin, A.W., \& Croft, D.B. (1963). Organizational climate of schools. Chicago: Midwest Administrative Center, University of Chicago.

Handler, M. W., Rey, J., Connell, J., Thier, K., Feinberg, A., \& Putnam, R. (2007). Practical considerations in creating school-wide positive behavior support in public schools. Psychology in the Schools, 44(1), 29-39.

Hawken, L. (2009). Secondary-tier interventions and supports. In W. Sailor, G. Dunlap, G. Sugai, \& R. Horner (Eds.), Handbook of Positive Behavior Support. (pp. 395420). New York: Springer.

Homana, G., Barber, C., \& Torney-Purta, J. (2006). Background of the school citizenship education climate assessment. Denver, Co: Education Commission of the States.

Horner, R. H., Sugai, G., Smolkowski, K., Eber, L., Nakasato, J., Todd, A. W., \& Esperanza, J. (2009). A randomized, wait-list controlled effectiveness trial assessing school-wide positive behavior support in elementary schools. Journal of Positive Behavior Interventions, 11, 133-144. 
Horner, R.H., Todd, A.W., Lewis-Palmer, T., Irvin, L.K., Sugai, G., \& Boland, J.B. (2004). The school-wide evaluation tool (SET): A research instrument for assessing school-wide positive behavior support. Journal of Positive Behavior Interventions, 6(1), 3-12.

Horner, R.H., Sugai, G., \& Vincent, C. (2005). School-wide positive behavior support: Investing in student success. Impact, 18(2), 4-5.

Hoy, W. K., \& Hannum, J. (1997). Middle school climate: An empirical assessment of organizational health and student achievement. Educational Administration Quarterly, 33, 290-311.

Hoy, W. K., Tarter, C. J., \& Bliss, J. R. (1990). Organizational climate, school health, and effectiveness: A comparative analysis. Educational Administration Quarterly, 26(3), 260- 279 .

Johnson, R. B., \& Christensen, L. B. (2000). Educational research: Quantitative and qualitative approaches. Boston: Allyn and Bacon.

Johnson, W. L., Johnson, A. M., \& Zimmerman, K., (1996). Assessing school climate priorities: A Texas study. The Clearing House, 70(2), 64-66.

Joyce, B., \& Showers, B. (2002). Student achievement through staff development (34d ed.). Alexandria, VA: Association for Supervision and Curriculum Development.

Kane, M. (2013). The argument-based approach to validation. School Psychology Review. 42(4), 448-457.

Kealey, A.K., Peterson, A.V., Gaul, M., \& Dinh, K.T., (2000). Teacher training as a behavior change process: Principles and results from a longitudinal study. Health Education and Behavior. 27(1), 64-81. 
Kentucky Department of Education. (2010). Nonacademic data. Retrieved January 4, 2011 from http://www.education.ky.gov/kde/administrative+resources/testing+ and+reporting +/reports/nonacademic+data

Kelleher, J. (2003). Professional development that works: a model for assessment-driven professional development. Phi Delta Kappan, 84, 751-764.

Kelm, J.L., \& McIntosh, K. (2012). Effects of school-wide behavior support on teacher self-efficacy. Psychology in the Schools. 49(2), 137-147.

Kentucky Department of Education (2015). Kentucky performance rating for educational progress: 2014-15 Technical manual. Frankfort: Author

Kincaid, D., Childs, K., \& George, H. P. (2005). School-wide benchmarks of quality. Retrieved from http://flpbs.fmhi.usf.edu/ProceduresTools.asp

Kirst, M., \& Jung, R. (1991). The utility of a longitudinal approach in assessing implementation: A thirteen-year view of Title I, ESEA. In A. R. Odden (Ed.), Education policy implementation (pp. 39-63). Albany: State University of New York Press.

Kumpermine, G.P., Leadbeater, B.J., \& Blatt, S.J. (2001). School social climate and individual differences in vulnerability to psychopathology among middle school students. Journal of School Psychology, 39, 141-159.

Lassen, S. R., Steele, M. M., \& Sailor, W. (2006). The relationship of school-wide positive behavior support to academic achievement in an urban middle school. Psychology in the Schools, 43, 701-712. 
Leech, N. L., Barrett, K. C., \& Morgan, G.A. (2012). SPSS for intermediate statistics: Use and interpretation (5th ed.). New York, NY: Lawrence Erlbaum Associates, Publishers.

Levene, H. (1960). "Contributions to Probability and Statistics: Essays in Honor of Harold Hotelling," I. Olkin, et. al., eds. Stanford University Press, Stanford, CA, pp. 278-292.

Lewis, D.M., \& Haug, C.A. (2005). Aligning policy and methodology to achieve consistent across-grade performance standards. Applied Measurement in Education, 18, (1), 11-34.

Lewis, T. J., Colvin, G., \& Sugai, G. (2000). The effects of pre-correction and active supervision on the recess behavior of elementary students. Education and Treatment of Children, 23, 109-121.

Lewis, T. J., Powers, L. J., Kelk, M., \& Newcomer, L. (2002). Reducing problem behaviors on the playground: An investigation of the application of schoolwide positive behavior supports. Psychology in the Schools, 39, 181-190.

Lewis, T. J., \& Sugai, G. (1999). Effective behavior support: A systems approach to proactive schoolwide management. Focus on Exceptional Children, 31, 1-24.

Lewis, T.J., Sugai, G., \& Larson, S. (1999). Using data to guide decisions about program implementation and effectiveness. Effective School Practices, 17(4), 47-53.

Linney, J. A., \& Seidman, E. (1989). The future of schooling. American Psychologist, 44, 336-340. 
Luiselli, J. K., Putnam, R. F., Handler, M. W., \& Feinberg, A. B. (2005). Whole-school positive behavior support: Effects on student discipline problems and academic performance. Educational Psychology, 25, 183-198.

Mackenzie, D.E. (1983). Research for school improvement: An appraisal of some recent trends. Educational Researcher, 12(4), 5-17

Manning, M. L., \& Saddlemire, R. (1996). Developing a sense of community in secondary schools. NASSP Bulletin, 80(584), 41-48.

Marshall, M. L. (2004). Examining school climate: Defining factors and educational influences [white paper, electronic version]. Retrieved from Georgia State University Center for School Safety, School Climate and Classroom Management website http://education.gsu.edu/schoolsafety/

Mayer, R.G. (1998). Constructive discipline for school personnel. Education and Treatment of Children, 22, 36-54.

Mayer, G. R., Butterworth, T., Nafpaktitis, M., \& Sulzer-Azaroff, B. (1983). Preventing school vandalism and improving discipline: A three-year study. Journal of Applied Behavior Analysis, 16, 355-369.

McDonnell, L. M. (2004). Politics, persuasion, and educational testing. Cambridge, MA: Harvard University Press.

McIntosh, K., \& Turri, M. G. (2014). Positive behavior support: Sustainability and continuous regeneration. In C. R. Reynolds, K. J. Vannest \& E. Fletcher-Janzen (Eds.), Encyclopedia of special education: A reference for the education of children, adolescents, and adults with disabilities and other exceptional individuals. ( pp. 2061-2064). Hoboken, NJ: Wiley. 
McIntosh, K., Chard, D.J., Boland, J.B., \& Horner, R.H. (2006). Demonstration of combined efforts in school-wide academic and behavioral systems and incidence of reading and behavior challenges in early elementary grades. Journal of Positive Behavior Supports, 8(3), 146-154.

Means, B., Padilla, C., DeBarger, A., \& Bakia, M. (2009). Implementing data-informed decision making in schools-teacher access, supports and use. Report prepared for U.S. Department of Education, Office of Planning, Evaluation and Policy Development. Prepared by SRI International, Menlo Park, CA.

Medley, N. S., Little, S. G., \& Akin-Little, A. (2008). Comparing individual behavior plans from schools with and without schoolwide positive behavior support: A preliminary study. Journal of Behavioral Education, 17, 93-110.

Moncher, F. J., \& Prinz, R. J. (1991). Treatment fidelity in outcome studies. Clinical Psychology Review, 11(3), 247-266.

Moos, R.H. (1979). Evaluating educational environments. San Francisco: Jossey-Bass. Murnane, R., Willett, J., \& Levy, F. (1995). The growing importance of cognitive skills in wage determination. The Review of Economics and Statistics, 77, 251-66.

Muscott, H. S., Mann, E. L., \& LeBrun, M. R. (2008). Positive behavior interventions and supports in New Hampshire: Effects of large-scale implementation of schoolwide positive behavior support on student discipline and academic achievement. Journal of Positive Behavior Interventions, 10, 190-205.

National Center for Educational Statistics. (2015). National Assessment of Educational Progress (2015 Math and Reading Assessments). Retrieved from http://www.nationsreportcard.gov/reading_math_2015/\#mathematics ?grade=4 
National Center on Response to Intervention. (2010). RTI practices glossary. Retrieved from http://www.rti4success.org.

National Commission on Excellence in Education. (1983). A nation at risk: The imperative for educational reform. Washington, DC: Department of Education.

National School Climate Center. (2015). How do we define school climate? Retrieved from http://www.schoolclimate.org/climate/.

Nelson, J. R., Colvin, G., \& Smith, D. J. (1996). The effects of setting clear standards on students' social behavior in common areas of the school. The Journal of At-Risk Issues, 3,(1), 10-17.

Newton, J. S., Horner, R. H., Algozzine, R. F., Todd, A. W., \& Algozzine, K. M. (2009). Using a problem-solving model to enhance data-based decision making in schools. In W. Sailor, G. Dunlap, G. Sugai, \& R. H. Horner (Eds.), Handbook of positive behavior support (pp. 551-580). New York: Springer.

Nichols, S. L., Glass, G. V, \& Berliner, D.C. (2012) High-stakes testing and student achievement: Updated analyses with NAEP data. Education Policy Analysis Archives, 20(20), 1-35. Retrieved August 3, 2014, from http://epaa.asu.edu/ojs/article/view/1048

No Child Left Behind Act of 2002, Pub. L. No. 107-110, 20 U. S. C. § 6301.

Office of Special Education Programs Center on Positive Behavioral Interventions and Supports. (2005). School-wide positive behavior support: Implementers' blueprint and self-assessment. Retrieved from www.pbis.org 
Office of Special Education Programs Center on Positive Behavioral Interventions and Supports. (2011). School-wide positive behavior support: Implementers' blueprint and self-assessment. Retrieved from www.pbis.org

Office of Special Education Programs Center on Positive Behavioral Interventions and Supports. (2015). School-wide positive behavior support: Implementers' blueprint and self-assessment. Retrieved October 11, 2016, from www.pbis.org Office of the Superintendent of Public Instruction. (2007). Nine characteristics of highperforming schools: A research-based resource for schools and districts to assist with improving student learning. Olympia, WA: Author. Retrieved from http://www.k12.wa.us/research/default.aspx

Perry, A. (1908). The management of a city school. New York: Macmillan.

Positive behavior supports: A wise investment of economic stimulus funds. (2009). Southern Poverty Law Center. Retrieved from http://www.pbis.org/common/ pbisresources/publication/PBS_WiseInvestmentofEconomicStimulusFunds.pdf

Public Agenda. (2004). Teaching interrupted: Do discipline policies in today's public schools foster the common good? New York: Public Agenda.

Purkey, S., \& Smith, M. (1983). Effective schools: A review. Elementary School Journal, $83,110-115$.

Romney S., Israel N., \& Zlatevski D. (2014). Exploration-stage implementation variation: Its effect on the cost-effectiveness of an evidence-based parenting program. Journal of Psychology, 222(1), 37-48.

Rylance, B. J. (1997). Predictors of high school graduation or dropping out for youths with severe emotional disturbances. Behavior Disorders, 23, 5-17. 
Sadler, C., \& Sugai, G. (2009). Effective behavior and instructional support: A district model for early identification and prevention of reading and behavior problems. Journal of Positive Behavior Interventions, 11, 35-46.

Safran, S. P., \& Oswald, K. (2003). Positive behavior supports: Can schools reshape disciplinary practices? Exceptional Children, 69 (3), 361-373.

Sarama, J., Lange, A.A., Clements, D.H., \& Wolfe, C.B. (2011). The impacts of an early mathematics curriculum on oral language and literacy. Early Childhood Research Quarterly, 27(3), 489-502.

Sarason, S.B. (1971). The culture of the school and the problem of change. Boston: Allyn \& Bacon.

Scott, T.M., \& Nelson, C.M. (1999). Using functional behavior assessment to develop effective intervention plans: Practical classroom applications. Journal of Positive Behavior Interventions, 1, 242-251.

Scott, T. M. (2003). Making behavior intervention planning decisions in a schoolwide system of positive behavior support. Focus on Exceptional Children, 36, 1-18.

Scott, T., \& Hunter, J. (2001). Initiating schoolwide support systems: An administrator's guide to the process. Beyond Behavior, 11(1), 13-15.

Scott, T. M., \& Barrett, S. B. (2004). Using staff and student time engaged in disciplinary procedures to evaluate the impact of school-wide PBS. Journal of Positive Behavior Interventions, 6, 21-27.

Scott, T. M., \& Martinek, G. (2006). Coaching positive behavior support in school settings. Journal of Positive Behavior Interventions, 8, 165-173. 
Scotti, J.R., Evans, I.M., Meyer, L.H. \& Walker, P. (1991). A meta-analysis of intervention research with problem behavior: Treatment validity and standards of practice. American Journal on Mental Retardation, 96 (3), 233-256.

Senge, P.M. (2006). The fifth discipline. New York: Doubleday

Shaked, H., \& Schechter, C. (2013). Seeing wholes: The concept of systems thinking and its implementation in school leadership. International Review of Education, 59(6), 771-791.

Simonsen, B., \& Sugai, G. (2007). Using school-wide data systems to make decisions efficiently and effectively. School Psychology Forum: Research in Practice, 1(2), 46-58.

Sirin, D.R. (2005). Socioeconomic status and academic achievement: A meta-analytic review of the research. Review of Educational Research, 75, 417-453.

Slaven, R. (2007). Educational research in an age of accountability. Boston, MA: Pearson Education, Inc.

Sparks, S. (2016). 50 years seeking educational equality: Revisiting the Coleman Report. EdNews, 35(36), 10.

Stevens, J. P. (2009). Applied multivariate statistics for the social sciences (5th ed.). Mahwah, NJ: Routledge Academic.

Sugai, G. (1996). Providing effective behavior support to all students: Procedures and processes. SAIL, 11(1), 1-4.

Sugai, G., \& Horner, R. H. (1999). Discipline and behavioral support: Preferred processes and practices. Effective School Practices, 17(4), 10-22. 
Sugai, G. (2007). Promoting behavioral competence in schools: A commentary on exemplary practices. Psychology in the Schools, 44, 113-118.

Sugai, G., \& Horner, R. H. (2002). The evolution of discipline practices: School-wide positive behavior supports. Child and Family Therapy, 24, 23-50.

Sugai, G., \& Horner, R. H. (2006). A promising approach for expanding and sustaining school-wide positive behavior support. School Psychology Review, 35, 245-259.

Sugai, G., \& Horner, R. H. (2009). Defining and describing schoolwide positive behavior support. In W. Sailor, G. Dunlap, G. Sugai, \& R. Horner (Eds.), Handbook of Positive Behavior Support (pp. 307-326). New York: Springer.

Thapa, A., Cohen, J., Guffey, S., \& Higgins-D’Alessandro. (2013). A review of school climate research. Review of Educational Research, 83, 357-385.

Thomas, A.R., (1976). The organizational climate of schools. International Review of Education, 22(4), 441-463.

Thomas, J.Y. \& Brady, K.P. (2005). The Elementary and Secondary Education Act at 40: Equity, accountability, and the evolving federal role in public education. Review of Research in Education, 29, 51-67.

Turnbull, A. P., Edmonson, H., Griggs, P., Wickham, D., Sailor, W., Freeman, R., Guess, D., Hale, N., Lassen, S., McCart, A., Riffel, L., Schmerchek, D., Turnbull, H.R., Warren, J., \& Wilcox, B. (2002). A blueprint for schoolwide positive behavior support: Implementation of three components. Exceptional Children, 68 (3), 377.

Horner, R. H., Sugai, G., Bullis, M., Sprague, J., Bricker, D., \& Kaufman, M. J. (1996). Integrated approaches to preventing antisocial behavior patterns among school- 
age children and youth. Journal of Emotional and Behavioral Disorders, 4, 194209.

U.S. Department of Education, National Center for Education Statistics, National Assessment of Educational Progress (NAEP), 2005, 2013, and 2015 Mathematics Assessments, NAEP Data Explorer. See Digest of Education Statistics 2015, table 222.10 .

U.S. Department of Education, Office of Special Education Programs. (2011). Technical assistance center on positive behavioral interventions and supports: Final report. Washington, DC: Author.

U.S. Department of Education, Office of Special Education Programs. (2015). Technical assistance center on positive behavioral interventions and supports: Final report. Washington, DC: Author.

Walker, H., Horner, R. H., Sugai, G., Bullis, M., Sprague, J., Bricker, D., \& Kaufman, M. J. (1996). Integrated approaches to preventing antisocial behavior patterns among school-age children and youth. Journal of Emotional and Behavioral Disorders, 4, 194-209.

Wallace Foundation. (2006). Leadership for learning: Making the connection among state, district and school policies and practices. New York: Author.

Wang, M.C., Haertel, G.D., \& Walberg, H.J. (1997). What helps students learn? Spotlight on student success. Office of Educational Research and Improvement. Retrieved from ERIC database. (ED461694). 
Wang, M., \& Holcombe, R. (2010). Adolescents' perceptions of school environment, engagement, and academic achievement in middle school. American Educational Research Journal, 47(3), 633-662.

Watt, H.M.G. (2006). The role of motivations in gendered educational and occupational trajectory related to mathematics. Educational Research and Evaluation, 12, 305322.

Warren, J. S., Bohanon-Edmonson, H. M., Turnbull, A. P., Sailor, W., Wickham, D., Griggs, P., Beech, S. E. (2006). School-wide positive behavior support: Addressing behavior problems that impede student learning. Educational Psychology Review, 18(2), 187-198.

Webb, R.B., \& Ashton, P.T. (1986). Teacher motivation and the conditions of teaching: A call for ecological reform. Journal of Thought, 21(2), 43-60.

Yoon, K. S., Duncan, T., Lee, S. W.-Y., Scarloss, B., \& Shapley, K. (2007). Reviewing the evidence on how teacher professional development affects student achievement (Issues \& Answers Report, REL 2007-No. 033). Washington, DC: U.S. Department of Education, Institute of Education Sciences, National Center for Education Evaluation and Regional Assistance, Regional Educational Laboratory Southwest. Retrieved from http://ies.ed.gov/ncee/edlabs

Young, B.S. (1980). Principals can be promoters of teaching effectiveness. Thrust for Educational Leadership, 9, 11-12. 


\section{APPENDIX A}

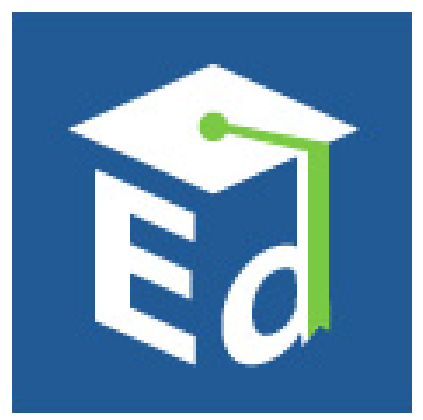

U.S. Department of Education

Key Policy Letters Signed by the Education Secretary or Deputy Secretary

July 31, 2009

Dear Chief State School Officers:

On May 19, the Education and Labor Committee in the U.S. House of Representatives held a hearing to examine the abusive and potentially deadly misapplication of seclusion and restraint techniques in schools. Related to this hearing was the testimony issued on the same day by the Government Accountability Office on "Seclusions and Restraints: Selected Cases of Death and Abuse at Public and Private Schools and Treatment Centers." The testimony is available on the Internet at the following Web address: http://www.gao.gov/new.items/d09719t.pdf.

I was deeply troubled by the testimony, as I am sure you would have been. As education leaders, our first responsibility should be to make sure that schools foster learning in a safe environment for all of our children and teachers. Therefore, I am encouraging each State to review its current policies and guidelines regarding the use of restraints and 
seclusion in schools to ensure every student is safe and protected, and if appropriate, develop or revise its policies and guidelines.

My home State of Illinois has what I believe to be one good approach, including both a strong focus upon Positive Behavior Intervention and Supports (PBIS) as well as State regulations that limit the use of seclusion and restraint under most circumstances (see http://www.isbe.state.il.us/rules/archive/pdfs/oneark.pdf).The State's requirements, which I found to be extremely helpful as chief executive officer of the Chicago Public Schools, were described in testimony at the hearing. Illinois prohibits the use of seclusion or restraint for the purpose of punishment or exclusion, and allows trained staff to restrain students only in narrow circumstances. The State allows the use of isolated time out or physical restraint only in situations when it is absolutely necessary to preserve the safety of self or others; includes rules that must be followed when these techniques are used; and requires documentation of each incident to be provided to parents within 24 hours. Several other States have also adopted effective seclusion and/or restraint policies, but there are many jurisdictions that have not, leaving students and teachers vulnerable.

Approximately 8,000 schools across the country are already implementing PBIS, a systems approach to establishing the social culture needed for schools to achieve social and academic gains while minimizing problem behavior for all children. PBIS provides a framework for decision making that guides the implementation of evidence-based academic and behavioral practices throughout the entire school, frequently resulting in significant reductions in office disciplinary referrals, suspensions, and expulsions. While the successful implementation of PBIS typically results in improved social and academic outcomes, it will not eliminate all behavior incidents in a school. However, PBIS is an important preventative approach that can increase the capacity of the school staff to support children with the most complex behavioral needs, thus reducing the instances that require intensive interventions.

The American Recovery and Reinvestment Act provides significant one-time resources that districts can use to implement a school-wide system of PBIS. Districts could, 
consistent with program requirements, use funds provided for the State Fiscal Stabilization Fund, Title I of the Elementary and Secondary Education Act, the Individuals with Disabilities Education Act, and State and local funds to provide professional development, develop data systems, and offer coaching to establish and sustain these programs. The Department's Office of Special Education Programs funds the Center on Positive Behavioral Interventions and Supports, with a Web site (http://www.pbis.org/) where additional information and technical assistance on PBIS can be obtained free of charge.

I urge each of you to develop or review and, if appropriate, revise your State policies and guidelines to ensure that every student in every school under your jurisdiction is safe and protected from being unnecessarily or inappropriately restrained or secluded. I also urge you to publicize these policies and guidelines so that administrators, teachers, and parents understand and consent to the limited circumstances under which these techniques may be used; ensure that parents are notified when these interventions do occur; and provide the resources needed to successfully implement the policies and hold school districts accountable for adhering to the guidelines.

I encourage you to have your revised policies and guidance in place prior to the start of the 2009-2010 school year to help ensure that no child is subjected to the abusive or potentially deadly use of seclusion or restraint in a school. I have asked Fran Walter of our Office of Elementary and Secondary Education to work with staff from our regional Comprehensive Centers to contact your office by August 15, to discuss the status of your State's efforts with regard to limiting the use of seclusion and restraint to protect our students. During this contact, we expect to discuss relevant State laws, regulations, policies, and guidance that affect the use of seclusion and restraint, and any plans for further development or revisions. We expect to post the results of these discussions on the Department's Web site to assist in the sharing of information that will help protect our students.

In the meantime, please feel free to contact Ms. Walter at (202) 205-9198 or at 
Fran.Walter@ed.gov with any information or questions about your State's efforts to limit the use of restraints and seclusion in schools.

Thank you for your cooperation on this important topic.

Sincerely,

Arne Duncan 


\title{
APPENDIX B
}

\section{BENCHMARKS OF QUALITY (BoQ) SCORING GUIDE:}

\author{
(Adapted from Florida PBIS)
}

\section{When \& Why}

Benchmarks of Quality for School-wide Positive Behavior Interventions and Support should be completed two times a year in the November and April.

The Benchmarks are used by leadership teams to identify areas of success, areas for improvement, and by the State Leadership Team to identify model PBIS schools.

\section{Procedures for Completing the BoQ}

\section{Step 1 -}

As a leadership team, with guidance from the School Coordinator and/or SU/District Coordinator use the Scoring Guide to determine appropriate point value for the 53 items on the BoQ Scoring Form and come to consensus on each item. Do not leave any items blank.

\section{Step 2 -}

The Leadership Team will then place a check mark next to the items identified as an area in need of development.

\section{Step 3 -}

After Step 2, use the Team Summary sheet to identify Areas of Strength and Areas in Need of Development. Place the items identified in Step 2 under Areas in Need of Development. If there are other Action Items, place those under the Other Action Items section on the Team Summary sheet.

\section{Step 4 - Scoring and Reporting}

The electronic scoring form will automatically calculate your score on the bottom of the spreadsheet. The maximum score is 107 and teams implementing with fidelity achieve a score of $70 \%$ or above. Benchmarks of Quality Scoring Rubric to guide the rating of each item is on the following pages. 


\begin{tabular}{|c|c|c|c|c|}
\hline \multicolumn{5}{|c|}{ Benchmarks of Quality Scoring Rubric } \\
\hline Benchmark & 3 points & 2 points & 1 point & 0 points \\
\hline $\begin{array}{l}\text { 1. Team has } \\
\text { administrative } \\
\text { support }\end{array}$ & $\begin{array}{l}\text { Administrator( } \\
\text { s) attended } \\
\text { training, play } \\
\text { an active role } \\
\text { in the PBIS } \\
\text { process, } \\
\text { actively } \\
\text { communicate } \\
\text { their } \\
\text { commitment, } \\
\text { support the } \\
\text { decisions of } \\
\text { the PBIS } \\
\text { Team, and } \\
\text { attend all team } \\
\text { meetings. }\end{array}$ & $\begin{array}{l}\text { Administrator( } \\
\text { s) support the } \\
\text { process, take } \\
\text { as active a role } \\
\text { as the rest of } \\
\text { the team, } \\
\text { and/or attend } \\
\text { most meetings }\end{array}$ & $\begin{array}{l}\text { Administrator( } \\
\text { s) support the } \\
\text { process but } \\
\text { don't take as } \\
\text { active a role as } \\
\text { the rest of the } \\
\text { team, and/or } \\
\text { attends only a } \\
\text { few meetings. }\end{array}$ & $\begin{array}{l}\text { Administrator( } \\
\text { s) do not } \\
\text { actively } \\
\text { support the } \\
\text { PBIS process. }\end{array}$ \\
\hline $\begin{array}{l}\text { 2. Team has } \\
\text { regular } \\
\text { meetings (at } \\
\text { least } \\
\text { monthly) }\end{array}$ & & $\begin{array}{l}\text { Team meets } \\
\text { monthly (min. } \\
\text { of } 9 \text { one-hour } \\
\text { meetings each } \\
\text { school year). }\end{array}$ & $\begin{array}{l}\text { Team meetings } \\
\text { are not } \\
\text { consistent (5- } \\
\text { 8) monthly } \\
\text { meetings each } \\
\text { school year). }\end{array}$ & $\begin{array}{l}\text { Team seldom } \\
\text { meets (fewer } \\
\text { than five } \\
\text { monthly } \\
\text { meetings } \\
\text { during the } \\
\text { school year). }\end{array}$ \\
\hline $\begin{array}{l}\text { 3. Team has } \\
\text { established a } \\
\text { clear } \\
\text { mission/purpo } \\
\text { se }\end{array}$ & & & $\begin{array}{l}\text { Team has a } \\
\text { written } \\
\text { purpose/missio } \\
\text { n statement for } \\
\text { the PBS team } \\
\text { (commonly } \\
\text { completed on } \\
\text { the cover sheet } \\
\text { of the action } \\
\text { plan). }\end{array}$ & $\begin{array}{l}\text { No mission } \\
\text { statement/purp } \\
\text { ose written for } \\
\text { the team. }\end{array}$ \\
\hline $\begin{array}{l}\text { 4. Faculty are } \\
\text { aware of } \\
\text { behavior } \\
\text { problems } \\
\text { across } \\
\text { campus } \\
\text { through } \\
\text { regular data } \\
\text { sharing }\end{array}$ & & $\begin{array}{l}\text { Data regarding } \\
\text { school-wide } \\
\text { behavior are } \\
\text { shared with } \\
\text { faculty } \\
\text { monthly (min. } \\
\text { of } 8 \text { times per } \\
\text { year). }\end{array}$ & $\begin{array}{l}\text { Data regarding } \\
\text { school-wide } \\
\text { behavior are } \\
\text { occasionally } \\
\text { shared with } \\
\text { faculty (3-7 } \\
\text { times per } \\
\text { year). }\end{array}$ & $\begin{array}{l}\text { Data are not } \\
\text { regularly } \\
\text { shared with } \\
\text { faculty. } \\
\text { Faculty may } \\
\text { be given an } \\
\text { update } 0 \text {-2 } \\
\text { times per year }\end{array}$ \\
\hline
\end{tabular}




\begin{tabular}{|c|c|c|c|}
\hline $\begin{array}{l}\text { 5. Faculty are } \\
\text { involved in } \\
\text { establishing } \\
\text { and reviewing } \\
\text { goals }\end{array}$ & $\begin{array}{l}\text { Most faculty } \\
\text { participate in } \\
\text { establishing } \\
\text { PBIS goals on } \\
\text { at least an } \\
\text { annual basis. }\end{array}$ & $\begin{array}{l}\text { Some of the } \\
\text { faculty } \\
\text { participates in } \\
\text { establishing } \\
\text { PBIS goals on } \\
\text { at least an } \\
\text { annual basis. }\end{array}$ & $\begin{array}{l}\text { Faculty does } \\
\text { not participate } \\
\text { in establishing } \\
\text { PBIS goals. }\end{array}$ \\
\hline $\begin{array}{l}\text { 6. Faculty } \\
\text { feedback is } \\
\text { obtained } \\
\text { throughout } \\
\text { year }\end{array}$ & $\begin{array}{l}\text { Faculty is } \\
\text { given } \\
\text { opportunities } \\
\text { to provide } \\
\text { feedback, to } \\
\text { offer } \\
\text { suggestions, } \\
\text { and to make } \\
\text { choices in } \\
\text { every step of } \\
\text { the PBIS } \\
\text { process. } \\
\text { Nothing is } \\
\text { implemented } \\
\text { without the } \\
\text { majority of } \\
\text { faculty } \\
\text { approval. }\end{array}$ & $\begin{array}{l}\text { Faculty are } \\
\text { given some } \\
\text { opportunities } \\
\text { to provide } \\
\text { feedback, to } \\
\text { offer } \\
\text { suggestions, } \\
\text { and to make } \\
\text { some choices } \\
\text { during the } \\
\text { PBIS process. } \\
\text { However, the } \\
\text { team also } \\
\text { makes } \\
\text { decisions } \\
\text { without input } \\
\text { from staff. }\end{array}$ & $\begin{array}{l}\text { Faculty are } \\
\text { rarely given } \\
\text { the } \\
\text { opportunity to } \\
\text { participate in } \\
\text { the PBS } \\
\text { process (fewer } \\
\text { than } 2 \text { times } \\
\text { per school } \\
\text { year). }\end{array}$ \\
\hline $\begin{array}{l}\text { 7. Discipline } \\
\text { process } \\
\text { described in } \\
\text { narrative } \\
\text { format or } \\
\text { depicted in } \\
\text { graphic } \\
\text { format }\end{array}$ & $\begin{array}{l}\text { Team has } \\
\text { established } \\
\text { clear, written } \\
\text { procedures that } \\
\text { lay out the } \\
\text { process for } \\
\text { handling both } \\
\text { major and } \\
\text { minor } \\
\text { discipline } \\
\text { incidents. } \\
\text { (Includes } \\
\text { crisis } \\
\text { situations) }\end{array}$ & $\begin{array}{l}\text { Team has } \\
\text { established } \\
\text { clear, written } \\
\text { procedures that } \\
\text { lay out the } \\
\text { process for } \\
\text { handling both } \\
\text { major and minor } \\
\text { discipline } \\
\text { incidents. } \\
\text { (Does not } \\
\text { include crisis } \\
\text { situations.) }\end{array}$ & $\begin{array}{l}\text { Team has not } \\
\text { established } \\
\text { clear, written } \\
\text { procedures for } \\
\text { discipline } \\
\text { incidents } \\
\text { and/or there is } \\
\text { no } \\
\text { differentiation } \\
\text { between major } \\
\text { and minor } \\
\text { incidents. }\end{array}$ \\
\hline
\end{tabular}




\begin{tabular}{|c|c|c|c|c|}
\hline $\begin{array}{l}\text { 8. Discipline } \\
\text { process includes } \\
\text { documentation } \\
\text { procedures }\end{array}$ & & & $\begin{array}{l}\text { There is a } \\
\text { documentation } \\
\text { procedure to } \\
\text { track both major } \\
\text { and minor } \\
\text { behavior } \\
\text { incidents (i.e., } \\
\text { form, database } \\
\text { entry, file in } \\
\text { room, etc.). }\end{array}$ & $\begin{array}{l}\text { There is not a } \\
\text { documentation } \\
\text { procedure to } \\
\text { track both } \\
\text { major and } \\
\text { minor behavior } \\
\text { incidents (i.e., } \\
\text { form, database } \\
\text { entry, file in } \\
\text { room, etc.). }\end{array}$ \\
\hline $\begin{array}{l}\text { 9. Discipline } \\
\text { referral form } \\
\text { includes } \\
\text { information } \\
\text { useful in } \\
\text { decision making }\end{array}$ & & $\begin{array}{l}\text { Information } \\
\text { on the } \\
\text { referral form } \\
\text { includes } \\
\text { ALL of the } \\
\text { required } \\
\text { fields: } \\
\text { Student's } \\
\text { name, date, } \\
\text { time of } \\
\text { incident, } \\
\text { grade level, } \\
\text { referring } \\
\text { staff, } \\
\text { location of } \\
\text { incident, } \\
\text { gender, } \\
\text { problem } \\
\text { behavior, } \\
\text { possible } \\
\text { motivation, } \\
\text { others } \\
\text { involved, } \\
\text { and } \\
\text { administrati } \\
\text { ve decision. }\end{array}$ & $\begin{array}{l}\text { The referral } \\
\text { form includes all } \\
\text { of the required } \\
\text { fields, but also } \\
\text { includes } \\
\text { unnecessary } \\
\text { information that } \\
\text { is not used to } \\
\text { make decisions } \\
\text { and may cause } \\
\text { confusion. }\end{array}$ & $\begin{array}{l}\text { The referral } \\
\text { form lacks one } \\
\text { or more of the } \\
\text { required fields } \\
\text { or does not } \\
\text { exist. }\end{array}$ \\
\hline $\begin{array}{l}\text { 10. Problem } \\
\text { behaviors are } \\
\text { defined }\end{array}$ & $\begin{array}{l}\text { Written } \\
\text { documentatio } \\
n \text { exists that } \\
\text { includes } \\
\text { clear } \\
\text { definitions of } \\
\text { all behaviors } \\
\text { listed. }\end{array}$ & $\begin{array}{l}\text { All of the } \\
\text { behaviors } \\
\text { are defined } \\
\text { but some of } \\
\text { the } \\
\text { definitions } \\
\text { are unclear. }\end{array}$ & $\begin{array}{l}\text { Not all } \\
\text { behaviors are } \\
\text { defined or some } \\
\text { definitions are } \\
\text { unclear. }\end{array}$ & $\begin{array}{l}\text { No written } \\
\text { documentation } \\
\text { of definitions } \\
\text { exists. }\end{array}$ \\
\hline
\end{tabular}




\begin{tabular}{|c|c|c|c|c|}
\hline $\begin{array}{l}11 . \\
\text { Major/minor } \\
\text { behaviors are } \\
\text { clearly } \\
\text { differentiated }\end{array}$ & & $\begin{array}{l}\text { Most staff } \\
\text { are clear } \\
\text { about which } \\
\text { behaviors } \\
\text { are staff } \\
\text { managed } \\
\text { and which } \\
\text { are sent to } \\
\text { the office. } \\
\text { (i.e. } \\
\text { appropriate } \\
\text { use of office } \\
\text { referrals) } \\
\text { Those } \\
\text { behaviors } \\
\text { are clearly } \\
\text { defined, } \\
\text { differentiate } \\
\text { d and } \\
\text { documented. }\end{array}$ & $\begin{array}{l}\text { Some staff are } \\
\text { unclear about } \\
\text { which behaviors } \\
\text { are staff } \\
\text { managed and } \\
\text { which are sent } \\
\text { to the office (i.e. } \\
\text { appropriate) use } \\
\text { of office } \\
\text { referrals) or no } \\
\text { documentation } \\
\text { exists. }\end{array}$ & $\begin{array}{l}\text { Specific } \\
\text { major/minor } \\
\text { behaviors are } \\
\text { not clearly } \\
\text { defined, } \\
\text { differentiated } \\
\text { or documented. }\end{array}$ \\
\hline $\begin{array}{l}\text { 12. Suggested } \\
\text { array of } \\
\text { appropriate } \\
\text { responses to } \\
\text { major (office- } \\
\text { managed) } \\
\text { problem } \\
\text { behaviors }\end{array}$ & & & $\begin{array}{l}\text { There is } \\
\text { evidence that all } \\
\text { administrative } \\
\text { staff are aware } \\
\text { of and use an } \\
\text { array of } \\
\text { predetermined } \\
\text { appropriate } \\
\text { responses to } \\
\text { major behavior } \\
\text { problems. }\end{array}$ & $\begin{array}{l}\text { There is } \\
\text { evidence that } \\
\text { some } \\
\text { administrative } \\
\text { staff are not } \\
\text { aware of, or do } \\
\text { not follow, an } \\
\text { array of } \\
\text { predetermined } \\
\text { appropriate } \\
\text { responses to } \\
\text { major behavior } \\
\text { problems. }\end{array}$ \\
\hline $\begin{array}{l}\text { 13. Data system } \\
\text { is used to collect } \\
\text { and analyze } \\
\text { ODR data }\end{array}$ & $\begin{array}{l}\text { The database } \\
\text { can quickly } \\
\text { output data in } \\
\text { graph format } \\
\text { and allows } \\
\text { the team } \\
\text { access to } \\
\text { ALL of the } \\
\text { following } \\
\text { information: } \\
\text { average } \\
\text { referrals per } \\
\text { day per }\end{array}$ & $\begin{array}{l}\text { ALL of the } \\
\text { information } \\
\text { can be } \\
\text { obtained } \\
\text { from the } \\
\text { database } \\
\text { (average } \\
\text { referrals per } \\
\text { day per } \\
\text { month, by } \\
\text { location, by } \\
\text { problem } \\
\text { behavior, by }\end{array}$ & $\begin{array}{l}\text { Only partial } \\
\text { information can } \\
\text { be obtained } \\
\text { (lacking either } \\
\text { the number of } \\
\text { referrals per day } \\
\text { per month, } \\
\text { location, } \\
\text { problem } \\
\text { behavior, time } \\
\text { of day, student, } \\
\text { and compare }\end{array}$ & $\begin{array}{l}\text { The data } \\
\text { system is not } \\
\text { able to provide } \\
\text { any of the } \\
\text { necessary } \\
\text { information the } \\
\text { team needs to } \\
\text { make school- } \\
\text { wide decisions. }\end{array}$ \\
\hline
\end{tabular}




\begin{tabular}{|c|c|c|c|c|}
\hline & $\begin{array}{l}\text { month, by } \\
\text { location, by } \\
\text { problem } \\
\text { behavior, by } \\
\text { time of day, } \\
\text { by student, } \\
\text { and compare } \\
\text { between } \\
\text { years. }\end{array}$ & $\begin{array}{l}\text { time of day, } \\
\text { by student, } \\
\text { and compare } \\
\text { between } \\
\text { years), } \\
\text { though it } \\
\text { may not be } \\
\text { in graph } \\
\text { format, may } \\
\text { require more } \\
\text { staff time to } \\
\text { pull the } \\
\text { information, } \\
\text { or require } \\
\text { staff time to } \\
\text { make sense } \\
\text { of the data. }\end{array}$ & $\begin{array}{l}\text { patterns between } \\
\text { years.) }\end{array}$ & \\
\hline $\begin{array}{l}\text { 14. Additional } \\
\text { data are } \\
\text { collected } \\
\text { (attendance, } \\
\text { grades, faculty } \\
\text { attendance, } \\
\text { surveys) and } \\
\text { used by SWPBS } \\
\text { team }\end{array}$ & & & $\begin{array}{l}\text { The team } \\
\text { collects and } \\
\text { considers data } \\
\text { other than } \\
\text { discipline data } \\
\text { to help } \\
\text { determine } \\
\text { progress and } \\
\text { successes (i.e. } \\
\text { attendance, } \\
\text { grades, faculty } \\
\text { attendance, } \\
\text { school surveys, } \\
\text { etc.) }\end{array}$ & $\begin{array}{l}\text { The team does } \\
\text { not collect or } \\
\text { consider data } \\
\text { other than } \\
\text { discipline data } \\
\text { to help } \\
\text { determine } \\
\text { progress and } \\
\text { successes (i.e. } \\
\text { attendance, } \\
\text { grades, faculty } \\
\text { attendance, } \\
\text { school surveys, } \\
\text { etc.). }\end{array}$ \\
\hline $\begin{array}{l}15 . \text { Data } \\
\text { analyzed by } \\
\text { team at least } \\
\text { monthly }\end{array}$ & & $\begin{array}{l}\text { Data are } \\
\text { printed, } \\
\text { analyzed, } \\
\text { and put into } \\
\text { graph format } \\
\text { or other easy } \\
\text { to } \\
\text { understand } \\
\text { format by a } \\
\text { member of } \\
\text { the team } \\
\text { monthly } \\
\text { (minimum) }\end{array}$ & $\begin{array}{l}\text { Data are printed, } \\
\text { analyzed, and } \\
\text { put into graph } \\
\text { format or other } \\
\text { easy to } \\
\text { understand } \\
\text { format by a } \\
\text { team member } \\
\text { less than once a } \\
\text { month. }\end{array}$ & $\begin{array}{l}\text { Data are not } \\
\text { analyzed. }\end{array}$ \\
\hline $\begin{array}{l}\text { 16. Data shared } \\
\text { with team and }\end{array}$ & & $\begin{array}{l}\text { Data are } \\
\text { shared with }\end{array}$ & $\begin{array}{l}\text { Data are shared } \\
\text { with the PBIS }\end{array}$ & $\begin{array}{l}\text { Data are not } \\
\text { reviewed each }\end{array}$ \\
\hline
\end{tabular}




\begin{tabular}{|c|c|c|c|c|}
\hline $\begin{array}{l}\text { faculty monthly } \\
\text { (minimum) }\end{array}$ & & $\begin{array}{l}\text { the PBS } \\
\text { team and } \\
\text { faculty at } \\
\text { least once a } \\
\text { month. }\end{array}$ & $\begin{array}{l}\text { team and faculty } \\
\text { less than one } \\
\text { time a month. }\end{array}$ & $\begin{array}{l}\text { month by the } \\
\text { PBIS team and } \\
\text { shared with } \\
\text { faculty. }\end{array}$ \\
\hline $\begin{array}{l}17.3-5 \\
\text { positively stated } \\
\text { school-wide } \\
\text { expectations are } \\
\text { posted around } \\
\text { school }\end{array}$ & $\begin{array}{l}\text { 3-5 } \\
\text { positively } \\
\text { stated } \\
\text { school-wide } \\
\text { expectations } \\
\text { are visibly } \\
\text { posted } \\
\text { around the } \\
\text { school. } \\
\text { Areas posted } \\
\text { include the } \\
\text { classroom } \\
\text { and a } \\
\text { minimum of } \\
3 \text { other } \\
\text { school } \\
\text { settings (i.e., } \\
\text { cafeteria, } \\
\text { hallway, } \\
\text { front office, } \\
\text { etc.). }\end{array}$ & $\begin{array}{l}\text { 3-5 } \\
\text { positively } \\
\text { stated } \\
\text { expectations } \\
\text { are visibly } \\
\text { posted in } \\
\text { most } \\
\text { important } \\
\text { areas (i.e. } \\
\text { classroom, } \\
\text { cafeteria, } \\
\text { hallway), } \\
\text { but one area } \\
\text { may be } \\
\text { missed. }\end{array}$ & $\begin{array}{l}\text { 3-5 positively } \\
\text { stated } \\
\text { expectations are } \\
\text { not clearly } \\
\text { visible in } \\
\text { common areas. }\end{array}$ & $\begin{array}{l}\text { Expectations } \\
\text { are not posted } \\
\text { or team has } \\
\text { either too few } \\
\text { or too many } \\
\text { expectations. }\end{array}$ \\
\hline $\begin{array}{l}18 . \\
\text { Expectations } \\
\text { apply to both } \\
\text { students and } \\
\text { staff }\end{array}$ & $\begin{array}{l}\text { PBIS team } \\
\text { has } \\
\text { communicat } \\
\text { ed that } \\
\text { expectations } \\
\text { apply to all } \\
\text { students and } \\
\text { all staff. }\end{array}$ & $\begin{array}{l}\text { PBIS team } \\
\text { has } \\
\text { expectations } \\
\text { that apply to } \\
\text { all students } \\
\text { AND all } \\
\text { staff but } \\
\text { haven't } \\
\text { specifically } \\
\text { communicat } \\
\text { ed that they } \\
\text { apply to } \\
\text { staff as well } \\
\text { as students. }\end{array}$ & $\begin{array}{l}\text { Expectations } \\
\text { refer only to } \\
\text { student } \\
\text { behavior. }\end{array}$ & $\begin{array}{l}\text { There are no } \\
\text { expectations. }\end{array}$ \\
\hline $\begin{array}{l}\text { 19. Rules are } \\
\text { developed and } \\
\text { posted for } \\
\text { specific settings } \\
\text { (settings where } \\
\text { data suggested }\end{array}$ & & $\begin{array}{l}\text { Rules are } \\
\text { posted in all } \\
\text { of the most } \\
\text { problematic } \\
\text { areas in the } \\
\text { school. }\end{array}$ & $\begin{array}{l}\text { Rules are posted } \\
\text { in some, but } \\
\text { not all of the } \\
\text { most } \\
\text { problematic }\end{array}$ & $\begin{array}{l}\text { Rules are not } \\
\text { posted in any of } \\
\text { the most } \\
\text { problematic } \\
\text { areas of the } \\
\text { school. }\end{array}$ \\
\hline
\end{tabular}




\begin{tabular}{|c|c|c|c|c|}
\hline $\begin{array}{l}\text { rules are } \\
\text { needed) }\end{array}$ & & & $\begin{array}{l}\text { areas of the } \\
\text { school. }\end{array}$ & \\
\hline $\begin{array}{l}\text { 20. Rules are } \\
\text { linked to } \\
\text { expectations }\end{array}$ & & & $\begin{array}{l}\text { When taught or } \\
\text { enforced, staff } \\
\text { consistently link } \\
\text { the rules with } \\
\text { the school-wide } \\
\text { expectations. }\end{array}$ & $\begin{array}{l}\text { When taught or } \\
\text { enforced, staff } \\
\text { do not } \\
\text { consistently } \\
\text { link the rules } \\
\text { with the school- } \\
\text { wide } \\
\text { expectations } \\
\text { and/or rules are } \\
\text { taught or } \\
\text { enforced } \\
\text { separately from } \\
\text { expectations. }\end{array}$ \\
\hline $\begin{array}{l}\text { 21. Staff are } \\
\text { involved in } \\
\text { development of } \\
\text { expectations and } \\
\text { rules }\end{array}$ & & $\begin{array}{l}\text { Most staff } \\
\text { were } \\
\text { involved in } \\
\text { providing } \\
\text { feedback/inp } \\
\text { ut into the } \\
\text { development } \\
\text { of the } \\
\text { school-wide } \\
\text { expectations } \\
\text { and rules } \\
\text { (i.e., survey, } \\
\text { feedback, } \\
\text { initial } \\
\text { brainstormin } \\
\text { g session, } \\
\text { election } \\
\text { process, etc.) }\end{array}$ & $\begin{array}{l}\text { Some staff were } \\
\text { involved in } \\
\text { providing } \\
\text { feedback/input } \\
\text { into the } \\
\text { development of } \\
\text { the school-wide } \\
\text { expectations and } \\
\text { rules. }\end{array}$ & $\begin{array}{l}\text { Staff were not } \\
\text { involved in } \\
\text { providing } \\
\text { feedback/input } \\
\text { into the } \\
\text { development of } \\
\text { the school-wide } \\
\text { expectations } \\
\text { and rules. }\end{array}$ \\
\hline $\begin{array}{l}\text { 22. A system of } \\
\text { rewards has } \\
\text { elements that are } \\
\text { implemented } \\
\text { consistently } \\
\text { across campus }\end{array}$ & $\begin{array}{l}\text { The reward } \\
\text { system } \\
\text { guidelines } \\
\text { and } \\
\text { procedures } \\
\text { are } \\
\text { implemented } \\
\text { consistently } \\
\text { across } \\
\text { campus. } \\
\text { Almost all } \\
\text { members of } \\
\text { the school }\end{array}$ & $\begin{array}{l}\text { The reward } \\
\text { system } \\
\text { guidelines } \\
\text { and } \\
\text { procedures } \\
\text { are } \\
\text { implemented } \\
\text { consistently } \\
\text { across } \\
\text { campus. } \\
\text { However, } \\
\text { some staff } \\
\text { choose not }\end{array}$ & $\begin{array}{l}\text { The reward } \\
\text { system } \\
\text { guidelines and } \\
\text { procedures are } \\
\text { not } \\
\text { implemented } \\
\text { consistently } \\
\text { because several } \\
\text { staff choose not } \\
\text { to participate or } \\
\text { participation } \\
\text { does not follow }\end{array}$ & $\begin{array}{l}\text { There is no } \\
\text { identifiable } \\
\text { reward system } \\
\text { or a large } \\
\text { percentage of } \\
\text { staff are not } \\
\text { participating. }\end{array}$ \\
\hline
\end{tabular}




\begin{tabular}{|c|c|c|c|c|}
\hline & $\begin{array}{l}\text { are } \\
\text { participating } \\
\text { appropriately } \\
\text { at least } \mathbf{9 0 \%} \\
\text { participation }\end{array}$ & $\begin{array}{l}\text { to participate } \\
\text { or } \\
\text { participation } \\
\text { does not } \\
\text { follow the } \\
\text { established } \\
\text { criteria. } \\
\text { at least } \mathbf{7 5 \%} \\
\text { participation }\end{array}$ & $\begin{array}{l}\text { the established } \\
\text { criteria. } \\
\text { at least } \mathbf{5 0 \%} \\
\text { participation }\end{array}$ & \\
\hline $\begin{array}{l}\text { 23. A variety of } \\
\text { methods are } \\
\text { used to reward } \\
\text { students }\end{array}$ & & $\begin{array}{l}\text { The school } \\
\text { uses a } \\
\text { variety of } \\
\text { methods to } \\
\text { reward } \\
\text { students } \\
\text { (e.g. cashing } \\
\text { in } \\
\text { tokens/point } \\
\text { s). There } \\
\text { should be } \\
\text { opportunitie } \\
\text { s that } \\
\text { include } \\
\text { tangible } \\
\text { items, } \\
\text { praise/recog } \\
\text { nition and } \\
\text { social } \\
\text { activities/ev } \\
\text { ents. } \\
\text { Students } \\
\text { with } \\
\text { few/many } \\
\text { tokens/point } \\
\text { s have equal } \\
\text { opportunitie } \\
\text { s to cash } \\
\text { them in for } \\
\text { rewards. } \\
\text { However, } \\
\text { larger } \\
\text { rewards are } \\
\text { given to } \\
\text { those } \\
\text { earning }\end{array}$ & $\begin{array}{l}\text { The school uses } \\
\text { a variety of } \\
\text { methods to } \\
\text { reward students, } \\
\text { but students do } \\
\text { not have access } \\
\text { to a variety of } \\
\text { rewards in a } \\
\text { consistent and } \\
\text { timely manner. }\end{array}$ & $\begin{array}{l}\text { The school uses } \\
\text { only one set } \\
\text { methods to } \\
\text { reward students } \\
\text { (i.e., tangibles } \\
\text { only) or there } \\
\text { are no } \\
\text { opportunities } \\
\text { for children to } \\
\text { cash in tokens } \\
\text { or select their } \\
\text { reward. Only } \\
\text { students that } \\
\text { meet the quotas } \\
\text { actually get } \\
\text { rewarded, } \\
\text { students with } \\
\text { fewer tokens } \\
\text { cannot cash in } \\
\text { tokens for a } \\
\text { smaller reward. }\end{array}$ \\
\hline
\end{tabular}




\begin{tabular}{|c|c|c|c|c|}
\hline & & $\begin{array}{l}\text { more } \\
\text { tokens/point. }\end{array}$ & & \\
\hline $\begin{array}{l}\text { 24. Rewards are } \\
\text { linked to } \\
\text { expectations and } \\
\text { rules }\end{array}$ & $\begin{array}{l}\text { Rewards are } \\
\text { provided for } \\
\text { behaviors } \\
\text { that are } \\
\text { identified in } \\
\text { the } \\
\text { rules/expecta } \\
\text { tions and } \\
\text { staff } \\
\text { verbalize the } \\
\text { appropriate } \\
\text { behavior } \\
\text { when giving } \\
\text { rewards. }\end{array}$ & $\begin{array}{l}\text { Rewards are } \\
\text { provided for } \\
\text { behaviors } \\
\text { that are } \\
\text { identified in } \\
\text { the } \\
\text { rules/expect } \\
\text { ations and } \\
\text { staff } \\
\text { sometimes } \\
\text { verbalize } \\
\text { appropriate } \\
\text { behaviors } \\
\text { when giving } \\
\text { rewards. }\end{array}$ & $\begin{array}{l}\text { Rewards are } \\
\text { provided for } \\
\text { behaviors that } \\
\text { are identified in } \\
\text { the } \\
\text { rules/expectatio } \\
\text { ns but staff } \\
\text { rarely verbalize } \\
\text { appropriate } \\
\text { behaviors when } \\
\text { giving rewards. }\end{array}$ & $\begin{array}{l}\text { Rewards are } \\
\text { provided for } \\
\text { behaviors that } \\
\text { are not } \\
\text { identified in the } \\
\text { rules and } \\
\text { expectations. }\end{array}$ \\
\hline $\begin{array}{l}25 . \text { Rewards are } \\
\text { varied to } \\
\text { maintain student } \\
\text { interest }\end{array}$ & & $\begin{array}{l}\text { The rewards } \\
\text { are varied } \\
\text { throughout } \\
\text { year and } \\
\text { reflect } \\
\text { students' } \\
\text { interests } \\
\text { (e.g. } \\
\text { consider the } \\
\text { student age, } \\
\text { culture, } \\
\text { gender, and } \\
\text { ability level } \\
\text { to maintain } \\
\text { student } \\
\text { interest.) }\end{array}$ & $\begin{array}{l}\text { The rewards are } \\
\text { varied } \\
\text { throughout the } \\
\text { school year, but } \\
\text { may not reflect } \\
\text { students' } \\
\text { interests. }\end{array}$ & $\begin{array}{l}\text { The rewards are } \\
\text { not varied } \\
\text { throughout the } \\
\text { school year and } \\
\text { do not reflect } \\
\text { student's } \\
\text { interests. }\end{array}$ \\
\hline $\begin{array}{l}\text { 26. Ratios of } \\
\text { acknowledgeme } \\
\text { nt to corrections } \\
\text { are high }\end{array}$ & $\begin{array}{l}\text { Ratios of } \\
\text { teacher } \\
\text { reinforcemen } \\
t \text { of } \\
\text { appropriate } \\
\text { behavior to } \\
\text { correction of } \\
\text { inappropriate } \\
\text { behavior are }\end{array}$ & $\begin{array}{l}\text { Ratios of } \\
\text { teacher } \\
\text { reinforceme } \\
\text { nt of } \\
\text { appropriate } \\
\text { behavior to } \\
\text { correction of } \\
\text { inappropriat } \\
\text { e behavior }\end{array}$ & $\begin{array}{l}\text { Ratios of teacher } \\
\text { reinforcement of } \\
\text { appropriate } \\
\text { behavior to } \\
\text { correction of } \\
\text { inappropriate } \\
\text { behavior are } \\
\text { about the same } \\
\text { (e.g., } 1: 1) \text {. }\end{array}$ & $\begin{array}{l}\text { Ratios of } \\
\text { teacher } \\
\text { reinforcement } \\
\text { of appropriate } \\
\text { behavior to } \\
\text { correction of } \\
\text { inappropriate } \\
\text { behavior are } \\
\text { low (e.g., 1:4) }\end{array}$ \\
\hline
\end{tabular}




\begin{tabular}{|c|c|c|c|c|}
\hline & $\begin{array}{l}\text { high (e.g., } \\
4: 1) \text {. }\end{array}$ & $\begin{array}{l}\text { are } \\
\text { moderate } \\
\text { (e.g., 2:1). }\end{array}$ & & \\
\hline $\begin{array}{l}\text { 28. The system } \\
\text { includes } \\
\text { incentives for } \\
\text { staff/faculty }\end{array}$ & & $\begin{array}{l}\text { The system } \\
\text { includes } \\
\text { incentives } \\
\text { for } \\
\text { staff/faculty } \\
\text { and they are } \\
\text { delivered } \\
\text { consistently. }\end{array}$ & $\begin{array}{l}\text { The system } \\
\text { includes } \\
\text { incentives for } \\
\text { staff/faculty, but } \\
\text { they are not } \\
\text { delivered } \\
\text { consistently. }\end{array}$ & $\begin{array}{l}\text { The system } \\
\text { does not } \\
\text { include } \\
\text { incentives for } \\
\text { staff/faculty. }\end{array}$ \\
\hline $\begin{array}{l}29 . \text { A } \\
\text { behavioral } \\
\text { curriculum } \\
\text { includes } \\
\text { teaching } \\
\text { expectations and } \\
\text { rules }\end{array}$ & & $\begin{array}{l}\text { Lesson plans } \\
\text { are } \\
\text { developed } \\
\text { and used to } \\
\text { teach rules } \\
\text { and } \\
\text { expectations }\end{array}$ & $\begin{array}{l}\text { Lesson plans } \\
\text { were developed } \\
\text { and used to } \\
\text { teach rules, but } \\
\text { not developed } \\
\text { for expectations } \\
\text { or vice versa. }\end{array}$ & $\begin{array}{l}\text { Lesson plans } \\
\text { have not been } \\
\text { developed or } \\
\text { used to teach } \\
\text { rules or } \\
\text { expectations }\end{array}$ \\
\hline $\begin{array}{l}\text { 30. Lessons } \\
\text { include } \\
\text { examples and } \\
\text { non-examples }\end{array}$ & & & $\begin{array}{l}\text { Lesson plans } \\
\text { include both } \\
\text { examples of } \\
\text { appropriate } \\
\text { behavior and } \\
\text { examples of } \\
\text { inappropriate } \\
\text { behavior. }\end{array}$ & $\begin{array}{l}\text { Lesson plans } \\
\text { give no specific } \\
\text { examples or } \\
\text { non-examples } \\
\text { or there are no } \\
\text { lesson plans. }\end{array}$ \\
\hline $\begin{array}{l}\text { 31. Lessons use } \\
\text { a variety of } \\
\text { teaching } \\
\text { strategies }\end{array}$ & & $\begin{array}{l}\text { Lesson plans } \\
\text { are taught } \\
\text { using at least } \\
3 \text { different } \\
\text { teaching } \\
\text { strategies } \\
\text { (i.e., } \\
\text { modeling, } \\
\text { role-playing, } \\
\text { videotaping) }\end{array}$ & $\begin{array}{l}\text { Lesson plans } \\
\text { have been } \\
\text { introduced using } \\
\text { fewer than } 3 \\
\text { teaching } \\
\text { strategies. }\end{array}$ & $\begin{array}{l}\text { Lesson plans } \\
\text { have not been } \\
\text { taught or do not } \\
\text { exist. }\end{array}$ \\
\hline $\begin{array}{l}\text { 32. Lessons are } \\
\text { embedded into } \\
\text { subject area } \\
\text { curriculum }\end{array}$ & & $\begin{array}{l}\text { Nearly all } \\
\text { teachers } \\
\text { embed } \\
\text { behavior } \\
\text { teaching into } \\
\text { subject area } \\
\text { curriculum }\end{array}$ & $\begin{array}{l}\text { About 50\% of } \\
\text { teachers embed } \\
\text { behavior } \\
\text { teaching into } \\
\text { subject area } \\
\text { curriculum or } \\
\text { embed behavior } \\
\text { teaching fewer }\end{array}$ & $\begin{array}{l}\text { Less than } \mathbf{5 0 \%} \\
\text { of all teachers } \\
\text { embed behavior } \\
\text { teaching into } \\
\text { subject area } \\
\text { curriculum or } \\
\text { only } \\
\text { occasionally }\end{array}$ \\
\hline
\end{tabular}




\begin{tabular}{|c|c|c|c|}
\hline & $\begin{array}{l}\text { on a daily } \\
\text { basis. }\end{array}$ & $\begin{array}{l}\text { than } 3 \text { times per } \\
\text { week }\end{array}$ & $\begin{array}{l}\text { remember to } \\
\text { include } \\
\text { behavior } \\
\text { teaching in } \\
\text { subject areas. }\end{array}$ \\
\hline $\begin{array}{l}33 . \\
\text { Faculty/staff and } \\
\text { students are } \\
\text { involved in } \\
\text { development \& } \\
\text { delivery of } \\
\text { behavioral } \\
\text { curriculum }\end{array}$ & & $\begin{array}{l}\text { Faculty, staff, } \\
\text { and students are } \\
\text { involved in the } \\
\text { development } \\
\text { and delivery of } \\
\text { lesson plans to } \\
\text { teach behavior } \\
\text { expectations and } \\
\text { rules for specific } \\
\text { settings. }\end{array}$ & $\begin{array}{l}\text { Faculty, staff, } \\
\text { and students } \\
\text { are not } \\
\text { involved in the } \\
\text { development } \\
\text { and delivery of } \\
\text { lesson plans to } \\
\text { teach behavior } \\
\text { expectations } \\
\text { and rules for } \\
\text { specific } \\
\text { settings. }\end{array}$ \\
\hline $\begin{array}{l}\text { 34. Strategies to } \\
\text { share key } \\
\text { features of } \\
\text { SWPBS } \\
\text { program with } \\
\text { families/commu } \\
\text { nity are } \\
\text { developed and } \\
\text { implemented }\end{array}$ & & $\begin{array}{l}\text { The PBIS Plan } \\
\text { includes } \\
\text { strategies to } \\
\text { reinforce lessons } \\
\text { with families } \\
\text { and the } \\
\text { community (i.e., } \\
\text { after-school } \\
\text { programs teach } \\
\text { expectations, } \\
\text { newsletters with } \\
\text { tips for meeting } \\
\text { expectations at } \\
\text { home) }\end{array}$ & $\begin{array}{l}\text { The PBIS plan } \\
\text { does not } \\
\text { include } \\
\text { strategies to be } \\
\text { used by } \\
\text { families and the } \\
\text { community. }\end{array}$ \\
\hline $\begin{array}{l}35 . \text { A } \\
\text { curriculum to } \\
\text { teach } \\
\text { components of } \\
\text { the discipline } \\
\text { system to all } \\
\text { staff is } \\
\text { developed and } \\
\text { used }\end{array}$ & $\begin{array}{l}\text { The team } \\
\text { scheduled } \\
\text { time to } \\
\text { present and } \\
\text { train faculty } \\
\text { and staff on } \\
\text { the } \\
\text { discipline } \\
\text { procedures } \\
\text { and data } \\
\text { system } \\
\text { including } \\
\text { checks for }\end{array}$ & $\begin{array}{l}\text { The team } \\
\text { scheduled time } \\
\text { to present and } \\
\text { train faculty and } \\
\text { staff on the } \\
\text { discipline } \\
\text { procedures and } \\
\text { data system, but } \\
\text { there were no } \\
\text { checks for } \\
\text { accuracy of } \\
\text { information or } \\
\text { comprehension. }\end{array}$ & $\begin{array}{l}\text { Staff was either } \\
\text { not trained or } \\
\text { was given the } \\
\text { information } \\
\text { without formal } \\
\text { introduction } \\
\text { and } \\
\text { explanation. }\end{array}$ \\
\hline
\end{tabular}




\begin{tabular}{|c|c|c|c|}
\hline & $\begin{array}{l}\text { accuracy of } \\
\text { information } \\
\text { or } \\
\text { comprehensi } \\
\text { on. } \\
\text { Training } \\
\text { included all } \\
\text { components } \\
\text { : referral } \\
\text { process } \\
\text { (flowchart), } \\
\text { definitions } \\
\text { of problem } \\
\text { behaviors, } \\
\text { explanation } \\
\text { of major vs. } \\
\text { minor forms, } \\
\text { and how the } \\
\text { data will be } \\
\text { used to } \\
\text { guide the } \\
\text { team in } \\
\text { decision } \\
\text { making. }\end{array}$ & $\begin{array}{l}\text { OR training } \\
\text { did not include } \\
\text { all components } \\
\text { (i.e., referral } \\
\text { process } \\
\text { (flowchart), } \\
\text { definitions of } \\
\text { problem } \\
\text { behaviors, } \\
\text { explanation of } \\
\text { major vs. minor } \\
\text { forms, and how } \\
\text { the data will be } \\
\text { used to guide } \\
\text { the team in } \\
\text { decision } \\
\text { making.) }\end{array}$ & \\
\hline $\begin{array}{l}\text { 36. Plans for } \\
\text { training staff to } \\
\text { teach students } \\
\text { expectations/rul } \\
\text { es and rewards } \\
\text { are developed, } \\
\text { scheduled and } \\
\text { delivered }\end{array}$ & $\begin{array}{l}\text { The team } \\
\text { scheduled } \\
\text { time to } \\
\text { present and } \\
\text { train faculty } \\
\text { and staff on } \\
\text { lesson plans } \\
\text { to teach } \\
\text { students } \\
\text { expectations } \\
\text { and rules } \\
\text { including } \\
\text { checks for } \\
\text { accuracy of } \\
\text { information } \\
\text { or } \\
\text { comprehensi } \\
\text { on. } \\
\text { Training } \\
\text { included all } \\
\text { components } \\
\text { : plans to }\end{array}$ & $\begin{array}{l}\text { The team } \\
\text { scheduled time } \\
\text { to present and } \\
\text { train faculty and } \\
\text { staff on lesson } \\
\text { plans to teach } \\
\text { students } \\
\text { expectations and } \\
\text { rules but there } \\
\text { were no checks } \\
\text { for accuracy of } \\
\text { information or } \\
\text { comprehension. } \\
\text { OR Training } \\
\text { didn't include } \\
\text { all components: } \\
\text { plans to } \\
\text { introduce } \\
\text { expectations and } \\
\text { rules to all } \\
\text { students, } \\
\text { explanation of }\end{array}$ & $\begin{array}{l}\text { Staff was either } \\
\text { not trained or } \\
\text { was given the } \\
\text { information } \\
\text { without formal } \\
\text { introduction } \\
\text { and } \\
\text { explanation. }\end{array}$ \\
\hline
\end{tabular}




\begin{tabular}{|c|c|c|c|c|}
\hline & & $\begin{array}{l}\text { introduce the } \\
\text { expectations } \\
\text { and rules to } \\
\text { all students, } \\
\text { explanation } \\
\text { of how and } \\
\text { when to use } \\
\text { formal } \\
\text { lesson plans, } \\
\text { and how to } \\
\text { embed } \\
\text { behavior } \\
\text { teaching into } \\
\text { daily } \\
\text { curriculum. }\end{array}$ & $\begin{array}{l}\text { how and when } \\
\text { to use formal } \\
\text { lesson plans, } \\
\text { and how to } \\
\text { embed behavior } \\
\text { teaching into } \\
\text { daily } \\
\text { curriculum. }\end{array}$ & \\
\hline $\begin{array}{l}\text { 37. A plan for } \\
\text { teaching } \\
\text { students' } \\
\text { expectations/ } \\
\text { rules/rewards is } \\
\text { developed } \\
\text { scheduled and } \\
\text { delivered }\end{array}$ & $\begin{array}{l}\text { Students are } \\
\text { introduced/ta } \\
\text { ught all of } \\
\text { the } \\
\text { following: } \\
\text { school } \\
\text { expectations, } \\
\text { rules for } \\
\text { specific } \\
\text { setting, and } \\
\text { the reward } \\
\text { system } \\
\text { guidelines. }\end{array}$ & $\begin{array}{l}\text { Students are } \\
\text { introduced/t } \\
\text { aught two } \\
\text { (2) of the } \\
\text { following: } \\
\text { school } \\
\text { expectations, } \\
\text { rules for } \\
\text { specific } \\
\text { setting, and } \\
\text { the reward } \\
\text { system } \\
\text { guidelines. }\end{array}$ & $\begin{array}{l}\text { Students are } \\
\text { introduced/taugh } \\
\text { t only one (1) of } \\
\text { the following: } \\
\text { school } \\
\text { expectations, } \\
\text { rules for specific } \\
\text { setting, and the } \\
\text { reward system } \\
\text { guidelines. }\end{array}$ & $\begin{array}{l}\text { Students are not } \\
\text { introduced/taug } \\
\text { ht any of the } \\
\text { following: } \\
\text { school } \\
\text { expectations, } \\
\text { rules for } \\
\text { specific setting, } \\
\text { and the reward } \\
\text { system } \\
\text { guidelines. }\end{array}$ \\
\hline $\begin{array}{l}\text { 38. Booster } \\
\text { sessions for } \\
\text { students and } \\
\text { staff are } \\
\text { planned, } \\
\text { scheduled, and } \\
\text { implemented }\end{array}$ & & $\begin{array}{l}\text { Booster } \\
\text { sessions are } \\
\text { planned and } \\
\text { delivered to } \\
\text { reteach } \\
\text { staff/student } \\
\text { s at least } \\
\text { once in the } \\
\text { year and } \\
\text { additionally } \\
\text { at times } \\
\text { when the } \\
\text { data suggest } \\
\text { problems by } \\
\text { an increase } \\
\text { in discipline } \\
\text { referrals per } \\
\text { day per }\end{array}$ & $\begin{array}{l}\text { Booster sessions } \\
\text { are not utilized } \\
\text { fully. For } \\
\text { example: } \\
\text { booster sessions } \\
\text { are held for } \\
\text { students but not } \\
\text { staff; booster } \\
\text { sessions are held } \\
\text { for staff, but not } \\
\text { students; booster } \\
\text { sessions are not } \\
\text { held, but rules \& } \\
\text { expectations are } \\
\text { reviewed at least } \\
\text { weekly with } \\
\text { students. }\end{array}$ & $\begin{array}{l}\text { Booster } \\
\text { sessions for } \\
\text { students and } \\
\text { staff are not } \\
\text { scheduled/plan } \\
\text { ned. } \\
\text { Expectations } \\
\text { and rules are } \\
\text { reviewed with } \\
\text { students once a } \\
\text { month or less. }\end{array}$ \\
\hline
\end{tabular}




\begin{tabular}{|c|c|c|c|}
\hline & $\begin{array}{l}\text { month or a } \\
\text { high number } \\
\text { of referrals } \\
\text { in a } \\
\text { specified } \\
\text { area. } \\
\text { Expectations } \\
\text { and rules are } \\
\text { reviewed } \\
\text { with } \\
\text { students } \\
\text { regularly (at } \\
\text { least 1x per } \\
\text { week). }\end{array}$ & & \\
\hline $\begin{array}{l}\text { 39. Schedule } \\
\text { for } \\
\text { rewards/incentiv } \\
\text { es for the year is } \\
\text { planned }\end{array}$ & & $\begin{array}{l}\text { There is a clear } \\
\text { plan for the type } \\
\text { and frequency of } \\
\text { rewards/incentiv } \\
\text { es to be } \\
\text { delivered } \\
\text { throughout the } \\
\text { year. }\end{array}$ & $\begin{array}{l}\text { There is no } \\
\text { plan for the } \\
\text { type and } \\
\text { frequency of } \\
\text { rewards/incenti } \\
\text { ves to be } \\
\text { delivered } \\
\text { throughout the } \\
\text { year. }\end{array}$ \\
\hline $\begin{array}{l}\text { 40. Plans for } \\
\text { orienting } \\
\text { incoming staff } \\
\text { and students are } \\
\text { developed and } \\
\text { implemented }\end{array}$ & $\begin{array}{l}\text { Team has } \\
\text { planned for } \\
\text { and carries } \\
\text { out the } \\
\text { introduction } \\
\text { of School- } \\
\text { wide PBIS } \\
\text { and training } \\
\text { of new staff } \\
\text { and students } \\
\text { throughout } \\
\text { the school } \\
\text { year. }\end{array}$ & $\begin{array}{l}\text { Team has } \\
\text { planned for the } \\
\text { introduction of } \\
\text { School-wide } \\
\text { PBS and } \\
\text { training of either } \\
\text { new students or } \\
\text { new staff, but } \\
\text { does not include } \\
\text { plans for } \\
\text { training both. } \\
\text { OR the team has } \\
\text { plans but has not } \\
\text { implemented } \\
\text { them. }\end{array}$ & $\begin{array}{l}\text { Team has not } \\
\text { planned for the } \\
\text { introduction of } \\
\text { School-wide } \\
\text { PBIS and } \\
\text { training of new } \\
\text { staff or students }\end{array}$ \\
\hline $\begin{array}{l}\text { 41. Plans for } \\
\text { involving } \\
\text { families/commu } \\
\text { nity are } \\
\text { developed and } \\
\text { implemented }\end{array}$ & & $\begin{array}{l}\text { Team has } \\
\text { planned for the } \\
\text { introduction and } \\
\text { on-going } \\
\text { involvement of } \\
\text { school-wide } \\
\text { PBIS to } \\
\text { families/commu }\end{array}$ & $\begin{array}{l}\text { Team has not } \\
\text { introduced } \\
\text { school-wide } \\
\text { PBIS to } \\
\text { families/comm } \\
\text { unity. }\end{array}$ \\
\hline
\end{tabular}




\begin{tabular}{|c|c|c|c|}
\hline & & $\begin{array}{l}\text { nity (i.e., } \\
\text { newsletter, } \\
\text { brochure, PTA, } \\
\text { open-house, } \\
\text { team member, } \\
\text { etc.) }\end{array}$ & \\
\hline $\begin{array}{l}\text { 42. Classroom } \\
\text { rules are defined } \\
\text { for each of the } \\
\text { school-wide } \\
\text { expectations and } \\
\text { are posted in } \\
\text { classrooms }\end{array}$ & $\begin{array}{l}\text { Evident in } \\
\text { most } \\
\text { classrooms } \\
\text { (>75\% of } \\
\text { classrooms) }\end{array}$ & $\begin{array}{l}\text { Evident in many } \\
\text { classrooms (50- } \\
75 \% \text { of } \\
\text { classrooms) }\end{array}$ & $\begin{array}{l}\text { Evident in only } \\
\text { a few } \\
\text { classrooms } \\
\text { (less than } 50 \% \\
\text { of classrooms) }\end{array}$ \\
\hline $\begin{array}{l}\text { 43. Classroom } \\
\text { routines and } \\
\text { procedures are } \\
\text { explicitly } \\
\text { identified for } \\
\text { activities where } \\
\text { problems often } \\
\text { occur (e.g. } \\
\text { entering class, } \\
\text { asking } \\
\text { questions, } \\
\text { sharpening } \\
\text { pencil, using } \\
\text { restroom, } \\
\text { dismissal) }\end{array}$ & $\begin{array}{l}\text { Evident in } \\
\text { most } \\
\text { classrooms } \\
\text { (>75\% of } \\
\text { classrooms) }\end{array}$ & $\begin{array}{l}\text { Evident in many } \\
\text { classrooms (50- } \\
75 \% \text { of } \\
\text { classrooms) }\end{array}$ & $\begin{array}{l}\text { Evident in only } \\
\text { a few } \\
\text { classrooms } \\
\text { (less than } 50 \% \\
\text { of classrooms) }\end{array}$ \\
\hline $\begin{array}{l}\text { 44. Expected } \\
\text { behavior } \\
\text { routines in } \\
\text { classroom are } \\
\text { taught }\end{array}$ & $\begin{array}{l}\text { Evident in } \\
\text { most } \\
\text { classrooms } \\
\text { (>75\% of } \\
\text { classrooms) }\end{array}$ & $\begin{array}{l}\text { Evident in many } \\
\text { classrooms (50- } \\
75 \% \text { of } \\
\text { classrooms) }\end{array}$ & $\begin{array}{l}\text { Evident in only } \\
\text { a few } \\
\text { classrooms } \\
\text { (less than } 50 \% \\
\text { of classrooms) }\end{array}$ \\
\hline $\begin{array}{l}\text { 45. Classroom } \\
\text { teachers use } \\
\text { immediate and } \\
\text { specific praise }\end{array}$ & $\begin{array}{l}\text { Evident in } \\
\text { most } \\
\text { classrooms } \\
(>75 \% \text { of } \\
\text { classrooms) }\end{array}$ & $\begin{array}{l}\text { Evident in many } \\
\text { classrooms ( } 50- \\
75 \% \text { of } \\
\text { classrooms) }\end{array}$ & $\begin{array}{l}\text { Evident in only } \\
\text { a few } \\
\text { classrooms } \\
\text { (less than } 50 \% \\
\text { of classrooms) }\end{array}$ \\
\hline
\end{tabular}




\begin{tabular}{|c|c|c|c|}
\hline $\begin{array}{l}46 . \\
\text { Acknowledgeme } \\
\text { nt of students } \\
\text { demonstrating } \\
\text { adherence to } \\
\text { classroom rules } \\
\text { and routines } \\
\text { occurs more } \\
\text { frequently than } \\
\text { acknowledgeme } \\
\text { nt of } \\
\text { inappropriate } \\
\text { behaviors }\end{array}$ & $\begin{array}{l}\text { Evident in } \\
\text { most } \\
\text { classrooms } \\
\text { (>75\% of } \\
\text { classrooms) }\end{array}$ & $\begin{array}{l}\text { Evident in many } \\
\text { classrooms }(50- \\
75 \% \text { of } \\
\text { classrooms) }\end{array}$ & $\begin{array}{l}\text { Evident in only } \\
\text { a few } \\
\text { classrooms } \\
\text { (less than } 50 \% \\
\text { of classrooms) }\end{array}$ \\
\hline $\begin{array}{l}\text { 47. Procedures } \\
\text { exist for } \\
\text { tracking } \\
\text { classroom } \\
\text { behavior } \\
\text { problems }\end{array}$ & $\begin{array}{l}\text { Evident in } \\
\text { most } \\
\text { classrooms } \\
\text { (>75\% of } \\
\text { classrooms) }\end{array}$ & $\begin{array}{l}\text { Evident in many } \\
\text { classrooms (50- } \\
75 \% \text { of } \\
\text { classrooms) }\end{array}$ & $\begin{array}{l}\text { Evident in only } \\
\text { a few } \\
\text { classrooms } \\
\text { (less than } 50 \% \\
\text { of classrooms) }\end{array}$ \\
\hline $\begin{array}{l}\text { 48. Classrooms } \\
\text { have a range of } \\
\text { consequences/ } \\
\text { interventions for } \\
\text { problem } \\
\text { behavior that are } \\
\text { documented and } \\
\text { consistently } \\
\text { delivered }\end{array}$ & $\begin{array}{l}\text { Evident in } \\
\text { most } \\
\text { classrooms } \\
\text { (>75\% of } \\
\text { classrooms) }\end{array}$ & $\begin{array}{l}\text { Evident in many } \\
\text { classrooms (50- } \\
75 \% \text { of } \\
\text { classrooms) }\end{array}$ & $\begin{array}{l}\text { Evident in only } \\
\text { a few } \\
\text { classrooms } \\
\text { (less than } 50 \% \\
\text { of classrooms) }\end{array}$ \\
\hline $\begin{array}{l}\text { 49. Students } \\
\text { and staff are } \\
\text { surveyed about } \\
\text { PBS }\end{array}$ & $\begin{array}{l}\text { Students and } \\
\text { staff are } \\
\text { surveyed at } \\
\text { least } \\
\text { annually (i.e. } \\
\text { items on } \\
\text { climate } \\
\text { survey or } \\
\text { specially } \\
\text { developed } \\
\text { PBIS plan } \\
\text { survey), and } \\
\text { information } \\
\text { is used to } \\
\text { address the } \\
\text { PBIS plan. }\end{array}$ & $\begin{array}{l}\text { Students and } \\
\text { staff are } \\
\text { surveyed at least } \\
\text { annually (i.e. } \\
\text { items on climate } \\
\text { survey or } \\
\text { specially } \\
\text { developed PBIS } \\
\text { plan survey), but } \\
\text { information is } \\
\text { not used to } \\
\text { address the } \\
\text { PBIS plan. }\end{array}$ & $\begin{array}{l}\text { Students and } \\
\text { staff are not } \\
\text { surveyed. }\end{array}$ \\
\hline
\end{tabular}




\begin{tabular}{|c|c|c|c|c|}
\hline $\begin{array}{l}\text { 50. Students } \\
\text { and staff can } \\
\text { identify } \\
\text { expectations and } \\
\text { rules }\end{array}$ & & $\begin{array}{l}\text { Almost all } \\
\text { students and } \\
\text { staff can } \\
\text { identify the } \\
\text { school-wide } \\
\text { expectations } \\
\text { and rules for } \\
\text { specific } \\
\text { settings. } \\
\text { (can be } \\
\text { identified } \\
\text { through } \\
\text { surveys, } \\
\text { random } \\
\text { interviews, } \\
\text { etc....) at } \\
\text { least } 90 \%\end{array}$ & $\begin{array}{l}\text { any students and } \\
\text { staff can identify } \\
\text { the school-wide } \\
\text { expectations and } \\
\text { rules for specific } \\
\text { settings. } \\
\text { at least } 50 \%\end{array}$ & $\begin{array}{l}\text { Few of students } \\
\text { and staff can } \\
\text { identify the } \\
\text { expectations } \\
\text { and rules for } \\
\text { specific settings } \\
\text { OR Evaluations } \\
\text { are not } \\
\text { conducted } \\
\text { less than } 50 \%\end{array}$ \\
\hline $\begin{array}{l}\text { 51. Staff use } \\
\text { referral process } \\
\text { (including } \\
\text { which behaviors } \\
\text { are office } \\
\text { managed vs. } \\
\text { which are } \\
\text { teacher } \\
\text { managed) and } \\
\text { forms } \\
\text { appropriately }\end{array}$ & $\begin{array}{l}\text { Almost all } \\
\text { staff know } \\
\text { the } \\
\text { procedures } \\
\text { for } \\
\text { responding to } \\
\text { inappropriate } \\
\text { behavior, use } \\
\text { forms as } \\
\text { intended and } \\
\text { fill them out } \\
\text { correctly. } \\
\text { (can be } \\
\text { identified by } \\
\text { reviewing } \\
\text { completed } \\
\text { forms, staff } \\
\text { surveys, } \\
\text { etc....) at } \\
\text { least } 90 \% \\
\text { know/use }\end{array}$ & $\begin{array}{l}\text { Many of the } \\
\text { staff know } \\
\text { the } \\
\text { procedures } \\
\text { for } \\
\text { responding } \\
\text { to } \\
\text { inappropriat } \\
\text { e behavior, } \\
\text { use forms as } \\
\text { intended and } \\
\text { fill them out } \\
\text { correctly. } \\
\\
\text { at least } 75 \% \\
\text { know/use }\end{array}$ & $\begin{array}{l}\text { Some of the } \\
\text { staff know the } \\
\text { procedures for } \\
\text { responding to } \\
\text { inappropriate } \\
\text { behavior, use } \\
\text { forms as } \\
\text { intended and fill } \\
\text { them out } \\
\text { correctly. }\end{array}$ & $\begin{array}{l}\text { Few staff know } \\
\text { the procedures } \\
\text { for responding } \\
\text { to inappropriate } \\
\text { behavior, use } \\
\text { forms as } \\
\text { intended and } \\
\text { fill them out } \\
\text { correctly OR } \\
\text { Evaluations are } \\
\text { not conducted. } \\
\\
\text { less than } 50 \% \\
\text { know/use }\end{array}$ \\
\hline $\begin{array}{l}\text { 52. Staff use } \\
\text { reward system } \\
\text { appropriately }\end{array}$ & $\begin{array}{l}\text { Almost all } \\
\text { staff } \\
\text { understand } \\
\text { identified } \\
\text { guidelines } \\
\text { for the } \\
\text { reward } \\
\text { system and }\end{array}$ & $\begin{array}{l}\text { Many of the } \\
\text { staff } \\
\text { understand } \\
\text { identified } \\
\text { guidelines } \\
\text { for the } \\
\text { reward } \\
\text { system and }\end{array}$ & $\begin{array}{l}\text { Some of the } \\
\text { staff understand } \\
\text { identified } \\
\text { guidelines for } \\
\text { the reward } \\
\text { system and are } \\
\text { using the reward }\end{array}$ & $\begin{array}{l}\text { Few staff } \\
\text { understand and } \\
\text { use identified } \\
\text { guidelines for } \\
\text { the reward } \\
\text { system OR } \\
\text { Evaluations are } \\
\text { not conducted }\end{array}$ \\
\hline
\end{tabular}




\begin{tabular}{|c|c|c|c|c|}
\hline & $\begin{array}{l}\text { are using the } \\
\text { reward } \\
\text { system } \\
\text { appropriately } \\
\text {. (can be } \\
\text { identified by } \\
\text { reviewing } \\
\text { reward token } \\
\text { distribution, } \\
\text { surveys, } \\
\text { etc....) } \\
\text { at least } 90 \% \\
\text { understand/u } \\
\text { se }\end{array}$ & $\begin{array}{l}\text { are using the } \\
\text { reward } \\
\text { system } \\
\text { appropriatel } \\
\text { y. } \\
\text { at least } 75 \% \\
\text { understand/u } \\
\text { se }\end{array}$ & $\begin{array}{l}\text { system } \\
\text { appropriately. }\end{array}$ & $\begin{array}{l}\text { at least yearly } \\
\text { or do not assess } \\
\text { staff knowledge } \\
\text { and use of the } \\
\text { reward system. } \\
\text { less than } 50 \% \\
\text { understand/use }\end{array}$ \\
\hline $\begin{array}{l}\text { 53. Outcomes } \\
\text { (behavior } \\
\text { problems, } \\
\text { attendance, and } \\
\text { morale) are } \\
\text { documented and } \\
\text { used to evaluate } \\
\text { PBIS plan }\end{array}$ & $\begin{array}{l}\text { There is a } \\
\text { plan for } \\
\text { collecting } \\
\text { data to } \\
\text { evaluate } \\
\text { PBIS } \\
\text { outcomes, } \\
\text { most data are } \\
\text { collected as } \\
\text { scheduled, } \\
\text { and data are } \\
\text { used to } \\
\text { evaluate } \\
\text { PBIS plan. }\end{array}$ & $\begin{array}{l}\text { There is a } \\
\text { plan for } \\
\text { collecting } \\
\text { data to } \\
\text { evaluate } \\
\text { PBIS } \\
\text { outcomes, } \\
\text { some of the } \\
\text { scheduled } \\
\text { data have } \\
\text { been } \\
\text { collected, } \\
\text { and data are } \\
\text { used to } \\
\text { evaluate } \\
\text { PBIS plan. }\end{array}$ & $\begin{array}{l}\text { There is a plan } \\
\text { for collecting } \\
\text { data to evaluate } \\
\text { PBIS outcomes; } \\
\text { however, } \\
\text { nothing has been } \\
\text { collected to } \\
\text { date. }\end{array}$ & $\begin{array}{l}\text { There is no } \\
\text { plan for } \\
\text { collecting data } \\
\text { to evaluate } \\
\text { PBIS outcomes. }\end{array}$ \\
\hline
\end{tabular}


School-wide Positive Behavior Support

Benchmarks of Quality: Facilitator SCORING SHEET

School Name:

District:

Person Completing Form:

Date:

\begin{tabular}{|c|c|c|c|c|c|c|}
\hline $\begin{array}{l}\text { Critical } \\
\text { Elements }\end{array}$ & Benchmarks of Quality & \multicolumn{4}{|c|}{$\begin{array}{l}\text { Directions: Use Scoring } \\
\text { Guide to assist in } \\
\text { determining most } \\
\text { appropriate point value. } \\
\text { Circle Only One. }\end{array}$} & 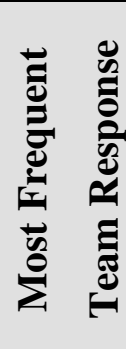 \\
\hline \multirow[t]{4}{*}{ PBS Team } & Team has broad representation & & & 1 & 0 & \\
\hline & $\begin{array}{l}\text { Team has administrative } \\
\text { support }\end{array}$ & 3 & 2 & 1 & 0 & \\
\hline & $\begin{array}{l}\text { Team has regular meetings (at } \\
\text { least monthly) }\end{array}$ & & 2 & 1 & 0 & \\
\hline & $\begin{array}{l}\text { Team has established a clear } \\
\text { mission/purpose }\end{array}$ & & & 1 & 0 & \\
\hline \multirow[t]{3}{*}{$\begin{array}{l}\text { Faculty } \\
\text { Commitme } \\
\text { nt }\end{array}$} & $\begin{array}{l}\text { Faculty aware of behavior } \\
\text { problems across campus } \\
\text { (regular data sharing) }\end{array}$ & & 2 & 1 & 0 & \\
\hline & $\begin{array}{l}\text { Faculty involved in } \\
\text { establishing goals }\end{array}$ & & 2 & 1 & 0 & \\
\hline & $\begin{array}{l}\text { Faculty feedback obtained } \\
\text { throughout year }\end{array}$ & & 2 & 1 & 0 & \\
\hline \multirow{2}{*}{$\begin{array}{l}\text { Effective } \\
\text { Procedures } \\
\text { for } \\
\text { Dealing }\end{array}$} & $\begin{array}{l}\text { Discipline process described in } \\
\text { narrative format or depicted in } \\
\text { graphic format }\end{array}$ & & 2 & 1 & 0 & \\
\hline & $\begin{array}{l}\text { Process includes } \\
\text { documentation procedures }\end{array}$ & & & 1 & 0 & \\
\hline
\end{tabular}




\begin{tabular}{|c|c|c|c|c|c|c|}
\hline $\begin{array}{l}\text { Critical } \\
\text { Elements }\end{array}$ & Benchmarks of Quality & \multicolumn{4}{|c|}{$\begin{array}{c}\text { Directions: Use Scoring } \\
\text { Guide to assist in } \\
\text { determining most } \\
\text { appropriate point value. } \\
\text { Circle Only One. }\end{array}$} & 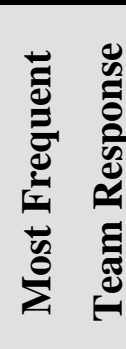 \\
\hline \multirow[t]{5}{*}{$\begin{array}{l}\text { with } \\
\text { Discipline }\end{array}$} & $\begin{array}{l}\text { 0. Discipline referral form } \\
\text { includes information useful in } \\
\text { decision making }\end{array}$ & & 2 & 1 & 0 & \\
\hline & 1. Behaviors defined & 3 & 2 & 1 & 0 & \\
\hline & $\begin{array}{l}\text { 2. Clearly identified major/minor } \\
\text { behaviors }\end{array}$ & & 2 & 1 & 0 & \\
\hline & $\begin{array}{l}\text { 3. Suggested array of appropriate } \\
\text { responses to minor (non office- } \\
\text { managed) problem behaviors }\end{array}$ & & & 1 & 0 & \\
\hline & $\begin{array}{l}\text { 4. Suggested array of appropriate } \\
\text { responses to major (office- } \\
\text { managed) problem behaviors }\end{array}$ & & & 1 & 0 & \\
\hline \multirow{5}{*}{$\begin{array}{l}\text { Data Entry } \\
\& \\
\text { Analysis } \\
\text { Plan } \\
\text { Establishe } \\
\text { d }\end{array}$} & $\begin{array}{l}\text { 5. Data system to collect and } \\
\text { analyze ODR data }\end{array}$ & 3 & 2 & 1 & 0 & \\
\hline & $\begin{array}{l}\text { 6. Additional data collected } \\
\text { (attendance, grades, faculty } \\
\text { attendance, surveys) }\end{array}$ & & & 1 & 0 & \\
\hline & $\begin{array}{l}\text { 7. Data entered weekly } \\
\text { (minimum) }\end{array}$ & & & 1 & 0 & \\
\hline & $\begin{array}{l}\text { 8. Data analyzed monthly } \\
\text { (minimum) }\end{array}$ & & 2 & 1 & 0 & \\
\hline & $\begin{array}{l}\text { 9. Data shared with team and } \\
\text { faculty monthly (minimum) }\end{array}$ & & 2 & 1 & 0 & \\
\hline
\end{tabular}




\begin{tabular}{|c|c|c|c|c|c|c|}
\hline \multirow{2}{*}{$\begin{array}{c}\text { Critical } \\
\text { Elements } \\
\text { Expectatio } \\
\text { ns \& Rules } \\
\text { Developed }\end{array}$} & \multirow[b]{2}{*}{$\begin{array}{l}\text { 0. 3-5 positively stated school- } \\
\text { wide expectations posted } \\
\text { around school }\end{array}$} & \multicolumn{4}{|c|}{$\begin{array}{c}\text { Directions: Use Scoring } \\
\text { Guide to assist in } \\
\text { determining most } \\
\text { appropriate point value. } \\
\text { Circle Only One. }\end{array}$} & \multirow[t]{2}{*}{ 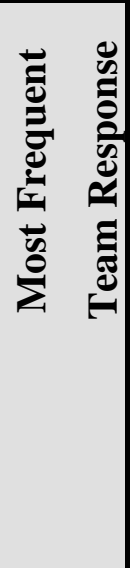 } \\
\hline & & 3 & 2 & 1 & 0 & \\
\hline & $\begin{array}{l}\text { 1. Expectations apply to both } \\
\text { students and staff in all settings }\end{array}$ & 3 & 2 & 1 & 0 & \\
\hline & $\begin{array}{l}\text { 2. Rules developed for specific } \\
\text { settings (where problems are } \\
\text { prevalent) }\end{array}$ & & 2 & 1 & 0 & \\
\hline & $\begin{array}{l}\text { 3. Rules are linked to } \\
\text { expectations }\end{array}$ & & & 1 & 0 & \\
\hline & $\begin{array}{l}\text { 4. Staff feedback/involvement in } \\
\text { expectations/rule development }\end{array}$ & & 2 & 1 & 0 & \\
\hline $\begin{array}{l}\text { Reward/ } \\
\text { Recognitio } \\
\text { n Program }\end{array}$ & $\begin{array}{l}\text { 5. A system of rewards has } \\
\text { elements that are consistent } \\
\text { across campus }\end{array}$ & 3 & 2 & 1 & 0 & \\
\hline \multirow[t]{3}{*}{$\begin{array}{l}\text { Establishe } \\
\text { d }\end{array}$} & $\begin{array}{l}\text { 6. Rewards are available at a } \\
\text { variety of levels (hierarchical, } \\
\text { tangible, intangible) }\end{array}$ & & 2 & 1 & 0 & \\
\hline & $\begin{array}{l}\text { 7. Rewards are linked to } \\
\text { expectations }\end{array}$ & 3 & 2 & 1 & 0 & \\
\hline & $\begin{array}{l}\text { 28. Rewards are varied to } \\
\text { maintain student interest. }\end{array}$ & & 2 & 1 & 0 & \\
\hline
\end{tabular}




\begin{tabular}{|c|c|c|c|c|c|c|}
\hline $\begin{array}{l}\text { Critical } \\
\text { Elements }\end{array}$ & Benchmarks of Quality & \multicolumn{4}{|c|}{$\begin{array}{c}\text { Directions: Use Scoring } \\
\text { Guide to assist in } \\
\text { determining most } \\
\text { appropriate point value. } \\
\text { Circle Only One. }\end{array}$} & 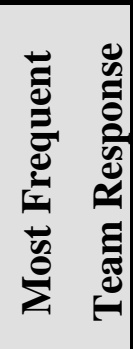 \\
\hline \multirow{4}{*}{$\begin{array}{l}\text { Reward/ } \\
\text { Recognitio } \\
\text { n Program } \\
\text { Establishe } \\
\text { d }\end{array}$} & $\begin{array}{l}\text { 29. System includes } \\
\text { opportunities for naturally } \\
\text { occurring } \\
\text { reinforcement }\end{array}$ & & & 1 & 0 & \\
\hline & $\begin{array}{l}\text { 30. Ratios of reinforcement to } \\
\text { corrections are high }\end{array}$ & 3 & 2 & 1 & 0 & \\
\hline & $\begin{array}{l}\text { 31. Students are involved in } \\
\text { identifying/developing } \\
\text { incentives }\end{array}$ & & & 1 & 0 & \\
\hline & $\begin{array}{l}\text { 32. The system includes } \\
\text { incentives for staff/faculty }\end{array}$ & & 2 & 1 & 0 & \\
\hline \multirow{6}{*}{$\begin{array}{l}\text { Lesson } \\
\text { Plans } \\
\text { Developed } \\
\text { for } \\
\text { Teaching } \\
\text { Expectatio } \\
\text { ns/ Rules }\end{array}$} & $\begin{array}{l}\text { 33. A behavioral curriculum } \\
\text { includes concept and skill level } \\
\text { instruction }\end{array}$ & & 2 & 1 & 0 & \\
\hline & $\begin{array}{l}\text { 34. Lessons include examples } \\
\text { and non-examples }\end{array}$ & & & 1 & 0 & \\
\hline & $\begin{array}{l}\text { 35. Lessons use a variety of } \\
\text { teaching strategies }\end{array}$ & & 2 & & 0 & \\
\hline & $\begin{array}{l}\text { 36. Lessons are embedded into } \\
\text { subject area curriculum }\end{array}$ & & 2 & 1 & 0 & \\
\hline & $\begin{array}{l}\text { 37. Strategies for use by } \\
\text { families/community are } \\
\text { developed }\end{array}$ & & & 1 & 0 & \\
\hline & $\begin{array}{l}\text { 38. Faculty/staff and students } \\
\text { are involved in development }\end{array}$ & & & 1 & 0 & \\
\hline
\end{tabular}




\begin{tabular}{|c|c|c|c|c|c|c|}
\hline $\begin{array}{c}\text { Critical } \\
\text { Elements }\end{array}$ & Benchmarks of Quality & \multicolumn{4}{|c|}{$\begin{array}{c}\text { Directions: Use Scoring } \\
\text { Guide to assist in } \\
\text { determining most } \\
\text { appropriate point value. } \\
\text { Circle Only One. }\end{array}$} & 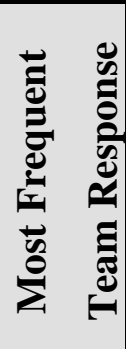 \\
\hline \multirow[t]{7}{*}{$\begin{array}{l}\text { Implement } \\
\text { ation Plan }\end{array}$} & $\begin{array}{l}\text { 39. Schedule/plans for teaching } \\
\text { staff the discipline and data } \\
\text { system are developed }\end{array}$ & & 2 & 1 & 0 & \\
\hline & $\begin{array}{l}\text { 40. Schedule/plans for teaching } \\
\text { staff the lesson plans for } \\
\text { students } \\
\quad \text { are developed }\end{array}$ & & 2 & 1 & 0 & \\
\hline & $\begin{array}{l}\text { 41. Schedule/plans for teaching } \\
\text { students } \\
\quad \text { expectations/rules/rewards } \\
\text { are developed }\end{array}$ & 3 & 2 & 1 & 0 & \\
\hline & $\begin{array}{l}\text { 42. Boosters sessions for } \\
\text { students and staff are } \\
\text { scheduled/planned }\end{array}$ & & 2 & 1 & 0 & \\
\hline & $\begin{array}{l}\text { 43. Schedule for } \\
\text { rewards/incentives for the year } \\
\text { is planned }\end{array}$ & & & 1 & 0 & \\
\hline & $\begin{array}{l}\text { 44. Plans for orienting } \\
\text { incoming staff and students are } \\
\text { developed }\end{array}$ & & 2 & 1 & 0 & \\
\hline & $\begin{array}{l}\text { 45. Plans for involving } \\
\text { families/community are } \\
\text { developed }\end{array}$ & & & 1 & 0 & \\
\hline
\end{tabular}




\begin{tabular}{|c|c|c|c|c|c|c|}
\hline $\begin{array}{l}\text { Critical } \\
\text { Elements }\end{array}$ & Benchmarks of Quality & \multicolumn{4}{|c|}{$\begin{array}{c}\text { Directions: Use Scoring } \\
\text { Guide to assist in } \\
\text { determining most } \\
\text { appropriate point value. } \\
\text { Circle Only One. }\end{array}$} & 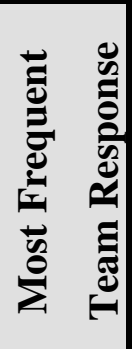 \\
\hline \multirow[t]{3}{*}{ Crisis Plan } & $\begin{array}{l}\text { 46. Faculty/staff are taught } \\
\text { how to respond to crisis } \\
\text { situations }\end{array}$ & & & 1 & 0 & \\
\hline & $\begin{array}{l}\text { 47. Responding to crisis } \\
\text { situations is rehearsed }\end{array}$ & & & 1 & 0 & \\
\hline & $\begin{array}{l}\text { 48. Procedures for crisis } \\
\text { situations are readily accessible }\end{array}$ & & & 1 & 0 & \\
\hline \multirow[t]{5}{*}{ Evaluation } & $\begin{array}{l}\text { 49. Annual surveys of students } \\
\text { and staff are collected/ } \\
\text { reviewed }\end{array}$ & & 2 & 1 & 0 & \\
\hline & $\begin{array}{l}\text { 50. Students and staff know } \\
\text { expectations and rules }\end{array}$ & & 2 & 1 & 0 & \\
\hline & $\begin{array}{l}\text { 51. Staff use discipline } \\
\text { system/documentation } \\
\text { appropriately }\end{array}$ & 3 & 2 & 1 & 0 & \\
\hline & $\begin{array}{l}\text { 52. Staff use reward system } \\
\text { appropriately }\end{array}$ & 3 & 2 & 1 & 0 & \\
\hline & $\begin{array}{l}\text { 53. Outcomes (behavior } \\
\text { problems, attendance, morale) } \\
\text { are } \\
\quad \text { documented }\end{array}$ & 3 & 2 & 1 & 0 & \\
\hline TOTALS & & & & & & \\
\hline
\end{tabular}




\section{CURRICULUM VITA}

NAME: $\quad$ Robert "Larry" Taylor

ADDRESS: 514 Foxwood Estates

Shelbyville, Kentucky 40065

DOB: $\quad$ Stearns, Kentucky-July 22, 1960

EDUCATION

\& TRAINING: $\quad$ B.S., Elementary and Special Education

Cumberland College

Spring 1982

M.Ed., Special Education

Cumberland College

Spring 1985

Ed.D., Educational Leadership and Organizational Development University of Louisville

Fall 2017

AWARDS: $\quad$ Teacher of the Year-Pine Knot Elementary School, 1995

Educator of the Year-McCreary County Chamber of Commerce, 2003 
Outstanding Special Education Administrator National Council of Special Education Administrator-2010

\section{PROFESSIONAL}

CERTIFICATIONS: School Superintendent, 1998

Eastern Kentucky University

Richmond, Kentucky

Director of Special Education, 1995

University of Kentucky

Lexington, Kentucky 
Supervisor of Instruction, 1993

Elementary Principal, 1991

Special Education Consultant, 1990

Elementary School Counselor, 1989

Eastern Kentucky University

Richmond, Kentucky

PROFESSIONAL

EXPERIENCE: $\quad$ Executive Director of the Kentucky Autism Training Center

College of Education and Human Development,

University of Louisville

July 2015-Present

Director of Exceptional Children Services

Ohio Valley Educational Cooperative

July 2011-July 2015

Interim Associate Commissioner

Office of Special Instructional Services

Kentucky Department of Education

January 2009-August 2011

State Director of Exceptional Children Services

Kentucky Department of Education

July 2005-June 2011

Adjunct Instructor 
University Louisville

Courses Taught:

EDSP 510 Legal Issues of Special Education

EDSP 240 Introduction to Exceptional Children

ELFH 613 Administration and Supervision of Special Education

Fall 2011-Spring 2017

Assistant Superintendent of Curriculum/Instruction and Personnel

McCreary County Schools

August 1998- June 2005

Adjunct Instructor

Somerset Community College

Course Taught:

EDP 202 Human Growth and Development

Fall 2000-Spring 2003

Director of Special Education and Preschool

McCreary County Schools

March 1996-July 1998

Assistant Director of Special Programs/Instructional Supervisor

Jessamine County Schools

July 1993-March 1996

Director of Student Services/Instructional Supervisor

Jessamine County Schools

July 1991-June 1993

Child Guidance Specialist

Wilmore Elementary School 


\author{
Jessamine County Schools \\ July 1989-June 1991 \\ Teacher of Exceptional Children/K-5 \\ Pine Knot Elementary School \\ McCreary County Schools \\ August 1982-June 1989
}

\title{
CURRENT COMMITTEES:
}

KY Advisory Council on Autism Spectrum Disorder

KY Council of Administrators of Special Education, Executive Board

KY Council for Exceptional Children Conference

KY Employment Partnership Project Grant

National Autism Leadership Collaborative 


\section{GRANTS AWARDED:}

Initiatives included: Positive Behavior Supports, Postsecondary Transition of Students with Disabilities, and Increasing Academic Outcomes for students with moderate to severe disabilities, the Recruitment and Retention of special educators, and reducing the overrepresentation of students with disabilities in early childhood education. State Personnel Development Grant from the Office of Special Education Programs, U.S. Department of Education in the Amount of \$5,800,000. August 2007.

Project UNITE-an initiative to address substance abuse among teenagers. The grant funds of \$50,000 assisted in the provision of a full-time counselor to for students at McCreary Central Academy. July 2004.

McCreary Central Academy (MCA) Alternative Program-Kentucky Center for School Safety. Funds awarded to help in establishing an alternative school $\mathbf{\$ 5 0 , 0 0 0}$ annually for 3 years. MCA was awarded Model School status from the Kentucky's Center for Safe Schools within 2 years of operation. December 2000.

Career Choices-grant awarded from the Federal Workforce Investment Act, Youth Opportunity Grant via Lake Cumberland Area Development District. Initiative to reduce drop out and increase academic performance of high school students. The initial award was \$195,155 and subsequent awards in excess of \$1,000,000. June 2000.

Bibliotherapy-Resources that Work-Jessamine County Education Foundation Grant. Purchased books to provided classroom guidance. Amount awarded \$500. January 1990.

\section{PRESENTATIONS:}

"Medical Diagnosis of Autism vs. Educational Eligibility for Autism". Systems of Care Academy. KY Cabinet for Health and Family Services. Lexington, Kentucky, June 2017. 
"Special Education Law: Implications for Medical Professionals". $7^{\text {th }}$ Annual Doctor Thomas H. Pinkstaff Memorial Lectureship. Pediatrics Grand Rounds. Co-Presentation with Laura Rothstein, J.D. Brandies School of Law, University of Louisville. Louisville, Kentucky, March 2017.

"Changes in the Diagnosis and Statistical Manual of Mental Disorders, DSM 5: Medical Diagnosis of Autism vs. Education Eligibility for Autism”. Kentucky Council for Exceptional Children Annual Conference. Louisville, Kentucky, November 2015.

"Key Questions for the Education of Students with Disabilities: How did we get where we are? Where are we? Where are we going?” Oldham County Schools Staff Opening Day, Goshen Kentucky, August 2012.

“Special Education Law for Families” Kentucky Autism Training Center Parent Professional Conference, Louis ville, Kentucky, June 2012.

“Special Education Coops and the State Performance Plan” Kentucky School Boards Association Legal Update Conference, Lexington, Kentucky, August 2011.

"College and Career Readiness Standards-Implications for Students with Disabilities” Office of Special Education Programs, US Department of Education's Mega Conference, Crystal City, Virginia, August 2010.

"Staffing to Enhance Student Achievement" This training was submitted to and approved by the Kentucky Department of Education for approval to provide the required Effective Instruction Leadership Act hours for administrators. The training was provided to principals prior to their March 1 staffing allocation. McCreary County Schools, Stearns, Kentucky. February 2004. 
"Meeting the Needs of Students with Learning Disabilities" Job Corps National Academic Managers Training, Kansas City, Kansas, November 2002

"Career Choices: Designed for Success" Workforce Investment Act Summit, Georgetown, Kentucky, November 2002

“So Each May Learn” Kentucky Association of School Councils Annual Conference, Louisville, Kentucky, October 2002

“What Matters Most” Kentucky Association of School Councils Annual Conference, Louisville, Kentucky, October 2002

"Enhancing Student Achievement Through Personnel Selection and Utilization" Experience Site-Based Decision Making Training. Stearns, Kentucky. September 2002.

“Kentucky's Continuous Improvement Process for Compliance and Outcomes for Students with Disabilities with the Local District's Consolidated Planning” Team Leader Training for the Ohio Department of Education, Columbus, Ohio, August 2002

"We Build It-They Will Come-What Next: How to Sustaining a Highly Effective Alternative School" Center for Safe Schools Conference. Lexington, KY. May 2002.

"Principal Selection for SBDM Councils" Site Based Decision Making Councils are required to receive 3 hours of principal selection training prior to interviewing and recommending a principal candidate for hire. Smithtown Elementary School, Smithtown, Kentucky. August 2002.

"Using Artifacts to Learn Regional Culture" George Mason University State Multicultural Early Childhood Team Training, Fairfax, Virginia, June 2001. 
"Principal Selection for SBDM Councils" Site Based Decision Making Councils are required to receive 3 hours of principal selection training prior to interviewing and recommending a principal candidate for hire. Pine Knot Middle School, Pine Knot, Kentucky. September 2001.

"Examining Test Scores to Enhance Student Achievement for SBDM Councils" This training was developed and submitted for approval to meet the 3 hours of required training for experienced SBDM Council members. Stearns, Kentucky, July 2000.

"SBDM Basics for New Council Members" As a state credentialed trainer for Site Based Decision Making, I provided the required 6 hours of training for new SBDM council members. McCreary County Schools, Stearns, KY. July 2000.

"Why Collaborate? -- Bridging the Cross Agency Gap Might Help" $10^{\text {th }}$ Mental Health Institute, KY Division of Mental Health, Louisville, Kentucky, September 1999

\section{Key Accomplishments:}

Led the development of the Kentucky Head Start Association's Strategic Plan incorporating the input from the 32 Head Start Grantees. January-April 2014.

Compiled and submitted to the Council for Post Secondary Education the Kentucky Autism Training Center's Annual Report. July 2013 and August 2014.

Directed and allocated fiscal resources to support the development of the Guidance for the Related Services of Occupational Therapy, Physical Therapy and Speech Language Services in Kentucky Public Schools. This initiative was begun due to challenges among practitioners, parents, and professionals in the clinical setting not understanding educationally relevant service delivery. November 2012. 
Developed a Kentucky Department of Education guidance document entitled Collaborative Teaching Practices for Exceptional Children. Data from emails, phone calls, and site monitoring of local school districts indicated a need to provide guidance regarding collaborative teaching. June 2011.

Issued a Policy Letter on behalf of the State regarding the referral, eligibility and placement of exceptional children pursuant to IDEA 2004 that provided clarification on specific issues and addressed concerns from the states data. Practices as a result of this guidance resulted in improved state data and received federal attention from the US Department of Education initiated by Congress. http://education.ky.gov/specialed/excep/Documents/Guidance\%20Documents/KDE\%20P olicy\%20Letter\%20-\%20Referral,\%20Evaluation\%20and\%20Eligibility.pdf. August 2010.

Provided fiscal resources to begin the Academic and Behavior Response to Intervention lead by Dr. Terry Scott at the University of Louisville. This initiative was developed to provide professional learning, technical assistance, and research opportunites in Kentucky for local schools regarding multi-tiered systems of support. July 2009\$465,000, July 2010-\$525,000, July 2011, \$545,000 and July 2012, \$540,276.

Developed a proposal between the Kentucky Department of Education and Kentucky Autism Training Center that was submitted to the Frank Porter Graham Child Development Center at UNC Chapel Hill. This request for proposal was for professional development and technical assistance to provide training in evidence-based practices that were trained and implemented in school sites though Kentucky. This initiative has continued since its inception and is funded at \$391,000 annually. June 2009

Lead the process for the Kentucky Board of Education to promulgate the Kentucky Administrative Regulations for Exceptional Children (707 KAR 1:002-707 KAR 1:380 subsequent to the 2004 reauthorization of the Individuals with Disabilities Education Act. Aligned state regulations with federal regulations, conducted forums for constituent 
input, prepared statements of consideration from Public Hearings, presented the regulations to the Kentucky Board of Education and Kentucky Legislative Committees that review administrative regulations.

http://education.ky.gov/specialed/excep/Pages/Kentucky-Administrative-Regulationsand-Federal-IDEA-Regulations-for-Special-Education.aspx August 2008.

Submitted the newly required Kentucky's State Performance Plan (SPP) to the Office of Special Education Programs http://education.ky.gov/specialed/excep/Documents/Original\%20Submitted\%2020042005\%20State\%20Performance\%20Plan.doc. December 2005. Submitted subsequent Annual Performance Reports of the SPP. February 2006-2011.

Guided revisions to Kentucky's Alternate Assessment Program (KAAP) for students with moderate to severe disabilities. Revision to the KAAP resulted in the removal of the federally imposed special conditions of Kentucky's from Kentucky's IDEA Grant allocation that had been cited since 2004. August 2007.

Allocated fiscal resources to Murray State University to fund the first 2 years of tuition for instructional assistants employed by local schools districts toward acquiring their teaching certification to teach exceptional children. This initiative was based on a shortage of qualified applicants for exceptional children teacher vacancies. One hundred percent of the students entering the program completed their teacher certification and employed in the western region of the state. July 2006-\$150,000, July 2007-\$150,000, July 2008-\$150,000, July 2009-\$150,000, July 2010-\$150,000, and July 2011-\$150,000.

Allocated fiscal resources for the KY Traineeship Program to support the tuition for the certification of personnel for exceptional children positions for students attending institutes of higher education in KY. Northern Kentucky University was utilized as the fiscal agent. July 2006-July 2011, \$1,000,000 annually.

Allocated resources to the Human Development Institute, University of Kentucky for 
Initiated the states scholastic audit process in all schools in the school district (5 elementary schools, 2 middle schools and 1 high school) using the State Standards and Indicators for School Improvement. Directed the audits, compiled the findings, and developed a comprehension district improvement plan to address the needs identified. October 2004.

Developed a Comprehensive 3 Year District wide Professional Development Program based on data collected, compiled, and analyzed. Obtained national experts to address the challenges identified from the scholastic audits, secured funding and staff commitment to implement the professional development plan. February 2003.

Revised the local school districts board policies and administrative procedures. Served as a pilot district for the Kentucky School Boards Association in the electronic accessibility of the district's electronic policies and procedures. Provided training to the administrative personnel on the use of policies and procedures. January-June 2002.

Developed a Corrective Action Plan (CAP) to address significant noncompliance of programs for student with disabilities based on state monitoring of the district and multiple formal complaints under the resolution process of the IDEA. The CAP was implemented and closed within 1 year from inception. March 1996-June 1997.

Developed Policies and Procedures to meet the requirements of Section 504 for the local school district. Presented and obtained approval of the Section 504 policies and procedures from the local board of education. Trained all district administrators on the use of the policies and procedures. January 1999-June 1999.

Developed an Americans with Disabilities Transition Plan for Jessamine County Schools to become compliant with federal ADA requirements. This included all facilities and programs of the district. March-June 1994. 